\title{
Optical clearing of biological tissues: prospects of application in medical diagnostics and phototherapy
}

\author{
E.A. Genina ${ }^{1,2^{*}}$, A.N. Bashkatov ${ }^{1,2}$, Yu.P. Sinichkin ${ }^{1}$, I.Yu. Yanina ${ }^{3}$, V.V.Tuchin ${ }^{1,2,4}$ \\ ${ }^{1}$ N.G. Chernyshevsky Saratov State University, 83 Astrakhanskaya Str., Saratov, 410012, Russia \\ ${ }^{2}$ Tomsk State University, 36 Prosp. Lenina, Tomsk, 634050, Russia \\ ${ }^{3}$ V.I. Razumovsky Saratov State Medical University, 112 Bolshaya Kazachya Str., Saratov, 410012, Russia \\ ${ }^{4}$ Institute of Precision Mechanics and Control, Russian Academy of Sciences, 24 Rabochaya Str., Saratov, 410028, \\ Russia \\ *e-mail: eagenina@yandex.ru
}

\begin{abstract}
A review of specific features and methods of optical clearing and related interaction of light with tissues is presented. Physical and molecular mechanisms of immersion, compression, and photodynamic/photothermal optical clearing of some fibrous and cellular tissues are discussed. The possibility of efficient control of the tissue optical properties, particularly, the reduction of light scattering in tissues is demonstrated, which facilitates the increased efficiency of various optical visualisation methods (optical biopsy) used in medical purposes. (C) 2015 Samara State Aerospace University (SSAU).
\end{abstract}

Keywords: tissue, optical clearing, optical diagnostics, imaging.

Paper \#1992 received 2014.12.26; revised manuscript received 2015.02.03; accepted for publication 2015.02.05; published online 2015.03.28.

\section{References}

1. V. V. Tuchin (Ed.), Handbook of Optical Biomedical Diagnostics, SPIE Press, PM107, Bellingham (2002).

2. T. Vo-Dinh (Ed.), Biomedical Photonics Handbook, CRC Press, Boca Raton, FL, USA (2003); second edition (2014).

3. V. V. Tuchin, Tissue Optics: Light Scattering Methods and Instruments for Medical Diagnosis, Bellingham, SPIE Press (2015).

4. D. A. Boas, "A fundamental limitation of linearized algorithms for diffuse optical tomography," Opt. Express. 1, 404-413 (1997).

5. C. L. Smithpeter, A. K. Dunn, A. J. Welch, and R. Richards-Kortum, "Penetration depth limits of in vivo confocal reflectance imaging," Appl. Opt. 37, 2749-2754 (1998).

6. V. V. Tuchin, L. V. Wang, and D. A. Zimnyakov, Optical Polarization in Biomedical Applications, SpringerVerlag, New York, NY, USA (2006).

7. R. Drezek, A. Dunn, and R. Richards-Kortum, "Light scattering from cells: finite-difference time-domain simulations and goniometric measurements," Appl. Opt. 38(16), 3651-3661 (1999).

8. K. Sokolov, R. Drezek, K. Gossagee, and R. Richards-Kortum, "Reflectance spectroscopy with polarized light: is it sensitive to cellular and nuclear morphology," Opt. Express 5, 302-317 (1999).

9. D. W. Leonard, and K. M. Meek, "Refractive indices of the collagen fibrils and extrafibrillar material of the corneal stroma," Biophysical J. 72, 1382-1387 (1997).

10. A. G. Borovoi, E. I. Naats, and U. G. Oppel, "Scattering of light by a red blood cell," J. Biomed. Opt. 3, 364$372(1998)$.

11. A. N. Yaroslavsky, A. V. Priezzhev, J. Rodriguez, I. V. Yaroslavsky, and H. Battarbee, "Optics of blood," Chap. 2 in Handbook of Optical Biomedical Diagnostics, V. V. Tuchin, Ed., pp. 169-216, PM107 SPIE Press, Bellingham, WA, USA (2002).

12. G. Mazarevica, T. Freivalds, and A. Jurka, "Properties of erythrocyte light refraction in diabetic patients," J. Biomed. Opt. 7, 244-247 (2002).

13. M. Friebel, and M. Meinke, "Model function to calculate the refractive index of native hemoglobin in the wavelength range of 250-1100 nm dependent on concentration," Appl. Opt. 45(12), 2838-2842 (2006). 
14. E. Gratton, "Deeper tissue imaging with total detection," Science 331, 1016-1017 (2011).

15. W. Denk, J. H. Strickler, and W. W. Webb, "Two-photon laser scanning fluorescence microscopy," Science, 248, 73-76 (1990).

16. C. A. Combs, A. Smirnov, D. Chess, D. B. Mcgavern, J. L. Schroeder, J. Riley, S. S. Kang, M. LugarHammer, A. Gandjbakhche, J. R. Knutson, and R. S. Balaban, "Optimizing multiphoton fluorescence microscopy light collection from living tissue by noncontact total emission detection (epiTED), " J. Microsc. 241(2), 153-161 (2011).

17. C. A. Combs, A. V. Smirnov, J. D. Riley, A. H. Gandjbakhche, J. R. Knutson, and R. S. Balaban, "Optimization of multiphoton excitation microscopy by total emission detection using a parabolic light reflector," J. Microsc. 228(3), 330-337 (2007).

18. R. K. Wang, and V. V. Tuchin, "Optical coherence tomography. Light scattering and imaging enhancement," Chap. 16 in Handbook of Coherent-Domain Optical Methods. Biomedical Diagnostics, Environmental Monitoring, and Material Science, $2^{\text {nd }}$ ed., V. V. Tuchin, Ed., pp. 665-742, New York, Heidelberg, Dordrecht, London: Springer (2013).

19. L. V. Wang, and S. Hu, "Photoacoustic tomography: in vivo imaging from organelles to organs," Science 335 , 1458-1462 (2012).

20. Y. M. Liew, R. A. McLaughlin, F. M. Wood, and D. D. Sampson, "Reduction of image artifacts in threedimensional optical coherence tomography of skin in vivo," J. Biomed. Opt. 16(11), 116018 (2011).

21. V. V. Tuchin, “A clear vision for laser diagnostics (Review),” IEEE J. Sel. Top. Quantum Electron. 13, 16211628 (2007).

22. V. V. Tuchin, Optical Clearing of Tissues and Blood, SPIE Press, Bellingham, WA, USA (2006).

23. R. Cicchi, F. S. Pavone, D. Massi, and D. D. Sampson, "Contrast and depth enhancement in two-photon microscopy of human skin ex vivo by use of optical clearing agents," Opt. Exp. 13, 2337-2344 (2005).

24. S. Plotnikov, V. Juneja, A. B. Isaacson, W. A. Mohler, and P. J. Campagnola, "Optical clearing for improved contrast in second harmonic generation imaging of skeletal muscle," Biophys. J. 90, 328-339 (2006).

25. E. A. Genina, A. N. Bashkatov, Yu. P. Sinichkin, and V. V. Tuchin, "Optical clearing of the eye sclera in vivo caused by glucose," Quantum Electronics 36(12), 1119-1124 (2006).

26. G. Vargas, J. K. Barton, and A. J. Welch, "Use of hyperosmotic chemical agent to improve the laser treatment of cutaneous vascular lesions," J. Biomed. Opt. 13(2), 021114 (2008).

27. M. H. Khan, S. Chess, B. Choi, K. M. Kelly, and J. S. Nelson, "Can topically applied optical clearing agents increase the epidermal damage threshold and enhance therapeutic efficacy?," Lasers Surg. Med. 35, 93-95 (2004).

28. P. D. Agrba, M. Yu. Kirillin, A. I. Abelevich, E. V. Zagaynova, and V. A. Kamensky, "Compression as a method for increasing the informativity of optical coherence tomography of biotissue," Optics and Spectroscopy 107(6), 853-858 (2009).

29. C. Drew, T. E. Milner, and C. G. Rylander, "Mechanical tissue optical clearing devices: evaluation of enhanced light penetration in skin using optical coherence tomography," J. Biomed. Opt. 14(6), 064019 (2009).

30. N. Guzelsu, J. F. Federici, H. C. Lim, H. R. Chauhdry, A. B. Ritter, and T. Findley, "Measurement of skin strech via light reflection," J. Biomed. Opt. 8, 80-86 (2003).

31. C. G. Rylander, O. F. Stumpp, T. E. Milner, N. J. Kemp, J. M. Mendenhall, K. R. Diller, and A. J. Welch, "Dehydration mechanism of optical clearing in tissue," J. Biomed. Opt. 11, 041117 (2006).

32. T. Yu, X. Wen, V. V. Tuchin, Q. Luo, and D. Zhu, "Quantitative analysis of dehydration in porcine skin for assessing mechanism of optical clearing," J. Biomed. Opt. 16, 095002 (2011).

33. W.-C. Lin, M. Motamedi, and A. J. Welch, "Dynamics of tissue optics during laser heating of turbid media," Appl. Opt. 35(19), 3413-3420 (1996).

34. D. Zhu, J. Wang, Z. Zhi, X. Wen, and Q. Luo, "Imaging dermal blood flow through the intact rat skin with an optical clearing method," J. Biomed. Opt. 15, 026008 (2010).

35. K. V. Larin, M. G. Ghosn, A. N. Bashkatov, E. A. Genina, N. A. Trunina, and V. V. Tuchin, "Optical clearing for OCT image enhancement and in-depth monitoring of molecular diffusion," IEEE J. Select. Tops. Quantum Electron. 18, 1244-1259 (2012).

36. D. Zhu, K. Larin, Q. Luo, and V. V. Tuchin, "Recent progress in tissue optical clearing," Laser \& Photonics Reviews 7(5), 732-757 (2013).

37. V. A. Doubrovskii, I. Yu. Yanina, and V. V. Tuchin, "Kinetics of changes in the coefficient of transmission of the adipose tissue in vitro as a result of photodynamic action," Biophysics 57(1), 94-98 (2012).

38. I. Yu. Yanina, N. A. Trunina, and V. V. Tuchin, "Optical coherence tomography of adipose tissue at photodynamic/photothermal treatment in vitro," Journal of Innovative Optical Health Sciences 6(2), 1350010 (2013).

39. E. A. Genina, A. N. Bashkatov, and V. V. Tuchin, “Tissue optical immersion clearing," Expert Rev. Med. Devices 7, 825-842 (2010). 
40. R. Barer, "Spectrophotometry of clarified cell suspensions," Science 121, 709-715 (1955).

41. V. V. Bakutkin, and L. P. Shubochkin, "The increase in light transmission of the sclera and the diseased cornea," Ophthalmological Journal 2, 105-107 (1991) (in Russian).

42. V. V. Tuchin, I. L. Maksimova, D. A. Zimnyakov, I. L. Kon, A. H. Mavlutov, and A. A. Mishin, "Light propagation in tissues with controlled optical properties," Proc. SPIE 2925, 118-142 (1996).

43. V. V. Tuchin, I. L. Maksimova, D. A. Zimnyakov, I. L. Kon, A. H. Mavlutov, and A. A. Mishin, "Light propagation in tissues with controlled optical properties," J. Biomed. Opt. 2, 401-417 (1997).

44. A. N. Bashkatov, E. A. Genina, V. I. Kochubey, V. V. Tuchin, and Yu. P. Sinichkin, "The influence of osmotically active chemical agents on the transport of light in the scleral tissue," Proc. SPIE 3726, 403-409 (1998).

45. V. V. Tuchin, A. N. Bashkatov, E. A. Genina, Yu. P. Sinichkin, and N. A. Lakodina, "In vivo investigation of the immersion-liquid-induced human skin clearing dynamics," Technical Physics Letters 27(6), 489-490 (2001).

46. E. A. Genina, Investigation of optical immersion and staining of biological tissues in vivo for optical diagnostics and laser therapy, Ph.D. thesis, Saratov State University, Saratov, Russia (2002) (in Russia).

47. A. N. Bashkatov, Control of tissue optical properties by means of osmotically active immersion liquids, $\mathrm{Ph}$. $\mathrm{D}$. thesis, Saratov State University, Saratov, Russia (2002) (in Russia).

48. I. V. Meglinskii, A. N. Bashkatov, E. A. Genina, D. Yu. Churmakov, and V. V. Tuchin, "Study of the possibility of increasing the probing depth by the method of reflection confocal microscopy upon immersion clearing of near-surface human skin layers," Quantum Electronics 32(10), 875-882 (2002).

49. I. V. Meglinski, A. N. Bashkatov, E. A. Genina, D. Y. Churmakov, and V. V. Tuchin, "The enhancement of confocal images of tissues at bulk optical immersion," Laser Physics 13(1), 65-69 (2003).

50. E. I. Galanzha, V. V. Tuchin, A. V. Solovieva, T. V. Stepanova, Q. Luo, and H. Cheng, J., "Skin backreflectance and microvascular system functioning at the action of osmotic agents," Phys. D: Appl. Phys. 36, 1739-1746 (2003).

51. V. V. Tuchin, D. M. Zhestkov, A. N. Bashkatov, and E. A. Genina, "Theoretical study of immersion optical clearing of blood in vessels at local hemolysis," Optics Express 12(13), 2966-2971 (2004).

52. E. A. Genina, A. N. Bashkatov, V. I. Kochubey, and V. V. Tuchin, "Optical clearing of human dura mater," Optics and Spectroscopy 98(3), 470-476 (2005).

53. A. N. Bashkatov, D. M. Zhestkov, E. A. Genina, and V. V. Tuchin, "Immersion clearing of human blood in the visible and near-infrared spectral regions," Optics and Spectroscopy 98(4), 638-646 (2005).

54. V. V. Tuchin, "Optical clearing of tissues and blood using the immersion method," J. Phys. D: Appl. Phys. 38, 2497-2518 (2005).

55. V. V. Tuchin, "Optical immersion as a new tool for controlling the optical properties of tissues and blood," Laser Phys. 15, 1109-1136 (2005).

56. E. A. Genina, A. N. Bashkatov, A. A. Korobko, E. A. Zubkova, V. V. Tuchin, I. V. Yaroslavsky, and G. B. Altshuler, "Optical clearing of human skin: comparative study of permeability and dehydration of intact and photothermally perforated skin,” J. Biomed. Opt. 13, 021102 (2008).

57. E. A. Genina, A. N. Bashkatov, and V. V. Tuchin. "Optical clearing of cranial bone," Advanced Optical Technologies 267867 (2008).

58. E. A. Genina, A. N. Bashkatov, K. V. Larin, and V. V. Tuchin, "Light-tissue interaction at optical clearing," Chap. 7 in Laser Imaging and Manipulation in Cell Biology, F. S. Pavone, Ed., pp. 115-164, Wiley-VCH Verlag GmbH \& Co. KGaA, Weinheim (2010).

59. I. V. Larina, E. F. Carbajal, V. V. Tuchin, M. E. Dickinson, and K. V. Larin, "Enhanced OCT imaging of embryonic tissue with optical clearing," Laser Phys. Lett. 5, 476-479 (2008).

60. S. G. Proskurin, and I. V. Meglinski, "Optical coherence tomography imaging depth enhancement by superficial skin optical clearing," Laser Phys. Lett. 4, 824-826 (2007).

61. M. Bonesi, S. G. Proskurin, and I. V. Meglinski, "Imaging of subcutaneous blood vessels and flow velocity profiles by optical coherence tomography," Laser Phys. 20, 891-899 (2010).

62. G. Vargas, E. K. Chan, J. K. Barton, H. G. Rylander, and A. J. Welch, "Use of an agent to reduce scattering in skin," Lasers Surg. Med. 24(2), 133-141 (1999).

63. G. Vargas, "Reduction of light scattering in biological tissue: implications for optical diagnostics and therapeutics," PhD Thesis, The University of Texas, USA (2001).

64. G. Vargas, K. F. Chan, S. L. Thomsen, and A. J. Welch, "Use of osmotically active agents to alter optical properties of tissue: effects on the detected fluorescence signal measured through skin," Lasers Surg. Med. 29(3), 213-220 (2001).

65. G. Vargas, A. Readinger, S. S. Dosier, and A. J. Welch, "Morphological changes in blood vessels produced by hyperosmotic agents and measured by optical coherence tomography," Photochem. Photobiol. 77, 541-549 (2003). 
66. R. K. Wang, X. Xu, V. V. Tuchin, and J. B. Elder, "Concurrent enhancement of imaging depth and contrast for optical coherence tomography by hyperosmotic agents," J. Opt. Soc. Am. B 18, 948-953 (2001).

67. X. Xu, and R. K. Wang, "The role of water desorption on optical clearing of biotissue: studied with near infrared reflectance spectroscopy," Med. Phys. 30, 1246-1253 (2003).

68. Y. He, R. K. Wang, and D. Xing, "Enhanced sensitivity and spatial resolution for in vivo imaging with lowlevel light-emitting probes by use of biocompatible chemical agents," Opt. Lett. 28, 2076-2078 (2003).

69. Y. He, and R. K. Wang, "Dynamic optical clearing effect of tissue impregnated with hyperosmotic agents and studied with optical coherence tomography," J. Biomed. Opt. 9, 200-206 (2004).

70. M. H. Khan, B. Choi, S. Chess, K. M. Kelly, J. McCullough, and J. S. Nelson, "Optical clearing of in vivo human skin: implications for light-based diagnostic imaging and therapeutics," Lasers Surg. Med. 34, 83-85 (2004).

71. H. Cheng, Q. Luo, S. Zeng, S. Chen,W. Luo, and H. Gong, "Hyperosmotic chemical agent's effect on in vivo cerebral blood flow revealed by laser speckle," Appl. Opt. 43, 5772-5777 (2004).

72. R. LaComb, O. Nadiarnykh, S. Carey, and P. J. Campagnola, "Quantitative second harmonic generation imaging and modeling of the optical clearing mechanism in striated muscle and tendon,” J. Biomed. Opt. 13, 021109 (2008).

73. O. Nadiarnykh, and P. J. Campagnola, "Retention of polarization signatures in SHG microscopy of scattering tissues through optical clearing," Opt. Exp. 17, 5794-5806 (2009).

74. D. Zhu, Q. Luo, and J. Cen, "Effects of dehydration on the optical properties of in vitro porcine liver," Lasers Surg. Med. 33, 226-231 (2003).

75. D. Zhu, J. Zhang, H. Cui, Z. Mao, P. Li, and Q. Luo, "Short-term and long-term effects of optical clearing agents on blood vessels in chick chorioallantoic membrane," J. Biomed. Opt. 13(2), 021106 (2008).

76. X. Wen, Z. Mao, Z. Han, V. V. Tuchin, and D. Zhu, "In vivo skin optical clearing by glycerol solutions: mechanism," J. Biophotonics 3(1-2), 44-52 (2010).

77. J. Wang, D. Zhu, M. Chen, and X. Liu, "Assessment of optical clearing induced improvement of laser speckle contrast imaging,” J. Innovat. Opt. Health Sci. 3, 159-167 (2010).

78. T. Yu, X. Wen, V. V. Tuchin, Q. Luo, and D. Zhu, "Quantitative analysis of dehydration in porcine skin for assessing mechanism of optical clearing," J. Biomed. Opt. 16(9), 095002 (2011).

79. J. Wang, Y. Zhang, T. Xu, Q. Luo, and D. Zhu, "An innovative transparent cranial window based on skull optical clearing," Laser Phys. Lett. 9, 469-473 (2012).

80. X. Wen, S. L. Jacques, V. V. Tuchin, and D. Zhu, "Enhanced optical clearing of skin in vivo and optical coherence tomography in-depth imaging," J. Biomed. Opt. 17, 066022 (2012).

81. J. Wang, Y. Zhang, P. Li, Q. Luo, and D. Zhu, "Review: tissue optical clearing window for blood flow monitoring," IEEE J. Sel. Topics in Quantum Electron. 20(2), 6801112 (2014).

82. M. Kinnunen, R. Myllylä, and S. Vainio, "Detecting glucose-induced changes in in vitro and in vivo experiments with optical coherence tomography,” J. Biomed. Opt. 13, 021111 (2008).

83. R. Dickie, R. M. Bachoo, M. A. Rupnick, S. M. Dallabrida, G. M. DeLoid, J. Lai, R. A. DePinho, and R. A. Rogers, "Three-dimensional visualization of microvessel architecture of whole-mount tissue by confocal microscopy," Microvasc. Res. 72, 20-26 (2006).

84. V. Hovhannisyan, P.-S. Hu, S.-J. Chen, C.-S. Kim, and C.-Y. Dong, "Elucidation of the mechanisms of optical clearing in collagen tissue with multiphoton imaging,” J. Biomed. Opt. 18(4), 046004 (2013).

85. H. Hama, H. Kurokawa, H. Kawano, R. Ando, T. Shimogori, H. Noda, K. Fukami, A. Sakaue-Sawano, and A. Miyawaki, "Scale: a chemical approach for fluorescence imaging and reconstruction of transparent mouse brain," Nature Neurosci. 14, 1481-1488 (2011).

86. H. U. Dodt, U. Leischner, A. Schierloh, N. Jährling, C. P. Mauch, K. Deininger, J. M. Deussing, M. Eder, W. Zieglgnsberger, and K. Becker, "Ultramicroscopy: three-dimensional visualization of neuronal networks in the whole mouse brain," Nature Methods 4(4), 331-336 (2007).

87. A. Ertürk, C. P. Mauch, F. Hellal, F. Förstner, T. Keck, K. Becker, N. Jährling, H. Steffens, M. Richter, M. Hübener, E. Kramer, F. Kirchhoff, H. U. Dodt, and F. Bradke, "Three-dimensional imaging of the unsectioned adult spinal cord to assess axon regeneration and glial responses after injury," Nature Med. 18, 166-171 (2012).

88. A. N. Bashkatov, E. A. Genina, Yu. P. Sinichkin, V. I. Kochubey, N. A. Lakodina, and V. V. Tuchin, "Glucose and mannitol diffusion in human dura mater," Biophys. J. 85(5), 3310-3318 (2003).

89. M. G. Ghosn, V. V. Tuchin, and K. V. Larin, "Depth-resolved monitoring of glucose diffusion in tissues by using optical coherence tomography," Opt. Lett. 31, 2314-2316 (2006).

90. A. N. Bashkatov, E. A. Genina, and V. V. Tuchin, "Measurement of glucose diffusion coefficients in human tissues," Chap. 19 in Handbook of Optical Sensing of Glucose in Biological Fluids and Tissues, V. V. Tuchin, Ed., pp. 587-621, Taylor \& Francis Group LLC, CRC Press (2009).

91. A. N. Bashkatov, E. A. Genina, Yu. P. Sinichkin, V. I. Kochubei, N. A. Lakodina, and V. V. Tuchin, "Estimation of the glucose diffusion coefficient in human eye sclera," Biophysics 48(2), 292-296 (2003). 
92. E. A. Genina, A. N. Bashkatov, E. A. Zubkova, T. G. Kamenskikh, and V. V. Tuchin, "Measurements of Retinalamin diffusion coefficient in human sclera by optical spectroscopy," Optics and Lasers in Engineering 46, 915-920 (2008).

93. E. A. Genina, A. N. Bashkatov, V. V. Tuchin, M. G. Ghosn, K. V. Larin, and T. G. Kamenskikh, "Cortexin diffusion in human eye sclera," Quantum Electronics 41(5), 407-413 (2011).

94. E. A. Zubkina, E. A. Genina, A. N. Bashkatov, and V. V. Tuchin, "Optical clearing of eye tissues," Proceedings of the Samara Scientific Center of the Russian Academy of Sciences 13(4(2)), 588-594 (2011) (in Russia).

95. M. G. Ghosn, V. V. Tuchin, and K. V. Larin, "Nondestructive quantification of analyte diffusion in cornea and sclera using optical coherence tomography," Invest. Ophthal. Visual Sci. 48, 2726-2733 (2007).

96. M. G. Ghosn, E. F. Carbajal, N. Befrui, V. V. Tuchin, and K. V. Larin, "Differential permeability rate and percent clearing of glucose in different regions in rabbit sclera," J. Biomed. Opt. 13, 021110 (2008).

97. M. G. Ghosn, N. Sudheendran, M. Wendt, A. Glasser, V. V. Tuchin, and K. V. Larin, "Monitoring of glucose permeability in monkey skin in vivo using optical coherence tomography," J. Biophotonics 3, 25-33 (2010).

98. X. Guo, Z. Guo, H. Wei, H. Yang, Y. He, S. Xie, G. Wu, X. Deng, Q. Zhao, and L. Li, “In vivo comparison of the optical clearing efficacy of optical clearing agents in human skin by quantifying permeability using optical coherence tomography," Photochem. Photobiol. 87, 734-740 (2011).

99. K. V. Larin, M. G. Ghosn, S. N. Ivers, A. Tellez, and J. F. Granada, "Quantification of glucose diffusion in arterial tissues by using optical coherence tomography," Laser Physics Letters 4(4), 312-317 (2007).

100.X. Guo, G. Wu, H. Wei, X. Deng, H. Yang, Y. Ji, Y. He, Z. Guo, S. Xie, H. Zhong, Q. Zhao, and Z. Zhu, "Quantification of glucose diffusion in human lung tissues by using Fourier domain optical coherence tomography," Photochem. Photobiol. 88, 311-316 (2012).

101.S. Tanev, V. V. Tuchin, and P. Paddon, "Cell membrane and gold nanoparticles effects on optical immersion experiments with noncancerous and cancerous cells: finite-difference time-domain modeling," J. Biomed. Opt. 11, 064037 (2006).

102.M. G. Ghosn, E. F. Carbajal, N. A. Befrui, A. Tellez, J. F. Granada, and K. V. Larin, "Permeability of hyperosmotic agent in normal and atherosclerotic vascular tissues," J. Biomed. Opt. 13, 010505 (2008).

103.H. Q. Zhong, Z. Y. Guo, H. J. Wei, C. C. Zeng, H. L. Xiong, Y. H. He, and S. H. Liu, "Quantification of glycerol diffusion in human normal and cancer breast tissues in vitro with optical coherence tomography," Laser Phys. Lett. 7, 315-320 (2010).

104.Q. L. Zhao, J. L. Si, Z. Y. Guo, H. J. Wei, H. Q. Yang, G. Y. Wu, S. S. Xie, X. Y. Li, X. Guo, H. Q. Zhong, and L. Q. Li, "Quantifying glucose permeability and enhanced light penetration in ex vivo human normal and cancerous esophagus tissues with optical coherence tomography," Laser Phys. Lett. 8, 71-77 (2011).

105.Z. Zhu, G. Wu, H. Wei, H. Yang, Y. He, S. Xie, Q. Zhao, and X. Guo, "Investigation of the permeability and optical clearing ability of different analytes in human normal and cancerous breast tissues by spectral domain OCT," J. Biophoton. 5, 1-8 (2012).

106.B. Choi, L. Tsu, E. Chen, T. S. Ishak, S. M. Iskandar, S. Chess, and J. S. Nelson, "Determination of chemical agent optical clearing potential using in vitro human skin," Lasers Surg. Med. 36, 72-75 (2005).

107.Z. Mao, D. Zhu, Y. Hu, X. Wen, and Z. Han, "Influence of alcohols on the optical clearing effect of skin in vitro," J. Biomed. Opt. 13, 021104 (2008).

108.E. A. Genina, A. N. Bashkatov, Yu. P. Sinichkin, and V. V. Tuchin, "Optical clearing of skin under action of glycerol: ex vivo and in vivo investigations," Optics and Spectroscopy 109(2), 225-231 (2010).

109.J. Hirshburg, B. Choi, J. S. Nelson, and A. T. Yeh, "Correlation between collagen solubility and skin optical clearing using sugars," Lasers Surg. Med. 39, 140-144 (2007).

110.J. M. Hirshburg, K. M. Ravikumar, W. Hwang, and A. T. Yeh, "Molecular basis for optical clearing of collagenous tissues," J. Biomed. Opt. 15(5), 055002 (2010).

111.J. Wang, N. Ma, R. Shi, Y. Zhang, T. Yu, and D. Zhu, "Sugar-induced skin optical clearing: from molecular dynamics simulation to experimental demonstration," IEEE J. Selected Topics in Quantum Electronics 20(2), 7101007 (2014).

112.A. T. Yeh, and J. Hirshburg, "Molecular interactions of exogenous chemical agents with collagen-implications for tissue optical clearing," J. Biomed. Opt. 11(1), 014003 (2006).

113. Y. Ding, J. Wang, Z. Fan, D. Wei, R. Shi, Q. Luo, D. Zhu, and X. Wei, "Signal and depth enhancement for in vivo flow cytometer measurement of ear skin by optical clearing agents," Biomed. Opt. Exp. 4(11), 2518-2526 (2013).

114.J. Jiang, and R. K. Wang, "Comparing the synergistic effects of oleic acid and dimethyl sulfoxide as vehicles for optical clearing of skin tissue in vitro," Phys. Med. Biol. 49, 5283-5294 (2004).

115.Y. Liu, X. Yang, D. Zhu, and Q. Luo, "Optical clearing agents improve photoacoustic imaging in the optical diffusive regime," Optics Letters 38(20), 4236-4239 (2013). 
116.X. Xu, and R. K. Wang, "Synergistic effect of hyperosmotic agents of dimethyl sulfoxide and glycerol on optical clearing of gastric tissue studied with near infrared spectroscopy," Phys. Med. Biol. 49, 457-468 (2004).

117.J. Jiang, M. Boese, P. Turner, and R. K. Wang, "Penetration kinetics of dimethyl sulphoxide and glycerol in dynamic optical clearing of porcine skin tissue in vitro studied by Fourier transform infrared spectroscopic imaging," J. Biomed. Opt. 13(2), 021105 (2008).

118.E. A. Genina, A. N. Bashkatov, E. A. Kolesnikova, M. V. Basco, G. S. Terentyuk, and V. V. Tuchin, “Optical coherence tomography monitoring of enhanced skin optical clearing in rats in vivo," J. Biomed. Opt. 19(2), 021109 (2014).

119.A. N. Bashkatov, A. N. Korolevich, V. V. Tuchin, Y. P. Sinichkin, E. A. Genina, M. M. Stolnitz, N. S. Dubina, S. I. Vecherinski, and M. S. Belsley, "In vivo investigation of human skin optical clearing and blood microcirculation under the action of glucose solution," Asian J. Physics 15(1), 1-14 (2006).

120.E. A. Genina, A. N. Bashkatov, and V. V. Tuchin, "Glucose-induced optical clearing effects in tissues and blood," Chap. 21 in Handbook of Optical Sensing of Glucose in Biological Fluids and Tissues, V. V. Tuchin, Ed., pp. 657-692, Taylor \& Francis Group LLC, CRC Press (2009).

121.A. T. Yeh, B. Choi, J. S. Nelson, and B. J. Tromberg, "Reversible dissociation of collagen in tissues," J. Invest. Dermatol. 121, 1332-1335 (2003).

122.J. Hirshburg, B. Choi, J. S. Nelson, and A. T. Yeh, "Collagen solubility correlates with skin optical clearing," J. Biomed. Opt. 11, 040501 (2006).

123.J. W. Wiechers, J. C. Dederen, and A. V. Rawlings, "Moisturization mechanisms: internal occlusion by orthorhombic lipid phase stabilizers - a novel mechanism of action of skin moisturization," Chap. 9 in Skin Moisturization, $2^{\text {nd }}$ ed., A. V. Rawlings and J. J. Leyden, Eds., pp. 309-321, Informa Healthcare, Taylor \& Francis Group, New York (2009).

124.A. V. Papaev, G. V. Simonenko, V. V. Tuchin, and T. P. Denisova, "Optical anisotropy of a biological tissue under conditions of immersion clearing and without them," Optics and Spectroscopy 101(1), 46-53 (2006).

125.A. Roggan, M. Friebel, K. Dorschel, A. Hahn, and G. Mueller, "Optical properties of circulating human blood in the wavelength range 400-2500 nm," J. Biomed. Opt. 4, 36-46 (1999).

126.M. Friebel, J. Helfmann, and M. Meinke, "Influence of osmolarity on the optical properties of human erythrocytes," J. Biomed. Opt. 15(5), 055005 (2010).

127.I. Fine, B. Fikhte, and L. D. Shvartsman, "RBC aggregation assisted light transmission through blood and occlusion oximetry," Proc. SPIE 4162, 130-139 (2000).

128. V. V. Tuchin, X. Xu, and R. K. Wang, "Dynamic optical coherence tomography in studies of optical clearing, sedimentation, and aggregation of immersed blood," Appl. Opt. 41(1), 258-271 (2002).

129.H. Schaefer, and T. E. Redelmeier, Skin Barrier, Karger, Basel (1996).

130.C. Liu, Z. Zhi, V. V. Tuchin, Q. Luo, and D. Zhu, "Enhancement of skin optical clearing efficacy using photoirradiation," Lasers Surg. Med. 42, 132-140 (2010).

131.V. V. Tuchin, G. B. Altshuler, A. A. Gavrilova, A. B. Pravdin, D. Tabatadze, J. Childs, and I. V. Yaroslavsky, "Optical clearing of skin using flashlamp-induced enhancement of epidermal permeability," Lasers Surg. Med. 38, 824-836 (2006).

132.E. A. Kolesnikova, A. S. Kolesnikov, E. A. Genina, L. E. Dolotov, D. K. Tuchina, A. N. Bashkatov, and V. V. Tuchin, "Use of fractional laser microablation of skin for improvement of its immersion clearing," Proc. SPIE 8699, 86990B (2013).

133.E. A. Genina, A. N. Bashkatov, V. V. Tuchin, G. B. Altshuler, and I. V. Yaroslavski, "Possibility of increasing the efficiency of laser-induced tattoo removal by optical skin clearing," Quantum Electronics 38(6), 580-587 (2008).

134.X. Xu, Q. Zhu, and C. Sun, “Assessment of the effects of ultrasound-mediated alcohols on skin optical clearing," J. Biomed. Opt. 14, 034042 (2009).

135.H. Zhong, Z. Guo, H. Wei, C. Zeng, H. Xiong, Y. He, and S. Liu, “In vitro study of ultrasound and differentconcentration glycerol-induced changes in human skin optical attenuation assessed with optical coherence tomography," J. Biomed. Opt. 15, 036012 (2010).

136.O. Stumpp, B. Chen, and B. Welch, "Using sandpaper for noninvasive transepidermal optical skin clearing agent delivery," J. Biomed. Opt. 11, 041118 (2006).

137.J. Yoon, T. Son, E. Choi, B. Choi, J. S. Nelson, and B. Jung, "Enhancement of optical clearing efficacy using a microneedle roller," J. Biomed. Opt. 13(2), 021103 (2008).

138.J. Yoon, D. Park, T. Son, J. Seo, J. S. Nelson, and B. Jung, “A physical method to enhance transdermal delivery of a tissue optical clearing agent: combination of microneedling and sonophoresis," Lasers Surg. Med. 42, $412-417$ (2010).

139.M. A. Fox, D. G. Diven, K. Sra, A. Boretsky, T. Poonawalla, A. Readinger, M. Motamedi, and R. J. Nichols, "Dermal scatter reduction in human skin: a method using controlled application of glycerol," Lasers Surg. Med. 41, 251-255 (2009). 
140.C. G. Rylander, T. E. Milner, S. A. Baranov, and J. S. Nelson, "Mechanical tissue optical clearing devices: enhancement of light penetration in ex vivo porcine skin and adipose tissue," Lasers Surg. Med. 40, 688-694 (2008).

141.X. Xu, and Q. Zhu, "Evaluation of skin optical clearing enhancement with Azone as a penetration enhancer," Optics Communications 279, 223-228 (2007).

142.J. Jiang, and R. K. Wang, "How different molarities of oleic acid as enhancer exert its effect on optical clearing of skin tissue in vitro," Journal of X-Ray Science and Technology, 13, 149-159 (2005).

143.J. Jiang, M. Boese, P. Turner, and R. K. Wang, "Penetration kinetics of dimethyl sulphoxide and glycerol in dynamic optical clearing of porcine skin tissue in vitro studied by Fourier transform infrared spectroscopic imaging," J. Biomed. Opt. 13(2), 021105 (2008).

144.A. K. Bui, R. A. McClure, J. Chang, C. Stoianovici, J. Hirshburg, A. T. Yeh, and B. Choi, "Revisiting optical clearing with dimethyl sulfoxide (DMSO)," Lasers Surg. Med. 41, 142-148 (2009).

145.M. Zimmerley, R. A. McClure, B. Choi, and E. O. Potma, "Following dimethyl sulfoxide skin optical clearing dynamics with quantitative nonlinear multimodal microscopy,” Appl. Opt. 48(10), D79-D87 (2009).

146.S. Karma, J. Homan, C. Stoianovic, and B. Choi, "Enhanced fluorescence imaging with DMSO-mediated optical clearing," Journal of Innovative Optical Health Sciences 3(3), 153-158 (2010).

147.Z. Zhi, Z. Han, Q. Luo, and D. Zhu, "Improve optical clearing of skin in vitro with propylene glycol as a penetration enhancer," Journal of Innovative Optical Health Sciences 2(3), 269-278 (2009).

148.X. Xu, Q. Zhu, and C. Sun, "Combined effect of ultrasound-SLS on skin optical clearing," IEEE Photonic Technol. Lett. 20(24), 2117-2119 (2008).

149.H. Zhong, Z. Guo, H. Wei, L. Guo, C. Wang, Y. He, H. Xiong, and S. Liu, "Synergistic effect of ultrasound and thiazone-PEG 400 on human skin optical clearing in vivo," Photochem. Photobiol. 86(3), 732-737 (2010).

150.T. Kurihara-Bergstrom, K. Knutson, L. J. de Noble, and C. Y. Goates, "Percutaneous absorption enhancement of an ionic molecule by ethanol-water system in human skin," Pharm. Res. 7, 762-766 (1990).

151.A. C. Williams, and B. W. Barry, "Penetration enhancers," Adv. Drug Deliv. Rev. 56, 603-618 (2004).

152.J.-M. Andanson, K. L. A. Chan, and S. G. Kazarian, "High-throughput spectroscopic imaging applied to permeation through the skin," Appl. Spectrosc. 63(5), 512-517 (2009).

153.A. P. Funke, R. Schiller, H. W. Motzkus, C. Gunther, R. H. Muller, and R. Lipp, "Transdermal delivery of highly lipophilic drugs: in vitro fluxes of antiestrogens, permeation enhancers, and solvents from liquid formulations," Pharm. Res. 19(5), 661-668 (2002).

154.A. Pagnoni, A. Knuettel, P. Welker, M. Rist, T. Stoudemayer, L. Kolbe, I. Sadiq, and A. M. Kligman, “Optical coherence tomography in dermatology," Skin Res. Technol. 5(2), 83-87 (1999).

155.R. Samatham, K. G. Phillips, and S. L. Jacques, "Assessment of optical clearing agents using reflectance-mode confocal scanning laser microscopy,” J. Innovative Opt. Health Sci. 3(3), 183-188 (2010).

156.P. Liu, Y. Huang, Z. Guo, J. Wang, Z. Zhuang, and S. Liu, "Discrimination of dimethyl sulphoxide diffusion coefficient in the process of optical clearing by confocal micro-Raman spectroscopy," J. Biomed. Opt. 18(2), 020507 (2013).

157.G. Terentyuk, E. Panfilova, V. Khanadeev, D. Chumakov, E. Genina, A. Bashkatov, V. Tuchin, N. Khlebtsov, and B. Khlebtsov, "Gold nanorods with hematoporphyrin-loaded silica shell for dual-modality photodynamic and photothermal treatment of tumors in vivo," NanoResearch 7(3), 325-337 (2014).

158.O. Stumpp, A. J. Welch, and J. Neev, "Enhancement of transdermal skin clearing agent delivery using a 980 nm diode laser," Lasers Surg. Med. 37, 278-285 (2005).

159.A. Tezel, and S. Mitragotri, "Interaction of inertial cavitation bubbles with stratum corneum lipid bilayers during low frequency sonophoresis," Biophys. J. 85, 3502-3512 (2003).

160.A. K. Nugroho, G. L. Li, M. Danhof, and J. A. Bouwstra, "Transdermal iontophoresis of rotigotine across human stratum corneum in vitro: influence of $\mathrm{pH}$ and $\mathrm{NaCl}$ concentration," Pharm. Res. 21(5), 844-850 (2004).

161.O. Stumpp, and A. J. Welch, "Injection of glycerol into porcine skin for optical skin clearing with needle-free injection gun and determination of agent distribution using OCT and fluorescence microscopy," Proc. SPIE 4949, 44-50 (2003).

162.H.-J. Weigmann, J. Lademann, S. Schanzer, U. Lindemann, R. von Pelchrzim, H. Schaefer, W. Sterry, and V. Shah, "Correlation of the local distribution of topically applied substances inside the stratum corneum determined by tape stripping to differences in bioavailability," Skin Pharmacol. Appl. Skin Physiol. 14, 93103 (2001).

163.W. R. Lee, R. Y. Tsai, C. L. Fang, C. J. Liu, C. H. Hu, and J. Y. Fang, "Microdermabrasion as a novel tool to enhance drug delivery via the skin: an animal study," J. Dermatol. Surg. 32, 1013-1022 (2006).

164.A. N. Bashkatov, E. A. Genina, V. V. Tuchin, and G. B. Altshuler, "Skin optical clearing for improvement of laser tattoo removal," Laser Physics 19(6), 1312-1322 (2009).

165.X. Xu, and Q. Zhu, "Feasibility of sonophoretic delivery for effective skin optical clearing," IEEE Trans. Biomed. Eng. 55(4), 1432-1437 (2008). 
166.X. Xu, and Q. Zhu, "Sonophoretic delivery for contrast and depth improvement in skin optical coherence tomography," IEEE J. Sel. Top. Quantum Electron. 14(1), 56-61 (2008).

167.I. Lavon, N. Grossman, J. Kost, E. Kimmel, and G. Enden, "Bubble growth within the skin by rectified diffusion might play a significant role in sonophoresis," J. Controlled Release 117(2), 246-255 (2007).

168.X. Xu, and C. Sun, "Ultrasound enhanced skin optical clearing: microstructural changes," J. Innovative Opt. Health Sci. 3(3), 189-194 (2010).

169.A. K. Nugroho, O. Della Pasqua, M. Danhof, and J. A. Bouwstra, "Compartmental modeling of transdermal iontophoretic transport: I. in vitro model derivation and application," Pharmaceutical Research 21(11), 19741984 (2004).

170.J. Wang, X. Zhou, S. Duan, Z. Chen, and D. Zhu, "Improvement of in vivo rat skin optical clearing with chemical penetration enhancers," Proc. SPIE 7883, 78830Y (2011).

171.Yu. P. Sinichkin, and S. R. Utz, In vivo reflectance and fluorescence spectroscopy of human skin, Saratov: Saratov University Press (2001).

172. Yu. P. Sinichkin, N. Kollias, G. Zonios, S. R. Utz, and V. V. Tuchin, "Back reflectance and fluorescence spectroscopy of the human skin in vivo," in Handbook on Optical Biomedical Diagnostics and Imaging, V. V. Tuchin, Ed., pp. 725-785, Bellingham, SPIE Press (2002).

173.G. A. Askar'yan, "Enhancement of transmission of laser and other radiation by soft turbid physical and biological media," Sov. J. Quantum Electron. 12(7), 877-880 (1982).

174.E. K. Chan, B. Sorg, D. Protsenko, M. O’Neil, M. Motamedi, and A. J. Welch, "Effects of compression on soft tissue optical properties," IEEE J. Sel. Topics in Quantum Electr. 2(4), 943-950 (1996).

175.H. Shangguan, S. A. Prahl, S. L. Jacques, and L. W. Casperson, "Pressure effects on soft tissues monitored by changes in tissue optical properties," Proc. SPIE 3254, 366-371 (1998).

176. Yu. P. Sinichkin, S. R. Uts, and E. A. Pilipenko, "Spectroscopy of human skin in vivo: 1. Reflection spectra," Optics and Spectroscopy 80(2). C. 228-234 (1996).

177.B. W. Murphy, R. J. Webster, B. A. Turlach, C. J. Quirk, C. D. Clay, P. J. Heenan, and D. D. Sampson, "Toward the discrimination of early melanoma from common and dysplastic nevus using fiber optic diffuse reflectance spectroscopy," J Biomed. Opt. 10(6), 064020 (2005).

178. W. Chen, R. Liu, K. Xu, and R. K. Wang, "Influence of contact state on NIR diffuse reflectance spectroscopy in vivo," J. Phys. D: Appl. Phys. 38, 2691-2695 (2005).

179.L. L. Randeberg, Diagnostic applications of diffuse reflectance spectroscopy, PhD thesis, Norwegian University of Science and Technology, Trondheim, Norway (2005).

180.S. A. Carp, T. Kauffman, Q. Fang, E. Rafferty, R. Moore, D. Kopans, and D. Boas, "Compression-induced changes in the physiological state of the breast as observed through frequency domain photon migration measurements," J. Biomed. Opt. 11(6), 064016 (2006).

181.R. Reif, M. S. Amorosino, K. W. Calabro, O. A’Amar, S. K. Singh, and I. J. Bigio, “Analysis of changes in reflectance measurements on biological tissues subjected to different probe pressures," J. Biomed. Opt. 13(1), 010502 (2008).

182.Y. Ti, and W. C. Lin, "Effects of probe contact pressure on in vivo optical spectroscopy," Opt. Express 16(6), 4250-4262 (2008).

183. A. Cerussi, S. Siavoshi, A. Durkin, C. Chen, W. Tanamai, D. Hsiang, and B. J. Tromberg, "Effect of contact force on breast tissue optical property measurements using a broadband diffuse optical spectroscopy handheld probe," Appl. Opt. 48, 4270-4277 (2009).

184.J. A. Delgado Atencio, E. E. Orozco Guillén, S. Vázquezy Montiel, M. Cunill Rodríguez, J. Castro Ramos, J. L. Gutiérrez, and F. Martínez, "Influence of probe pressure on human skin diffuse reflectance spectroscopy measurements," Optical Memory \& Neural Networks (Information Optics) 18(1), 6-14 (2009).

185.L. Lim, B. Nichols, N. Rajaram, and J. W. Tunnell, "Probe pressure effects on human skin diffuse reflectance and fluorescence spectroscopy measurements," J. Biomed. Opt. 16(1), 011012 (2011).

186.S. Ruderman, A. J. Gomes, V. Stoyneva, J. D. Rogers, A. J. Fought, B. D. Jovanovic, and V. Backman, "Analysis of pressure, angle and temporal effects on tissue optical properties from polarization-gated spectroscopic probe measurements," Biomedical Optics Express 1(2), 489-499 (2010).

187. Yu. P. Sinichkin, S. R. Uts, I. V. Meglinskii, and E. A. Pilipenko, "Spectroscopy of human skin in vivo: II. Fluorescence spectra," Optics and Spectroscopy 80(3). C. 383-389 (1996).

188. A. Nath, K. Rivoire, S. Chang, D. Cox, E. N. Atkinson, M. Follen, and R. Richards-Kortum, "Effect of probe pressure on cervical fluorescence spectroscopy measurements," J. Biomed. Opt. 9(3), 523-533 (2004).

189.K. Rivoire, A. Nath, D. Cox, E. N. Atkinson, R. Richards-Kortum, and M. Follen, "The effects of repeated spectroscopic pressure measurements on fluorescence intensity in the cervix," Am. J. Obstet. Gynecol. 191(5), 1606-1617 (2004).

190.A. Izquierdo-Roman, W. C. Vogt, L. Hyacinth, and C. G. Rylander, "Mechanical tissue optical clearing technique increases imaging resolution and contrast through ex vivo porcine skin," Lasers Surg. Med. 43, 814823 (2011). 
191.V. V. Sapozhnikova, R. V. Kuranov, I. Cicenaite, R. O. Esenaliev, and D. S. Prough, "Effect on blood glucose monitoring of skin pressure exerted by an optical coherence tomography probe," J. Biomed. Opt. 13(2), 021112 (2008).

192. M. Y. Kirillin, P. D. Agrba, and V. A. Kamensky, 'In vivo study of the effect of mechanical compression on formation of OCT images of human skin," J. Biophotonics 3(12), 752-758 (2010).

193.A. A. Gurjarpadhye, W. C. Vogt, Y. Liu, and C. G. Rylander, "Effect of localized mechanical indentation on skin water content evaluated using OCT,” Int. J. Biomed. Imag. 2011, 817250 (2011).

194.M. H. Khan, B. Choi, S. Chess, K. M. Kelly, J. McCullought, and J. S. Nelson, "Optical clearing of in vivo human skin: Implications for light-based diagnostic imaging and therapeutics," Lasers Surg. Med. 34(2), 83-85 (2004).

195.H. Kang, T. Son, J. Yoon, K. Kwon, J. S. Nelson, and B. Jung, "Evaluation of laser beam profile in soft tissue due to compression, glycerol, and micro-needling," Laser Surg. Med. 40(8), 570-575 (2008).

196.C. G. Rylander, T. E. Milner, S. A. Baranov, and J. S. Nelson, "Mechanical tissue optical clearing devices: enhancement of light penetration in ex vivo porcine skin and adipose tissue," Lasers Surg. Med. 40(10), 688694 (2008).

197.I. V. Ermakov, and W. Gellermann, "Dermal carotenoid measurements via pressure mediated reflection spectroscopy," J. Biophotonics 5(7), 559-570 (2012).

198.L. E. Dolotov, and Yu. P. Sinichkin, "Features of applying fiber-optic sensors in spectral measurements of biological tissues," Optics and Spectroscopy 115(2), 187-192 (2013).

199.C. Li, J. Jiang, and K. Xu, "The variations of water in human tissue under certain compression: studied with diffuse reflectance spectroscopy,” J. Innov. Opt. Health Sci. 6(1), 1350005 (2013).

200.K. A. Martin, Direct measurement of moisture in skin by NIR spectroscopy," J. Soc. Cosm. Chem. 44, 249261 (1993).

201.C. W. J. Oomens, D. H. Vancampen, and H. J. Grootenboer, “A mixture approach to the mechanics of skin,” J. Biomech. 20(9), 877-885 (1987).

202.A. Hidenobu, and E. Mariko, "Non-contact skin moisture measurement based on near-infrared spectroscopy," Appl. Spectrosc. 58, 1439-1446 (2004).

203.A. N. Bashkatov, E. A. Genina, and V. V. Tuchin, "Optical properties of skin, subcutaneous and muscle tissues, a review," J. Innovative Opt. Health Sci. 14(1), 9-38 (2011).

204.T. L. Troy, and S. N. Thennadil, "Optical properties of human skin in the NIR wavelength range of 1000-2200 nm,” J. Biomed. Opt. 6, 167-176 (2001).

205.I. Yu. Yanina, G. V. Simonenko, and V. V. Tuchin, "Destructive fat tissue engineering using photodynamic and selective photothermal effects," Proc SPIE 7179, 71790C (2009).

206. V. A. Doubrovsky, I. Yu. Yanina, and V. V. Tuchin, "Inhomogeneity of photo-induced fat cell lipolysis," Proc. SPIE 7999, 79990M (2011).

207. Yu. A. Vladimirov, and A. Ya. Potapenko, Physico-chemical basis of photobiological processes, Moscow: Dropha (2006).

208. M. Wanner, M. Avram, D. Gagnon, M. C. Mihm Jr., D. Zurakowski, K. Watanabe, Z. Tannous, R. R. Anderson, and D. Manstein, "Effects of noninvasive, $1210 \mathrm{~nm}$ laser exposure on adipose tissue: results of a human pilot study," Lasers Surg. Med. 41, 401-407 (2009).

209. W. R. Chen, R. L. Adams, S. Heaton, D. T. Dickey, K. E. Bartels, and R. E. Nordquist, "Chromophoreenhanced laser-tumor tissue photothermal interaction using an 808-nm diode laser," Cancer Lett. 88, 15-19 (1995).

210.W. R. Chen, R. L. Adams, A. K. Higgins, K. E. Bartels, and R. E. Nordquist, "Photothermal effects on murine mammary tumors using indocyanine green and an 808-nm diode laser: an in vivo efficacy," Cancer Lett. 98, 169-173 (1996).

211.S. Fickweiler, R. M. Szeimies, W. Baumler, P. Steinbach, S. Karrer, A. E. Goetz, C. Abels, F. Hofstadter, and M. Landthaler, "Indocyanine green: intracellular uptake and phototherapeutic effects in vitro," J. Photochem. Photobiol. B 38, 178-183 (1997).

212.V. V. Tuchin, E. A. Genina, A. N. Bashkatov, G. V. Simonenko, O. D. Odoevskaya, and G. B. Altshuler, “A pilot study of ICG laser therapy of acne vulgaris: photodynamic and photothermolysis treatment," Lasers Surg. Med. 33(5), 296-310 (2003).

213.E. A. Genina, A. N. Bashkatov, G. V. Simonenko, O. D. Odoevskaya, V. V. Tuchin, and G. B. Altshuler, "Low-intensity Indocyanine green - laser phototherapy of acne vulgaris: Pilot study," J. Biomed. Opt. 9(4), 828-834 (2004).

214. V. I. Kochubey, T. V. Kulyabina, V. V. Tuchin, and G. B. Altshuler, "Spectral characteristics of indocyanine green upon its interaction with biological tissues," Optics and Spectroscopy 99(4), 560-566 (2005).

215.E. A. Genina, A. N. Bashkatov, Yu. P. Sinichkin, V. I. Kochubey, N. A. Lakodina, G. B. Altshuler, and V. V. Tuchin, "In vitro and in vivo study of dye diffusion into the human skin and hair follicles," J. Biomed. Opt. 7(3), 471-477 (2002). 
216.E. Engel, R. Schraml, T. Maisch, K. Kobuch, B. König, R.-M. Szeimies, J. Hillenkamp, W. Bäumler, and R. Vasold, "Light-induced decomposition of indocyanine green," Invest. Ophthalmol. Vis. Sci. 49, 1777-1783 (2008).

217.M. Sznitowska, "The influence of ethanol on permeation behavior of the porous pathway in the stratum corneum,” Int. J. Pharmacol. 137, 137-140 (1996).

218.A. K. Levang, K. Zhao, and J. Singh, "Effect of ethanol/propylene glycol on the in vitro percutaneous absorption of aspirin, biophysical changes and macroscopic barrier properties of the skin," Int. J. Pharm. 181, 255-263 (1999).

219.C. A. Squier, M. J. Kremer, and P. W. Wertz, "Effect of ethanol on lipid metabolism and epidermal permeability barrier of skin and oral mucosa in the rat," J. Oral Pathol. Med. 32, 595-599 (2003).

220. V. A. Dubrovskii, B. A. Dvorkin, I. Yu. Yanina, and V. V. Tuchin, "Photoaction upon adipose tissue cells in vitro," Cell and Tissue Biology 5(5), 520-529 (2011).

221.B. Alberts, D. Bray, J. Lewis, M. Raff, K. Roberts, and J. D. Watson, Molecular Biology of the Cell, $2^{\text {nd }}$ edition, Vol. 1, Garland Publishing. Inc. New York London (1989).

222.A. L. Lehninger, Principles of Biochemistry, Vol. 2, Worth Publisher, Inc. (1982).

223.L. Stryer, Biochemistry, W. H. Freeman and Company, San Francisco (1981).

224.I. Yu. Yanina, N. A. Trunina, and V. V. Tuchin, "Photoinduced cell morphology alterations quantified within adipose tissues by spectral optical coherence tomography," J. Biomed. Opt. 18(11), 111407 (2013).

225.R. K. Wang, and V. V. Tuchin, "Enhance light penetration in tissue for high resolution optical imaging techniques by the use of biocompatible chemical agents," J. X-Ray Science and Technol. 10, 167-176 (2002).

226.R. K. Wang, and J. B. Elder, "Propylene glycol as a contrasting agent for optical coherence tomography to image gastrointestinal tissues," Lasers Surg. Med. 30(3), 201-208 (2002).

227.H. Xiong, Z. Guo, C. Zeng, L. Wang, Y. He, and S. Liu, "Application of hyperosmotic agent to determine gastric cancer with optical coherence tomography ex vivo in mice," J. Biomed. Opt. 14(2), 024029 (2009).

228.H. Q. Zhong, Z. Y. Guo, H. J. Wei, J. L. Si, L. Guo, Q. L. Zhao, C. C. Zeng, H. L. Xiong, Y. H. He, and S. H. Liu, "Enhancement of permeability of glycerol with ultrasound in human normal and cancer breast tissues in vitro using optical coherence tomography," Laser Physics Letters 7(5), 388-395 (2010).

229.Z. Zhu, H. Wei, G. Wu, H. Yang, Y. He, and S. Xie, "Synergistic effect of hyperosmotic agents and sonophoresis on breast tissue optical properties and permeability studied with spectral domain optical coherence tomography," J. Biomed. Opt. 17(8), 086002 (2012).

230.D. J. Faber, F. J. van der Meer, M. C. G. Aalders, and T. G. van Leeuwen, "Quantitative measurement of attenuation coefficients of weakly scattering media using optical coherence tomography," Optics Express 12(19), 4353-4365 (2004).

231.P. Lee, W. Gao, and X. Zhang, "Performance of single-scattering model versus multiple-scattering model in the determination of optical properties of biological tissue with optical coherence tomography," Appl. Opt. 49(18), 3538-3544 (2010).

232.K. V. Larin, and V. V. Tuchin, "Monitoring of glucose diffusion in epithelial tissues with optical coherence tomography," Chap. 20 in Handbook of Optical Sensing of Glucose in Biological Fluids and Tissues, V. V. Tuchin, Ed., pp. 635-668, Taylor \& Francis Group LLC, CRC Press (2009).

233. T. Yamaguchi, N. Omatsu, E. Morimoto, H. Nakashima, K. Ueno, T. Tanaka, K. Satouchi, F. Hirose, and T. Osumi, "CGI-58 facilitates lipolysis on lipid droplets but is not involved in the vesiculation of lipid droplets caused by hormonal stimulation,” J. Lipid Res. 48(5), 1078-1089 (2007).

234.J. Sharpe, "Optical projection tomography,” Annual Review of Biomedical Engineering 6, 209-228 (2004).

235.J. Sharpe, U. Ahlgren, P. Perry, B. Hill, A. Ross, J. Hesksher-Sorensen, R. Baldock, and D. Davidson, “Optical projection tomography as a tool for 3D microscopy and gene expression studies," Science 296, 541-545 (2002).

236. T. Alanentalo, A. Asayesh, H. Morrison, C. E. Loren, D. Holmberg, J. Sharpe, and U. Ahlgren, "Tomographic molecular imaging and 3D quantification within adult mouse organs," Nature Methods 4(1), 31-33 (2007).

237.T. Alanentalo, C. E. Loren, A. Larefalk, J. Sharpe, D. Holmberg, and U. Ahlgren, "High-resolution threedimensional imaging of isletinfiltrate interactions based on optical projection tomography assessments of the intact adult mouse pancreas," J. Biomed. Opt. 13(5), 054070 (2008).

238.H. Schneckenburger, R. Steiner, W. S. L. Strauss, K. Stock, and R. Sailer, "Fluorescence Technologies in Biomedical Diagnostics," Chap. 15 in Handbook of Optical Biomedical Diagnostics, V. V. Tuchin (Ed.), pp. 825-874, SPIE Press, PM107, Bellingham (2002).

239.H. Ashkenazi, Z. Malik, Y. Harth, and Y. Nitzan, "Eradication of Propionibacterium acnes by its endogenic porphyrins after illumination with high intensity blue light,” FEMS Immunol. and Med. Microbiol. 35, 17-24 (2003).

240. Y. Kotoku, J. Kato, G. Akashi, Y. Hirai, and K. Ishihara, "Bactericidal effect of a 405-nm diode laser on Porphyromonas gingivalis," Laser Physics Letters 6(5), 388-392 (2009). 
241.K. König, G. Flemming, and R. Hibst, "Laser-induced autofluorescence spectroscopy of dental caries lesion," Cell. Mol. Biol. 44, 1293-1300 (1998).

242.E. G. Borisova, T. T. Uzunov, and L. A. Avramov, "Early differentiation between caries and tooth demineralization using laser-induced autofluorescence spectroscopy," Lasers Surg. Med. 34, 249-253 (2004).

243. E. Borisova, T. Uzunov, and L. Avramov, "Laser-induced autofluorescence study of caries model in vitro," Lasers Med. Sci. 21(1), 34-41 (2006).

244.R. R. Alfano, W. Lam, H. J. Zarrabi, M. A. Alfano, J. Cordero, D. B. Tata, and C. E. Swenberg, "Human teeth with and without caries studied by laser scattering, fluorescence, and absorption spectroscopy," IEEE J. Quantum Electronics QE-20(12), 1512-1516 (1984).

245.K. Konig, H. Schneckenburger, and R. Hibst, "Time-gated in vivo autofluorescence imaging of dental caries," Cell. Mol. Biol. 45, 233-239 (1999).

246.E. Borisova, P. Troyanova, P. Pavlova, and L. Avramov, "Diagnostics of pigmented skin tumors based on laser-induced autofluorescence and diffuse reflectance spectroscopy," Quantum Electronics 38(6), 597-605 (2008).

247.E. Borisova, E. Carstea, L. Cristescu, E. Pavlova, N. Hadjiolov, P. Troyanova, and L. Avramov, "Lightinduced fluorescence spectroscopy and optical coherence tomography of basal cell carcinoma," Journal of Innovative Optical Health Sciences 2(3), 261-268 (2009).

248.S. K. Chang, Y. N. Mirabal, E. N. Atkinson, D. Cox, A. Malpica, M. Follen, and R. R. Richards-Kortum, "Combined reflectance and fluorescence spectroscopy for in vivo detection of cervical pre-cancer," J. Biomed. Opt. 10(2), 024031 (2005).

249.A. Alimova, A. Katz, V. Sriramoju, Y. Budansky, A. A. Bykov, R. Zeylikovich, and R. R. Alfano, "Hybrid phosphorescence and fluorescence native spectroscopy for breast cancer detection," J. Biomed. Opt. 12(1), 014004 (2007).

250.A. Gerger, S. Koller, T. Kern, C. Massone, K. Steiger, E. Richtig, H. Kerl, and J. Smolle, "Diagnostic applicability of in vivo confocal laser scanning microscopy in melanocytic skin tumors," J. Invest. Dermatol. 124, 493-498 (2005).

251.S.-J. Tseng, Y.-H. Lee, Z.-H. Chen, H.-H. Lin, C.-Y. Lin, and S.-C. Tang, "Integration of optical clearing and optical sectioning microscopy for three-dimensional imaging of natural biomaterial scaffolds in thin sections," J. Biomed. Opt. 14(4), 044004 (2009).

252.Y.-Y. Fu, C.-W. Lin, G. Enikolopov, E. Sibley, A.-S. Chiang, and S.-C. Tang, "Microtome-free 3-dimensional confocal imaging method for visualization of mouse intestine with subcellular-level resolution," Gastroenterology 137(2), 453-465 (2009).

253.Y.-Y. Fu, and S.-C. Tang, "Optical clearing facilitates integrated 3D visualization of mouse ileal microstructure and vascular network with high definition," Microvascular Res. 80, 512-521 (2010).

254.Y.-A. Liu, Y. Chen, A.-S. Chiang, S.-J. Peng, P. J. Pasricha, and S.-C. Tang, "Optical clearing improves the imaging depth and signal-to-noise ratio for digital analysis and three-dimensional projection of the human enteric nervous system," Neurogastroenterology \& Motility 23, e446-e457 (2011).

255.Y.-Y. Fu, C.-H. Lu, C.-W. Lin, J.-H. Juang, G. Enikolopov, E. Sibley, A.-S. Chiang, and S.-C. Tang, “Threedimensional optical method for integrated visualization of mouse islet microstructure and vascular network with subcellular-level resolution,” J. Biomed. Opt. 15(4), 046018 (2010).

256.A.-S. Chiang, Y.-C. Liu, S.-L. Chiu, S.-H. Hu, C.-Y. Huang, and C.-H. Hsieh, "Three dimensional mapping of brain neuropils in the cockroach Diploptera punctata," J. Comp. Neurol. 440, 1-11 (2001).

257.A. S. Chiang, “Aqueous tissue clearing solution,” US Patent, US6472216 (2002).

258.J. Huisken, and D. Y. R. Stainier, "Selective plane illumination microscopy techniques in developmental biology,” Development 136, 1963-1975 (2009).

259.K. Becker, N. Jährling, E. R. Kramer, F. Schnorrer, and H.-U. Dodt, "Ultramicroscopy: 3D reconstruction of large microscopical specimens,” J. Biophotonics 1, 36-42 (2008).

260.K. Becker, N. Jährling, S. Saghafi, R. Weiler, and H. U. Dodt, "Chemical clearing and dehydration of GFP expressing mouse brains," PLOS One 7(3), e33916 (2012).

261.O. I. Efimova, and K. V. Anokhin, "Increase of optical permeability of isolated adult mouse brain structures," Bull. Exp. Biol. Med. 147(1), 4-7 (2009).

262.A. Ertürk, K. Becker, N. Jährling, C. P. Mauch, C. D. Hojer, J. G. Egen, F. Hellal, F. Bradke, M. Sheng, and H. U. Dodt, "Three-dimensional imaging of solvent-cleared organs using 3DISCO," Nature Protocols 7(11), 1983-1995 (2012).

263.R. G. M. Kolkman, E. Hondebrink, W. Steenbergen, and F. F. M. de Mul, "In vivo photoacoustic imaging of blood vessels using an extreme-narrow aperture sensor," IEEE J. Sel. Top. Quantum Electron. 9, 343-346 (2003).

264.R. G. M. Kolkman, J. H. G. M. Klaessens, E. Hondebrink, J. C. W. Hopman, F. F. M. de Mul, W. Steenbergen, J. M. Thijssen, and T. G. van Leeuwen, "Photoacoustic determination of blood vessel diameter," Phys. Med. Biol. 49, 4745-4756 (2004). 
265.K. Maslov, G. Stoica, and L. H. Wang, "In vivo dark-field reflection-mode photoacoustic microscopy," Opt. Lett. 30(6), 625-627 (2005).

266. A. A. Oraevsky, A. A. Karabutov, S. V. Solomatin, E. V. Savateeva, V. A. Andreev, Z. Gatalica, H. Singh, and R. D. Fleming, "Laser optoacoustic imaging of breast cancer in vivo," Proc. SPIE 4256, 6-15 (2001).

267.H. F. Zhang, K. Maslov, and L. H. Wang, "In vivo imaging of subcutaneous structures using functional photoacoustic microscopy," Nature Protocols 2(4), 797-804 (2007).

268.R. O. Esenaliev, I. V. Larina, K. V. Larin, D. J. Deyo, M. Motamedi, and D. S. Prough, "Optoacoustic technique for noninvasive monitoring of blood oxygenation: a feasibility study," Appl. Opt. 41, 4722-4731 (2002).

269.C. C. Harland, J. C. Bamber, B. A. Gusterson, and P. S. Mortime, "High frequency, high resolution B-scan ultrasound in the assessment of skin tumours," Br. J. Dermatol. 128, 525-532 (1993).

270.Y. Zhou, J. J. Yao, and L. H. Wang, "Optical clearing-aided photoacoustic microscopy with enhanced resolution and imaging depth,” Opt. Lett. 38(14), 2592-2595 (2013).

271.K. M. Quan, G. B. Christison, H. A. MacKenzie, and P. Hodgson, "Glucose determination by a pulsed photoacoustic technique: an experimental study using a gelatin-based tissue phantom,” Phys. Med. Biol. 38, 1911-1922 (1993).

272.M. Kinnunen, and R. Myllyla, "Application of optical coherence tomography, pulsed photoacoustic technique, and time-of-flight technique to detect changes in the scattering properties of a tissue-simulating phantom," J. Biomed. Opt. 13(2), 024005 (2008).

273.H. A. MacKenzie, H. S. Ashton, S. Spiers, Y. Shen, S. S. Freeborn, J. Hannigan, J. Lindberg, and P. Rae, "Advances in photoacoustic noninvasive glucose testing," Clin. Chem. 45, 1587-1595 (1999).

274.O. S. Khalil, "Non-invasive glucose measurement technologies: an update from 1999 to the dawn of the new millennium," Diabetes Technol. Ther. 6, 660-697 (2004).

275.R. Cicchi, S. Sestini, V. De Giorgi, D. Massi, T. Lotti, and F. S. Pavone, "Nonlinear laser imaging of skin lesions," J. Biophotonics 1(1), 62-73 (2008).

276.P. J. Campagnola, H. A. Clark, W. A. Mohler, A. Lewis, and L. M. Loew, "Second-harmonic imaging microscopy of living cells," J. Biomed. Opt. 6(3), 277-286 (2001).

277.P. J. Campagnola, A. C. Millard, M. Terasaki, P. E. Hoppe, C. J. Malone, and W. A. Mohler, "Threedimensional high-resolution second-harmonic generation imaging of endogenous structural proteins in biological tissues," Biophys. J. 82, 493-508 (2002).

278.P. Bianchini, and A. Diaspro, "Three-dimensional (3D) backward and forward second harmonic generation (SHG) microscopy of biological tissues," J. Biophotonics 1(6), 443-450 (2008).

279. V. Ajeti, O. Nadiarnykh, S. M. Ponik, P. J. Keely, K. W. Eliceiri, and P. J. Campagnola, "Structural changes in mixed Col I/Col V collagen gels probed by SHG microscopy: implications for probing stromal alterations in human breast cancer," Biomedical Optics Express 2(8), 2307-2316 (2011).

280.T. Yasui, Y. Tohno, and T. Araki, "Characterization of collagen orientation in human dermis by twodimensional second-harmonic-generation polarimetry,” J. Biomed. Opt. 9(2), 259-264 (2004).

281.H. G. Breunig, M. Weinigel, R. Buckle, M. Kellner-Hofer, J. Lademann, M. E. Darvin, W. Sterry, and K. Konig, "Clinical coherent anti-Stokes Raman scattering and multiphoton tomography of human skin with a femtosecond laser and photonic crystal fiber," Laser Physics Letters 10, 025604 (2013).

282.G. Deka, W.-W. Wu, and F.-J. Kao, "In vivo wound healing diagnosis with second harmonic and fluorescence lifetime imaging," J. Biomed. Opt. 18(6), 061222 (2013).

283.A. Ghazaryan, H. F. Tsai, G. Hayrapetyan, W.-L. Chen, Y.-F. Chen, M. Y. Jeong, C.-S. Kim, S.-J. Chen, and C.-Y. Dong, "Analysis of collagen fiber domain organization by Fourier second harmonic generation microscopy,” J. Biomed. Opt. 18(3), 031105 (2013).

284.R. Cicchi, L. Sacconi, and F. Pavone "Nonlinear Imaging of Tissues," Chap. 20 in Handbook of Photonics for Biomedical Science, V. V. Tuchin (Ed.), pp. 509-545, CRC Press, Taylor \& Francis Group, Boca Raton (2010).

285.M. Muller, J. A. Squier, T. Wilson, and G. Brakenhoff, “3D microscopy of transparent objects using thirdharmonic generation," J. Microsc. 191, 266-272 (1998).

286.G. Hall, K. W. Eliceiri, and P. J. Campagnola, "Simultaneous determination of the second-harmonic generation emission directionality and reduced scattering coefficient from three-dimensional imaging of thick tissues," J. Biomed. Opt. 18(1), 116008 (2013).

287.M. Zimmerley, R. A. McClure, B. Choi, and E. O. Potma, "Following dimethyl sulfoxide skin optical clearing dynamics with quantitative nonlinear multimodal microscopy," Appl. Opt. 48(10), D79-D87 (2009).

288. M. V. Schulmerich, J. H. Cole, K. A. Dooley, M. D. Morris, J. M. Kreider, and S. A. Goldstein, "Optical clearing in transcutaneous Raman spectroscopy of murine cortical bone tissue,” J. Biomed. Opt. 13(2), 021108 (2008).

289.D. Huang, W. Zhang, H. Zhong, H. Xiong, X. Guo, and Z. Guo, "Optical clearing of porcine skin tissue in vitro studied by Raman microspectroscopy,” J. Biomed. Opt. 17(1), 015004 (2012). 
290.P. J. Caspers, A. C. Williams, E. A. Carter, H. G. M. Edwards, B. W. Barry, H. A. Bruining, and G. J. Puppels, "Monitoring the penetration enhancer dimethyl sulfoxide in human stratum corneum in vivo by confocal Raman spectroscopy," Pharm. Res. 19(10), 1577-1580 (2002).

291.A. A. Angeluts, A. V. Balakin, M. G. Evdokimov, M. N. Esaulkov, M. M. Nazarov, I. A. Ozheredov, D. A. Sapozhnikov, P. M. Solyankin, O. P. Cherkasova, and A. P. Shkurinov, "Characteristic responses of biological and nanoscale systems in the terahertz frequency range," Quantum Electronics 44(7), 614-632 (2014).

292.M. Nazarov, A. Shkurinov, V. V. Tuchin, and X.-C. Zhang, "Terahertz tissue spectroscopy and imaging," Chapter 17 in Handbook of Photonics for Biomedical Science, V. V. Tuchin, Ed., pp. 592-617, CRC Press, London, Taylor \& Francis Group (2010).

293.M. M. Nazarov, A. P. Shkurinov, E. A. Kuleshov, and V. V. Tuchin, "Terahertz time-domain spectroscopy of biological tissues," Quantum Electronics 38(7), 647-654 (2008).

294.G. M. Png, J. W. Choi, B. W.-H. Ng, S. P. Mickan, D. Abbott, and X.-C. Zhang, "The impact of hydration changes in fresh bio-tissue on THz spectroscopic measurements," Phys. Med. Biol. 53, 3501-3517 (2008).

295.A. V. Borodin, V. Ya. Gayvoronsky, O. D. Kachkovsky, Ya. A. Prostota, A. V. Kargovskii, M. M. Nazarov, D. A. Sapozhnikov, Yu. L. Slominskii, I. N. Smirnova, and A. P. Shkurinov, "Structure sensitive changes in the terahertz absorption spectra of merocyanine dye derivatives," Optics and Spectroscopy 107(4), 505-514 (2009).

296.C. S. Joseph, R. Patel, V. A. Neel, R. H. Giles, and A. N. Yaroslavsky, "Imaging of ex vivo nonmelanoma skin cancers in the optical and terahertz spectral regions," J. Biophotonics 7(5), 295-303 (2014).

297.S. J. Oh, J. Kang, I. Maeng, J.-S. Suh, Y.-M. Huh, S. Haam, and J.-H. SonMarch, "Nanoparticle-enabled terahertz imaging for cancer diagnosis," Opt. Express 17(5), 3469-3475 (2009).

298.T. Yu, X. Wen, V. V. Tuchin, Q. Luo, and D. Zhu, "Quantitative analysis of dehydration in porcine skin for assessing mechanism of optical clearing," J. Biomed. Opt. 16, 095002 (2011).

299.A. S. Kolesnikov, E. A. Kolesnikova, A. P. Popov, M. M. Nazarov, A. P. Shkurinov, and V. V. Tuchin, "In vitro terahertz monitoring of muscle tissue dehydration under the action of hyperosmotic agents," Quantum Electronics 44(7), 633-640 (2014).

300.R. E. Beck, and J. S. Schultz, "Hindrance of solute diffusion within membranes as measured with microporous membranes of known pore geometry," Biochem. Biophys. Acta 255, 272-303 (1972).

301.A. Kotyk, and K. Janacek, Membrane Transport: An Interdisciplinary Approach, Plenum Press, New York (1977).

302.I. H. Blank, J. Moloney, A. G. Emslie, and I. Apt, "The diffusion of water across the stratum corneum as a function of its water content," J. Invest. Dermatol. 82, 188-194 (1984).

303.B. Sennhenn, K. Giese, K. Plamann, N. Harendt, and K. Kolmel, "In vivo evaluation of the penetration of topically applied drugs into human skin by spectroscopic methods," Skin Pharmacol. 6, 152-160 (1993).

304.K. D. Peck, A.-H. Ghanem, and W. I. Higuchi, "Hindered diffusion of polar molecules through and effective pore radii estimates of intact and ethanol treated human epidermal membrane," Pharmaceutical Research 11(9), 1306-1314 (1994).

305.T. Inamori, A.-H. Ghanem, W. I. Higuchi, and V. Srinivasan, "Macromolecule transport in and effective pore size of ethanol pretreated human epidermal membrane," Int. J. Pharmaceutics 105, 113-123 (1994).

306.R. Bertram, and M. Pernarowski, "Glucose diffusion in pancreatic islets of Langerhans,” Biophys. J. 74, 17221731 (1998)

307.P. Gribbon, and T. E. Hardingham, "Macromolecular diffusion of biological polymers measured by confocal fluorescence recovery after photobleaching," Biophys. J. 75, 1032-1039 (1998).

308. A. N. Yaroslavskaya, I. V. Yaroslavsky, C. Otto, G. J. Puppels, H. Guindam, G. F. J. M. Vrensen, J. Greve, and V. V. Tuchin, "Water exchange in human eye lens monitored by confocal Raman microspectroscopy," Biophysics 43(1), 109-114 (1998).

309.E. E. Alanis, G. G. Romero, and C. C. Martinez, "Interferometric measurement of diffusion coefficients through a scanning laser beam," Opt. Eng. 39(3), 744-750 (2000).

310.S. Papadopoulos, K. D. Jurgens, and G. Gros, "Protein diffusion in living skeletal muscle fibers: dependence on protein size, fiber type, and contraction," Biophys. J. 79, 2084-2094 (2000).

311.A. E. Kamholz, E. A. Schilling, and P. Yager, "Optical measurement of transverse molecular diffusion in a microchannel,” Biophys. J. 80, 1967-1972 (2001).

312.S. S. Olmsted, J. L. Padgett, A. I. Yudin, K. J. Whaley, T. R. Moench, and R. A. Cone, "Diffusion of macromolecules and virus-like particles in human cervical mucus," Biophys. J. 81, 1930-1937 (2001).

313.J. Kusba, L. Li, I. Gryczynski, G. Piszczek, M. Johnson, and J. R. Lakowicz, "Lateral diffusion coefficients in membranes measured by resonance energy transfer and a new algorithm for diffusion in two dimensions," Biophys. J. 82, 1358-1372 (2002).

314.W. Heller, "Remarks on refractive index mixture rules,” J. Phys. Chem. 69(4), 1123-1129 (1965). 
315.J. S. Maier, S. A. Walker, S. Fantini, M. A. Franceschini, and E. Gratton, "Possible correlation between blood glucose concentration and the reduced scattering coefficient of tissues in the near infrared," Opt. Lett. 19(24), 2062-2064 (1994).

316.M. Kohl, M. Esseupreis, and M. Cope, "The influence of glucose concentration upon the transport of light in tissue-simulating phantoms," Phys. Med. Biol. 40, 1267-1287 (1995).

317.J. M. Schmitt, and G. Kumar, "Optical scattering properties of soft tissue: a discrete particle model," Appl. Opt. 37(13), 2788-2797 (1998).

318.W. H. Press, S. A. Tuekolsky, W. T. Vettering, and B. P. Flannery, Numerical recipes in C: the art of scientific computing, Cambridge: Cambridge University Press (1992).

319.I. S. Grigoriev, and E. Z. Meylikhov (Eds.), Physical Values: Handbook, Moscow: EnergoAtomIzdat (1991).

\section{Contents}

1 Introduction: fundamentals of optical clearing of tissues and cells

2 Immersion clearing

3 Compression clearing

4 Photochemical and photothermal clearing

5 Applications of optical clearing

5.1 Optical coherence tomography

5.2 Optical projection tomography

5.3 Fluorescence imaging

5.4 Photoacoustic imaging

5.5 Nonlinear and Raman microscopy

5.6 Terahertz spectroscopy

5.7 Determination of diffusion coefficients of clearing agents and drugs in tissues

6 Conclusion

\section{Introduction: fundamentals of optical clearing of tissues and cells}

During the last 25 years the interest to the development and application of optical methods in clinical functional imaging of physiological conditions, diagnostics and therapy of cancer, and other diseases is permanently growing [1-3]. It is caused by the unique informativity, relative simplicity, safety, and sufficiently low cost of optical instruments, as compared, e.g., to X-ray computer tomography or magnetic resonance tomography (MRT). However, the main limitation of optical diagnostic methods, including the optical diffusion tomography, optical coherence tomography (OCT), confocal microscopy, reflection spectroscopy, etc., is the strong scattering of light in biological tissues and blood that reduces the contrast, spatial resolution, and probing depth [3-5].

The scattering coefficient $\left(\mu_{s}\right)$ and the scattering anisotropy factor $(g)$ mainly depend upon the refractive index mismatch between the components of the cells that form the tissue, such as the plasma membrane of the cell, mitochondria, nucleus, other organelles, cytoplasm, and extracellular fluid. In fibrous tissues (stroma of eye sclera and cornea, dermis, dura mater, connective tissue of vascular walls, fibrous components of muscle tissue and mammary gland, cartilage, tendon, etc.) the scattering is caused by the refractive index difference between the interstitial fluid or cytoplasm and the extensive chains of scleroproteins (collagen, elastin, and reticulin fibrils) $[3,6]$. The refractive index values for nuclei and cytoplasm organelles of animal cells, containing nearly the same amount of proteins and nucleic acids, lie within the relatively narrow interval from 1.38 to 1.41 [7]. In particular, for the nucleus the refractive index is $n_{n c}=1.39$ [8], and for the cytoplasm $n_{0}=1.35-1.37$ [3]. The scattering particles (organelles, protein fibrils, membranes, and globules) have greater density of proteins and lipids and, hence, higher refractive index $\left(n_{s}=1.39-1.47\right)$ in comparison with the base substance of the cytoplasm [6]. The refractive index values of the connective tissue fibrils lie in the range 1.41-1.53 and depend upon the degree of hydration of their major component, the collagen [9]. The refractive index of the interstitial fluid and the blood plasma amounts to nearly 1.33-1.35 depending on the wavelength $[3,10]$. The main scatterers in the blood are the red blood cells (erythrocytes), which are acaryocytes, containing $70 \%$ of water, $25 \%$ of haemoglobin, and $5 \%$ of lipids, sugars, salts, enzymes, and proteins [11]. The refractive index values of dehydrated erythrocytes at the wavelength of $550 \mathrm{~nm}$ fall within the range 1.61-1.66 [12]. The refractive index of the haemoglobin solution with the concentration of $32 \mathrm{~g} / \mathrm{dL}$, which is a typical concentration of haemoglobin in the erythrocyte, amounts to nearly 1.42 [13]. For the human blood the refractive index is 1.36-1.40 depending on the wavelength [3].

Numerous methods have been developed to increase the tissue probing depth [14]. For example, during a long time the limit probing depth in multiphoton microscopy did not exceed $100 \mu \mathrm{m}$ [15], however, the combination of multiphoton excitation of fluorescence with very high efficiency of light collection increased the imaging depth in a scattering medium to $2 \mathrm{~mm}[16$, 17]. The OCT allows the study of internal structure of tissues to the depth up to $3 \mathrm{~mm}$ with the spatial resolution 5-20 $\mu \mathrm{m}$ without disturbing the tissue integrity [18]. The probing depth up to a few centimetres is provided by the multimodal imaging method, combining the light absorption with acoustic detection (referred to as photoacoustic tomography) [19].

One of simple and efficient methods of solving the problem of increasing the depth and quality of intratissular structure imaging, as well as of increasing 
the precision of spectroscopic information from the deep tissue layers and the blood, is the temporary reduction of the tissue light scattering [20-22]. In nonlinear spectroscopy and imaging, as well as in highprecision laser surgery (particularly, in cell nanosurgery), the reduction of scattering in the tissue facilitates the decrease of the strongly focused laser beam divergence and provides its precise focusing onto the object, which essentially improves the efficiency of the procedure and allows the reduction of the radiation energy, necessary for successful visualisation or photoinduced effect [21-27].

According to Web of Science, PubMed and other sources, the interest to the optical clearing methods is permanently growing, which is caused by the progress of optical and laser technologies for application in biology and medicine (see Fig. 1).

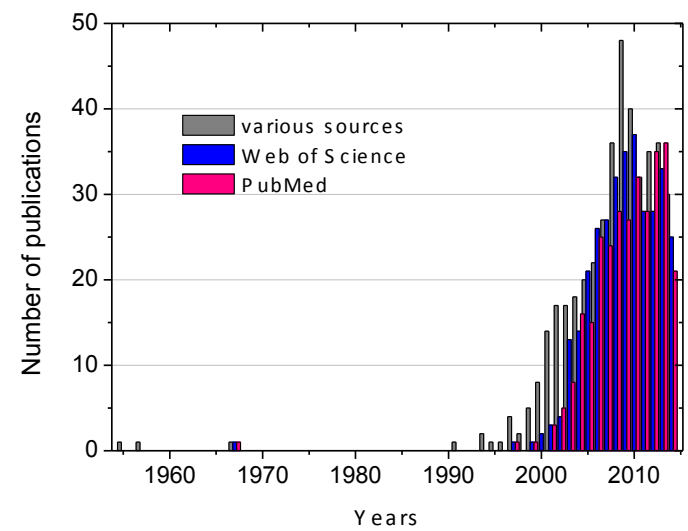

Fig. 1 Approximate evaluation of the number of publications related to the optical clearing of tissues from 1955 to August 2014. The dependences are plotted using the databases Web of Science, PubMed, and other available sources.

Numerous examples of physical and chemical impacts that allow one to control the scattering properties of tissues are reported. They include compression [28, 29], stretching [30], dehydration [31, 32], coagulation [33], immersion with biocompatible chemical agents $[20-27,34-36]$, as well as photochemical [37, 38] and photothermal [38] clearing.

The majority of methods reducing the tissue scattering are based on the matching of the refractive indices of the tissue components, either due to replacing the interstitial fluid with the immersion agent, possessing a higher refractive index, or due to increasing the concentration of proteins and mucopolysaccharides in the interstitial fluid as a result of water diffusion from the tissue caused by the osmose, making the refractive index of the interstitial fluid closer to that of the fibrils. In addition, the optical homogeneity can increase due to the compaction of scattering centres (e.g., collagen fibres) due to both pressing out the interstitial fluid from the affected volume and the dehydration at the expense of the agent impact or water evaporation. [22, 25, 26, 28-32, 39]. The particular mechanisms of optical clearing depend on the tissue type and the method used.

In the present review we discuss the physical and molecular mechanisms of immersion, compression, and photodynamic/photothermal methods of optical clearing of some fibrous and cellular tissues, as well as the application of these methods for increasing the probing depth and resolution power of optical diagnostic methods, such as optical coherence, projection, and photoacoustic tomography, fluorescence imaging, nonlinear and Raman microscopy, and terahertz imaging. This review is different from earlier published and cited ones (for example, Refs. [36, 39]) extended bibliography due to addition of new references and sections. In particular, the mechanisms and features of compression and photodynamic/photothermal clearing are described in details; sections on methods of OCA diffusion coefficient evaluation and applications of optical clearing technique ( $\mathrm{THz}$ spectroscopy, projection and photoacoustic tomography etc.) are extended significantly.

\section{Immersion clearing}

Following the development of immersion refractometry applied to cells, in 1955 Barer et al. [40] have first proposed the optical clearing of cell suspension by means of the protein solution having the same refractive index as the cell cytoplasm. In early 1990s the method of immersion optical clearing was first applied to the eye sclera and cornea [41].

After the appearance of the tissue optical clearing idea many research teams joined the intense studies of the specific features and mechanisms of this phenomenon and demonstrated the capabilities of the method in increasing the probing depth or contrasting the image of optical inhomogeneities inside a scattering medium [39, 42-88].

New original results obtained using the combination of optical clearing with the known optical visualisation methods, such as laser speckle-contrast imaging [34, 71, 75, 77, 79], OCT [20, 29, 35, 59-61, 65, 69, 80, 82], microscopic imaging [23, 24, 83, 84], ultra-microscopy [85-87], etc., demonstrated high potentiality of their mutual use not only for getting high-resolution structure and functional tissue images in vitro [72, 73, 83-87], but also for optical imaging and diagnostics in vivo [25, 34, $45,50,59,61,65,68,70,71,75-77,79-81]$. Table 1 shows the increase of the light penetration depth, caused by clearing agents in some diagnostic methods.

The studies of tissue scattering kinetics under the penetration of immersion agents allowed the development of techniques for assessing the diffusion coefficients and permeability [35, 43, 47, 88-94]. Using these techniques, the diffusion rates of glucose and other medicinal preparations and immersion fluids were determined for the tissues of eye [91-96], skin [45, 97, 98], dura mater [88], and other tissues [99, 100]. The monitoring of optical clearing agent diffusion with high resolution in time and depth allows differentiation 
between healthy and pathologically modified biotissues [101-105].

The optical immersion clearing, as already mentioned above, is based on the impregnation (immersion) of the tissue with a biocompatible chemical agent, possessing sufficiently high refractive index to match the refractive indices of the scatterers and the surrounding medium, penetrating into the interstitial liquid of the tissue. Commonly, the optical clearing agent (OCA) has hyperosmotic properties [21, 22]. Many chemical substances used in cosmetology in the composition of different preparations satisfy these conditions. These agents can be roughly divided into polyatomic alcohols (glycerol, polyethylene glycol (PEG), polypropylene glycol, combined mixtures on the base of polypropylene glycols and polyethylene glycols, mannitol, sorbitol, xylitol) [56, 57, 76, 84, 88, 103, 105108], sugars (glucose, dextrose, fructose, ribose, saccharose) [82, 88-91, 94, 96, 97, 99, 100, 104, 109111], organic acids (oleic and linoleic acid) [105, 113, 114], other organic solvents (dimethyl sulphoxide (DMSO)) [105, 114-117], and X-ray contrast agents (verografin, trasograph) [6, 42-44].

At present several physical and chemical mechanisms of the light scattering reduction under the action of OCA are proposed and thoroughly described $[29,31,32,39,43,46,47,55,56,58,63,67,72,76,78$, $84,88,106-112,118-122]$ : dehydration of tissue components, partial replacement of interstitial fluid with the immersion agent, and structure modification or dissociation of collagen. The first mechanism is related to the hyperosmotic properties of the OCA [31, 36, 39, $56,120]$. The contact of hyperosmotic OCA with the tissue surface causes the water diffusion from the tissue. These processes produce fast and considerable clearing effect, since, first, the concentration of salts and proteins dissolved in the interstitial fluid increases and, therefore, the refractive index of the interstitial fluid becomes closer to that of the scattering fibrils, and, second, the weight and the thickness of the tissue decrease, the tissue becomes denser, and the ordering of scattering components increases [36, 39].

Rylander et al. [31] compared the optical transmission of the rat skin under the application of DMSO and glycerol with that under dehydration. It was shown that in the course of natural water evaporation the light transmission through the skin sample increased in the same way as under dehydration caused by the OCA effect, but during a longer time.

In order to analyse the water loss in the process of tissue optical clearing quantitatively, the authors of Ref. [67] used the optical spectroscopy in the near IR range. Measuring the skin reflection coefficient at the wavelengths $\lambda_{1}=1100$ and $\lambda_{2}=1936 \mathrm{~nm}$ (the water absorption band), $\mathrm{Xu}$ and Wang used the double-wave analysis to assess the water content in the skin. The authors demonstrated that the change of the water content in the skin correlated with the optical clearing effect during the first minutes, namely, under the impact of $80 \%$ solutions of glycerol and propylene glycol the water content at first rapidly decreases, and then the dehydration process becomes slower.

The kinetics of skin dehydration degree under the action of $88 \%$ aqueous solution of glycerol and air, studied by Genina et al. [56] basing on the weight measurements of human skin samples (see Fig. 2a), allowed the assessment of the characteristic time $\tau$ of the process, i.e., the time, during which the dehydration degree increases by $e$ times. Under the action of OCA $\tau$ amounts to $193.4 \pm 12.3$ hours, while under the conditions of natural evaporation of interstitial water this parameter equals $1408.9 \pm 36.3$ hours.

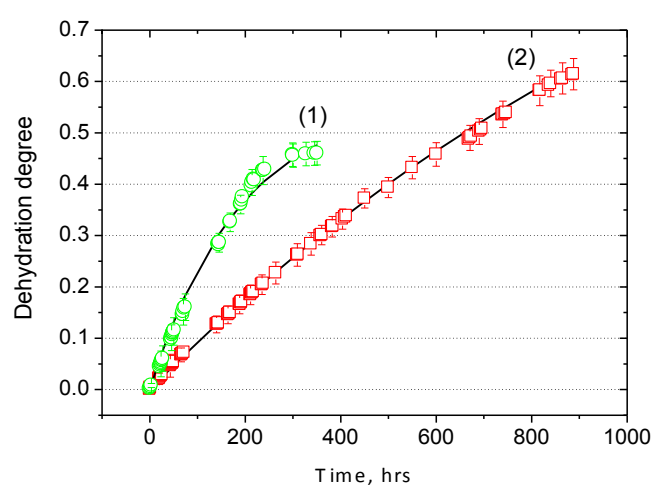

a

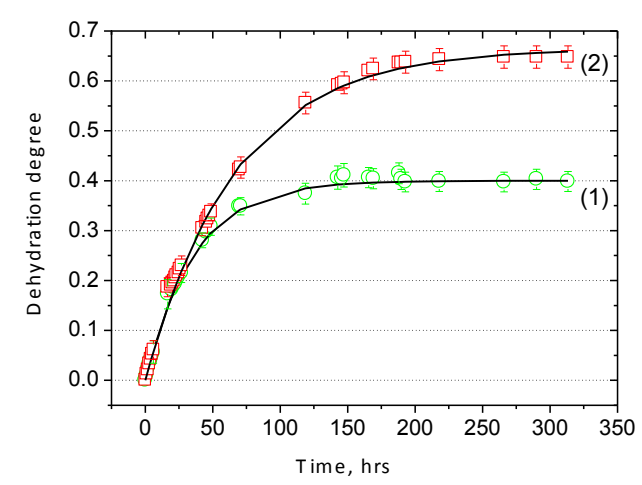

b

Fig. 2 Dehydration kinetics of human skin samples with intact (a) and perforated (b) epidermis under the action of $88 \%$ glycerol solution (1) and in the course of interstitial water evaporation in air (2). The symbols correspond to the averaged experimental data; the curves show the result of approximation. The vertical lines present the standard deviation (from the data of Ref. [56]).

At the same time, it is seen from the Fig. 2 that, in contrast to the natural drying in air, under the action of the OCA no full dehydration occurs, since a part of the OCA penetrates into the interstitial space and is mixed with the interstitial fluid. It is known, that most of the OCAs are hygroscopic and in the humid environment they adsorb water molecules till the saturation is achieved. Thus, for glycerol the saturation level 
amounts to 55 and for propylene glycol 32 percent in volume [123]. Therefore, OCAs inhibit complete dehydration by keeping a part of water in the tissue.

For fibrous tissues, such as sclera, dura mater, dermis, etc., both processes, namely, the water loss and the diffusion of the hyperosmotic agent into the skin, occur simultaneously, but the mechanism of the interstitial fluid replacement with the OCA solution is prevailing for all the agents used, since their molecular size is much smaller than the mean separation between the fibrils $[3,43]$.

In the case of transepidermal delivery of hydrophilic OCAs into the skin the diffusion is inhibited by the existence of the epidermis lipid barrier. The human skin dehydration at the delivery of the hyperosmotic OCA through the perforated stratum corneum (the perforation may be implemented, e.g., by fractional microablation) is presented in Fig. 2,b. The epidermis permeability improvement resulted in the accelerated diffusion of both water and $88 \%$ glycerol solution. Fig. 2 shows that when the samples with intact and perforated horny layer are dried under the identical conditions, their final dehydration degree should be practically similar. However, from the analysis of the dehydration characteristic time (for the perforated sample $\tau$ amounts to $71.2 \pm 1.9$ hours) it follows that the dehydration process in this case occurs by more than 20 folds faster than in the intact epidermis $(\tau=1408.9 \pm 36.3$ hours $)$. The value of $\tau$ for the sample with perforated epidermis under the action of the OCA was only $36.4 \pm 0.7$ hours, which is almost by 5.5 folds smaller than for the intact sample ( $\tau=193.4 \pm 12.3$ hours) [56].

In Fig. 2,b it is well seen that with the epidermis damaged the maximal value of dehydration degree under the evaporation of water from the tissue is essentially higher than under its osmotic removal. At the same time the skin dehydration rate due to evaporation is by nearly two times smaller than under osmotic water removal.

The study of water evaporation process allowed the separation of the dehydration mechanism of optical clearing from other mechanisms (i.e., the matching of refractive indices due to the penetration of OCA into the tissue and the collagen structure modification). The fact that attracts attention in the dehydration under the action of glycerol is that the degree of dehydration in the samples with perforated stratum corneum is smaller than that in the intact samples. As mention above, in both cases there are two counterpropagating fluxes, one of them is the water diffusion from lower layers of epidermis and from dermis into the surrounding solution, and the other one is the diffusion of the OCA from the surrounding solution into the tissue. Apparently, in the non-perforated sample the rate difference between these fluxes is greater than in the perforated one, since in the absence of the epidermis damage the drainage of water from the tissue considerably exceeds the glycerol delivery into the tissue. From the practical point of view, the topical injection of OCA into the skin through the channels in the epidermis hampers the formation of strong concentration gradient between the interstitial fluid and the OCA solution, which reduces the tissue dehydration and can be considered as a positive factor for optical clearing of skin in vivo.

Mao et al. [107] focused their attention on the study of the efficiency of six polyatomic alcohols with hydroxyl groups (1-butanol, 1,4-butanediol, 1,3propanediol, PEG-200, PEG-400, and glycerol) with molecular weights from 74 to $420 \mathrm{Da}$, and the refractive index values from 1.40 to 1.47 , affecting the degree of skin optical clearing. For better in vitro modelling of the topical OCA application to the skin in vivo, the agents were applied to the pig skin epidermis, while the dermis was moistened with saline. The relative transmission of the samples, measured using the integrating sphere, was used to assess the efficiency of optical clearing [107]. The authors found that the glycerol, which is a triatomic alcohol, caused the maximal clearing effect, the monoatomic alcohol 1-butanol caused the smallest effect, and four diatomic alcohols caused intermediate clearing effect. After checking the interrelation between the optical clearing efficiency and the refractive indices or molecular weight of the OCAs under study, the authors concluded that the clearing effect, caused by alcohols, should be related to the number of hydroxyl groups rather than to the refractive index or the molecular weight value of the OCA.

In fibrous tissues the optical clearing process can also incorporate the variations in the molecular structure of the basic component of these tissues, the collagen fibres, including the reversible solvability of collagen in sugars and polyatomic alcohols. The OCA-induced destabilisation of collagen structure can lead to the additional reduction of optical scattering in a tissue due to the decrease of the basic scatterer size. [121].

The collagen fibres have complex self-organising structure and are the main scattering centres in tissues [112]. They are widely presented in different tissues, particularly, in fibrous ones, such as skin dermis and eye sclera. It is established that the hydrogen bond is the main bonding force between the triple collagen helices. The OCAs with multiple hydroxyl groups possess a greater negative charge that destabilises the highlyordered collagen structure till its dissociation. Since the hydrogen bonds in the triple collagen helices belong to non-covalent interactions, the OCA-induced effect on the collagen dissociation can be easily reversed. Yeh et al. $[109,112,121,122]$ observed the dissociation of collagen fibres in the tissue in vitro, merged in glycerol. The subsequent replacement of glycerol with phosphatebuffer solution provided the restoration of the collagen structure.

Hirshburg et al. [110] performed mathematical modelling of molecular dynamics in order to clarify the formation of hydrogen bonds between the alcohol (glycerol, xylitol, and sorbitol) and collagen molecules. They divided the hydrogen bond bridges into different types depending on the position of hydroxyl groups, involved in the interaction, with respect to carbon 
atoms. They associated the type number with the number of carbon atoms in the hydrogen bond bridge. It was found that the bridges with large number, built in between the collagen molecules in the helix, can break the collagen-collagen and collagen-hydroxyl bonds more efficiently than the bridges with smaller numbers. Thus, the alcohols having pairs of hydroxyl groups with longer carbon chain between them should be more efficient in optical clearing that the alcohols having adjacent hydroxyl groups. The results of the modelling explain the fact that 1,3-propanediol demonstrated the optical clearing potential twice as great as that of 1,2propanediol, although both possessed similar molecular weight $(76.10 \mathrm{Da})$, close values of the refractive index (1.44 and 1.43), and osmolality (8.3 and $8.7 \mathrm{Osm} / \mathrm{kg}$ ). The reason is that 1,2-propanediol can form only the bridges of the type I, while 1,3-propanediol forms the bridges of the type II [110]. Since the modelling of molecular dynamics can clarify the specific features of interaction between the OCA and the structural elements of the tissue at the microscopic (molecular) level, it can be a powerful tool in the study of optical clearing mechanisms, particularly, for choosing new high-efficiency OCAs.

Of great practical interest is the optical clearing of hard tissues, such as bone, cartilage and tendon. The reduction of scattering in these tissues offers the possibility to develop minimally invasive methods of laser diagnostics and therapy of brain and other deeply located tissues. The possibility of studying brain blood circulation without damaging the scull bone was demonstrated by Wang et al. [81]. The experiments with laboratory mice in vivo have shown that the minimal microvascular diameter resolved in the observation through the bone tissue, preliminarily processed with the specially developed optical clearing solution, amounts to $14.4 \pm 0.8 \mu \mathrm{m}$. The optical clearing of the human skull bone in vitro was studied by Genina et al. [57]. The authors have shown that the exposure of the $\sim 5 \mathrm{~mm}$ thick skull bone sample to glycerol reduces the value of the transport scattering coefficients by $25 \%$ in the spectral range $1400-2000 \mathrm{~nm}$. In the present case the main role in the clearing process is played by the replacement of water in the interstitial space with OCA due to the specific structure of the bone tissue that possesses higher porosity than soft tissues.

The transparency increase was studied in the samples of cartilage tissue of the human nasal septum and knee joint in vitro under the impact of trasograph [124] and in the rodent tail cartilage ex vivo under the impact of glycerol $[112,121]$. The authors demonstrate the increase of the contrast in the image of the tissue by $2-2.5$ folds during 1 minute for the transverse section and by 1.6 folds during 8 minutes for the longitudinal one [124] and the reversible disorganisation of collagen fibrils under the action of OCA $[112,121]$.

Optical clearing of the mouse tail tendon in vitro exposed to the glycerol solutions with different concentration was demonstrated in the papers by LaComb et al. [72], Nadiarnykh and Campagnola [73], and Rylander et al. [31]. The authors managed to increase the probing depth in the second harmonic generation microscopy up to $450 \mu \mathrm{m}$ at the expense of considerable reduction of the scattering coefficient (up to 130 folds at the wavelength $890 \mathrm{~nm}$ during 5 hours) and increasing the packaging density of fibrils (according to the data of electron microscopy, the volume fraction of fibrils increased from 0.65 to 0.9 ) [31].

Blood vessels and capillaries transpierce practically all tissues, and the blood is a strongly scattering medium, so that its optical clearing is a serious problem for successful application of optical technologies both in diagnostics and in therapy/surgery. The difference between the refractive indices of the erythrocyte cytoplasm and the blood plasma, as well as the specific size and structure of blood corpuscles explain the blood scattering properties $[3,10,11]$. The refractive index of the erythrocyte cytoplasm is determined mainly by the haemoglobin concentration $[11,13,125]$. The volume and the shape of an individual erythrocyte are determined by the osmolality of the blood plasma $[125$, 126]. The blood scattering is also dependent on the ability of the red blood cells to aggregate or disaggregate [127].

When an OCA is injected into blood, the refractive index of the blood plasma increases and becomes comparable with the refractive index of the red blood cells. For example, the total attenuation coefficient of whole blood, diluted by two folds with saline, under the addition of $6.5 \%$ glycerol solution decreased from 4.2 to $2.0 \mathrm{~mm}^{-1}$, and, correspondingly, the optical probing depth at the wavelength $820 \mathrm{~nm}$ increased by $117 \%$. For other OCAs tested (glucose, dextran, propylene glycol, and trasograph) the increase of the probing depth was from 20 to $150 \%$ [22, 128]. It was also shown that the introduction of chemical agents is able to change the size and aggregation properties of erythrocytes, which allows the control of the blood optical properties, too [128].

Bashkatov et al. [53] have shown that the minimal light scattering is observed at the concentration of glucose in blood equal to $0.65 \mathrm{~g} / \mathrm{ml}$. In this case the blood appears to be completely immersed, but due to the difference in spectral dependence of refractive indices of the glucose solution and erythrocytes the residual scattering is still present. Obviously, such high concentration of glucose can be applied only topically and during a short period of time to prevent the destruction of blood and vascular wall cells. Nevertheless, the use of endoscopic optical imaging systems (OCT or confocal microscopy) and the controlled injection of small glucose volumes into the vascular lumen near the region of imaging may essentially facilitate obtaining a high-contrast image of an atherosclerosis plaque through the layer of blood.

The same group of authors showed the possibility of using a small volume of haemoglobin as an OCA. This haemoglobin can be obtained as a result of local haemolysis of erythrocytes in a blood vessel near the 
site of optical endoscopic probe [51]. The blood scattering coefficient reduction by $30-40 \%$ was demonstrated theoretically in the spectral region 400 $1000 \mathrm{~nm}$ under the increase of the local haemolysis by up to $20 \%$ in the immediate proximity of the optical probe.

Impregnation of blood-saturated tissues, such as the liver, with solutions having different osmolality also leads to the matching of refractive indices and scattering coefficient reduction, but the effect is not as prolonged as in fibrous tissues [22].

The optical clearing of tissues in vivo is, generally, more complex, since in this case a significant role begins to be played by the additional factors, on the one hand, the physiological temperature that accelerates the diffusion of OCA, and, on the other hand, the metabolic reaction of the living tissue, washing the OCA out. These factors can essentially modify the kinetic characteristics and the magnitude of the clearing effect $[25,34,45,59,61,68,70,76,77,79,80,82,97,98$, $108,113,118,119]$. In living tissues the refractive index is a function of the physiological or pathological condition of the tissue. Depending on the specific features of the tissue condition, the refractive index of scatterers and/or the base substance can change (increase or decrease), and correspondingly the light scattering will change $[3,22]$. In addition, the introduction of some OCAs, in particular, glycerol and glucose, into a tissue affects the condition of microcirculation in the tissue, causing a transient stasis of the microvessels $[50,65,71,77,108]$.

One of the most important problems in optical diagnostics and treatment is the reduction of skin scattering aimed at visualising the inhomogeneities hidden inside the skin or under it. However, it is rather difficult to obtain the optical clearing of skin using noninvasive or minimally-invasive means, since the stratum corneum of the skin epidermis is a natural barrier that impedes the OCA penetration into the dermis [129]. For in vivo applications of the optical clearing method one has to use direct exposure of the skin dermis, or intradermal OCA injection. However, at low concentrations OCAs do not provide sufficient optical clearing, while at high concentrations they can induce edema, chemical burn, partial necrosis and scarring $[45,65,108]$. To develop an efficient and safe way of breaking the integrity of the epidermis stratum corneum and accelerating the penetration of OCA into the dermis, various physical methods [56, 118, 130140], chemical enhancers of permeability $[114,118$, 141-147], and their combinations [118, 148, 149] have been proposed.

Chemical OCA diffusion enhancement is implemented using the agents that serve for increasing the tissue permeability in medicine and cosmetology [36, 39]. In particular, it is shown that Azone [141], oleic acid [142], DMSO [118, 143-146], ethanol [150], propylene glycol [147, 151], Thiazone [149] enhance the tissue permeability for OCAs and increase the efficiency of optical clearing.
The possible mechanism of diffusion enhancement using Azone may consist in increasing the fluidity of hydrophobic regions of the stratum corneum and the corresponding reduction of resistance to the penetration of agents [141]. For example, after 60 minutes exposure of in vitro skin to the mixture of $40 \%$ glycerol-Azone the absorption of light at the wavelength $1276 \mathrm{~nm}$ increased by $41.1 \%$, and the diffuse reflection at the wavelength $1066 \mathrm{~nm}$ decreased by $29.3 \%$, which considerably exceeded the values of these parameters under the application of more concentrated $80 \%$ aqueous solution of glycerol [141].

The oleic acid is a monounsaturated fatty acid that is widely used as a safe transdermal enhancer for drug delivery. In the region of skin clearing the synergetic effect of oleic acid as a promoter of OCA skin penetration was studied [142].

DMSO is a well-known agent widely used for improving the transdermal delivery of drugs. It is a polar aprotic solvent of stratum corneum lipids [143]. DMSO enhances the permeability of the stratum corneum for both hydrophilic and lipophilic agents [152, 153]. In addition, it possesses high refractive index and may serve as an OCA as well [144]. It also interacts with the highly organised structure of collagen fibres, changing the interfibrillar space at the submicrometre scale [145], which is of great importance for the skin optical clearing. However, the results on the DMSO optical clearing potential and safety are rather contradictory [106, 144, 154, 155]. In Ref. [106] it is shown that the optical clearing potential of DMSO is smaller than that of glycerol, propylene glycol, ethylene glycol, and some other OCAs. The application of highconcentration DMSO to the skin surface causes irritation, accompanied with epidermal spongiosis [154]. On the other hand, it was noticed that DMSO is a high-efficiency OCA of topical application, and no side effects under the 20-minute exposure of the rat skin surface in vivo were reported [144]. In spite of the controversial evaluation of the DMSO efficiency and safety, this substance is widely used for optical clearing in the mixtures with different OCAs [64, 118, 143-146, $152,153,156]$.

Ethanol is also a solvent that modifies the skin barrier properties. Under sufficiently high concentration ( $\sim 40 \%$ ) ethanol facilitates the formation of pores and essentially increases the transport of agents through them due to increasing the size and/or the density of pores in the epidermal membrane [150].

The mechanism of enhancing the permeability of the epidermis stratum corneum under the action of propylene glycol is the solvation of keratin in the process of water replacement in the binding hydrogen groups and the inclusion of propylene glycol into the polar heads of the lipid bilayer [151]. It was shown that the mixtures of different OCAs with propylene glycol increase the efficiency of the optical clearing effect, however, the clearing effect induced by propylene glycol itself is weaker than for these mixed OCAs [147].

The last of the diffusion enhancers mentioned above, 
Thiazone, is an innovative agent that increases the skin permeability nearly three folds stronger than Azon [36]. It is also more efficient as compared to propylene glycol $[36,147]$.

To increase the tissue permeability for OCAs one can use combinations of the abovementioned agents. For example, in Ref. [157] for the optical clearing of skin the combined OCA was used, including glycerol, PEG-300, ethanol and DMSO.

Beside the chemical agents, a number of physical methods of surmounting the skin barrier are proposed to enhance the diffusion, including low- and high-intensity irradiation [130, 158], fractional lamp [131, 133] and laser [132] microablation, mechanical microperforation [137, 138], ultrasonic (US) irradiation [134, 135, 159], electrophoresis [160], needleless injection [161], mechanical removal of the surface layer by means of abrasive paper [136], epidermal stripping [162], and microdermabrasion [163].

Different radiation sources (e.g., $\mathrm{CO}_{2}$ and $\mathrm{Nd}$ :YAG lasers, operating at the wavelengths 532 and $1064 \mathrm{~nm}$, respectively, broad-band sources of intense pulsed light, operating in the ranges $650-1200,525-1200$, and 470 $1400 \mathrm{HM}$ ) have been used to irradiate the skin in vivo before the OCA application with different doses and regimes of exposure. The measurements of reflection spectra before and after the exposure have shown that the radiation of Nd:YAG laser in the modes of Qmodulation and long pulses can induce the improvement of transepidermal penetration of OCA by $8-9$ folds as compared to the intact skin [130]. In the other study Stumpp et al. [158] used a diode laser, operating at the wavelength $980 \mathrm{~nm}$ for the rodent skin irradiation using artificially absorbing substrates on the surface. The laser radiation provided heating of the stratum corneum and caused the failure of the protective barrier function. After the removal of absorbing substrates the skin surface was subjected to glycerol application. The OCT study of skin in the exposed regions has shown the increase of the light penetration depth by up to $42 \%$.

The similar principle was used to create regions of microablation under the action of a broad-band flash lamp. The transparent mask with a set of absorbing carbon centres was applied to the skin surface in order to create the regions of epidermis microdefects under the light absorption [131, 133]. Increasing the skin transparency and image clearness of the tattoo, located under the skin at the depth of $300-400 \mu \mathrm{m}$, was demonstrated by Genina et al. [133] and Bashkatov et al. [164]. Fig. 3 presents the tattooed skin images before and after the action of the epidermis fractional thermal ablation and $88 \%$ glycerol solution.

Fractional laser microablation of skin surface by means of the erbium laser $(2940 \mathrm{~nm})$ with the pulse energy from 0.5 to $3.0 \mathrm{~J}$ is also an efficient tool of overcoming the barrier for hydrophilic and hydrophobic OCAs [132].

The integrity of the epidermis stratum corneum can be disturbed mechanically using a roller with multiple needles. Yoon et al. [137] used this device, applied in cosmetology, to create transdermal microchannels in samples of porcine skin ex vivo with the aim of improving the glycerol penetration into the depth of the skin. The combination of multiple needle perforation with low-frequency ultrasonic effect allowed the increase of the diffusion rate of the $70 \%$ glycerol solution into the skin by 2.3 folds in comparison with using the multiple-needle roller solely [138].

The low-frequency US effect (sonophoresis) is one of the noninvasive methods of improving the clearing effect for many OCAs, increasing the depth and rate of their delivery into tissues [134, 135, 165-168]. The combined use of OCA and US provided considerable increase of the depth and contrast of the OCT images of porcine skin in vitro and human skin in vivo [166]. Xu et al. [134] used the ultrasound with the frequency 1 $\mathrm{MHz}$ to enhance the penetration of $60 \%$ glycerol solution and $60 \%$ PEG-200 solution into the porcine skin in vitro. The OCT study has shown the increase of the imaging depth by $40 \%$ and $93 \%$, respectively, as compared to using OCA without US.
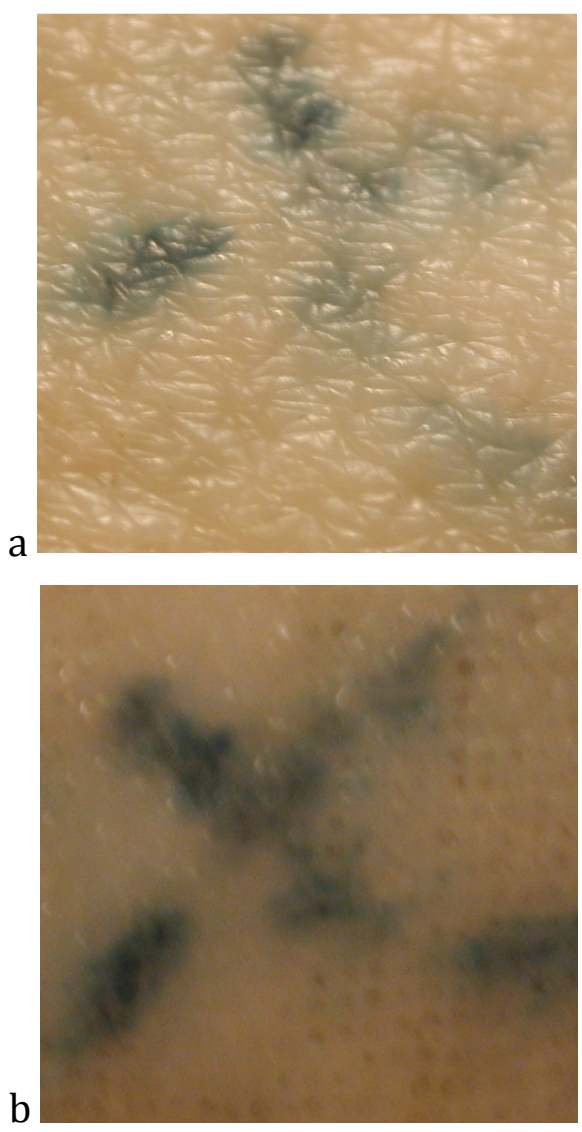

Fig. 3 Images of tattooed skin surface: a) the tattooed sample before the glycerol action; b) the tattooed sample after the surface microperforation and glycerol impact during 24 hours [133].

Cavitation is the main mechanism of the sonophoresis that explains the tissue permeability increase [159, 167]. The theoretical analysis of surface interaction of the cavitation bubbles with lipid bilayers of the epidermal stratum corneum considers three 
interaction modes, namely, the shock wave propagation, the penetration of microflux into the stratum corneum, and the impact of the microflux on the stratum corneum [159]. In the process of growth the bubbles can merge, forming larger bubbles that continue growing creating channels. The channels formed in the stratum corneum become larger with time in the direction towards the boundaries, which finally leads to the appearance of inner transport ways [167]. These processes induce disorder in the lipid bilayers of the epidermal stratum corneum, weaken the barrier function, and enhance the OCA penetration into the inner layers of skin [168].

The transdermal electrophoresis is a well-known and widely used method of controlled delivery of drugs through the skin aided by low-intensity electric current. The specific features of this method are the following: 1) the transport can be significantly intensified as compared to the passive diffusion; 2) the delivery rate may be actively controlled by modulating the electric current density, which allows individual dosage [169].

The electrophoresis can be applied not only with polar electrically charged agents. The dependence of electroosmotic diffusion upon $\mathrm{pH}$ of the solution and the content of $\mathrm{NaCl}$ ions in it was studied in Ref. [160]. In the experiments the solution containing $0.07 \mathrm{M}$ of $\mathrm{NaCl}$ and $0.13 \mathrm{M}$ of D-mannitol in $5 \mathrm{MM}$ of citric-acid buffer with $\mathrm{pH}=6$ was used. Compared to the passive diffusion, the volume flux of the agent gradually increased approximately by 20 folds after switching the current on, approaching a constant value. After switching the current off, the volume flux slowly decreased to the values, exceeding those before the beginning of the electrophoresis [160].

Stumpp et al. [161] proposed to use a pistol for needleless injection of glycerol with concentrations of 100,50 , and $25 \%$ into the porcine skin ex vivo.

The removal of the skin surface layer by slight rubbing with an abrasive paper also helps to enhance the OCA penetration through the epidermis stratum corneum and to improve the optical clearing effect. The abrasive paper with the gritness 220 was used by Stumpp et al. [136] for smooth rubbing of glycerol or dextrose solution into the depilated hamster skin in vivo. After 2-4 min of rubbing in, excluding any visible damage, the skin gradually became more transparent, allowing the observation of subcutaneous blood vessels. The quantitative analysis of the OCT signals has shown that the light penetration depth increased by $36-43 \%$.

The mechanical removal of outer cell layers of the epidermis can be also implemented via a sequence of surface epidermal strips. The procedure of gluing strips of adhesive tape to the skin surface and tearing them off repeated up to 30 times increases the permeability of skin without its essential damage [162]. In Ref. [139] the authors used slides with cyanoacrylate applied to the skin with moderate pressure, kept nearly 3 minutes, and then were left for 2 minutes more. When tearing the slide off the outer layer of the epidermis was removed. The procedure was repeated 3-6 times till the skin became shining. Then the OCA was applied to the processed surface under slight pressure that also improved the agent penetration into the skin.

The combined use of chemical and physical OCA diffusion enhancers facilitates further increase of the optical clearing efficiency $[118,148,149]$. Thus, Xu et al. [148] showed that the sodium lauryl sulphate, a surface-active agent often used as an enhancer of penetration of pharmaceutic and cosmetic products into skin, in combination with the US demonstrates a synergetic enhancing effect on the penetration of $60 \%$ glycerol solution into the skin. As a result the optical transmission and OCT probing depth increased and the time of reaching the maximal clearing decreased in comparison with the US used solely.

The US processing was also used in combination with Thiazone to improve the penetration of PEG-400 into the skin [149]. It was shown that after the complex processing with Thiazone, PEG-400, and US the diffuse reflection coefficient decreased by 33.7 folds as compared to the control measurements (without clearing). Using only PEG-400 or PEG-400 with Thiazone the reduction of the reflection coefficient was by 2.7 and 3.3 folds, respectively. The probing depth increased by $41.3 \%$ in comparison with the control samples.

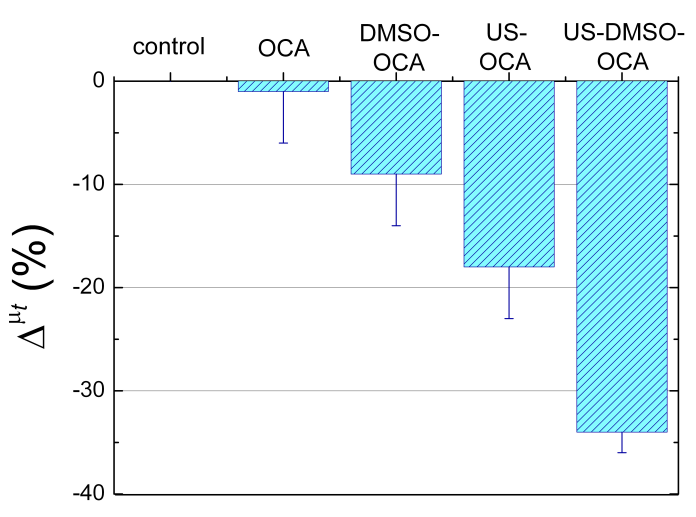

Fig. 4 The difference between the averaged coefficients of total light attenuation by the intact rat skin in vivo, calculated from the OCT data. The column "control" corresponds to the data, obtained before the OCA action. "OCA" - 20-minute topical action of OCA (glycerol-PEG-400 mixture in equal proportions); "DMSO-OCA" - 20-minute action of DMSO-OCA mixture; "US-OCA" - 4-minute action of lowfrequency ultrasound and OCA; "US-DMSO-OCA" combined 4-minute action of ultrasound and the DMSO-OCA (from the data of Ref. [118]).

The comparison of the coefficients of total light attenuation by the rat skin in vivo using physical and chemical penetration enhancers separately and in combinations was carried out in Ref. [118]. Fig. 4 presents the result of calculating the value $\Delta^{\mu_{t}}=\frac{\mu_{t(\text { treated })}-\mu_{t(\text { control })}}{\mu_{t(\text { control })}} \times 100 \%$ 
of the relative attenuation coefficient change as a result of the multimodal skin processing with respect to the control measurements. In this case the control group consisted of animals not subjected to the treatment. For this group $\Delta^{\mu_{t}}=0$. The results allow the assessment of the efficiency of different OCA diffusion enhancers (the OCA was a mixture of equal parts of glycerol and PEG400). It is seen that the OCA column has the minimal height, which means the minimal efficiency of the 20minute OCA action on the surface of intact skin (the optical clearing is absent). The 20-minute application of 9\% DMSO solution in OCA appeared to be less efficient than the 4-minute ultrasonophoresis. However, the maximal efficiency of optical clearing was observed under the combined use of US-DMSO-OCA during 4 minutes.

The combined use of surface epidermis stripping with chemical enhancers of diffusion, such as Thiazone, Azon and propylene glycol, was studied in the rat skin in vivo [170]. After tape strips from the skin surface the mixture of the enhancer with PEG-400 was applied to the prepared region. As a result the skin diffuse reflection coefficient was reduced, the greatest change being observed when using Thiazone-OCA, then, in descending order, Azon-OCA, propylene glycol-OCA and OCA without adding the permeability enhancer. These results differ from the data of in vitro studies of porcine skin, for which the optimal combination of OCA and enhancer was propylene glycol-OCA, and the minimal reduction of the reflection coefficient was demonstrated by Azon-OCA [147].

The influence of microdermabrasion on the skin permeability for hydrophilic and lipophilic agents was studied in Ref. [163]. Microdermabrasion is a partial ablation and homogenisation of the epidermal stratum corneum under the action of high-pressure flow of microparticles. Depending on the pressure (15-25 centimetres of mercury) and the time of exposure the skin permeability for hydrophilic agents increased by 824 folds, as compared to the intact skin. This method can be used for enhancing the OCA diffusion as well.

\section{Compression clearing}

The influence of external mechanical compression on the optical properties of biological tissues in vivo is interesting for several reasons. First, the specific features of light propagation in the tissue vary depending on its morphologic, biochemical, and physiological characteristics, therefore, the spectral composition of light, outgoing from the tissue, carries information on its morphologic and functional condition $[171,172]$. Second, as a result of local mechanical compression, produced, e.g., by the end of a fibreoptical probe (the area of the force application about a few square millimetres) at the compression site a gradient of the refractive index is induced, and this volume of the tissue plays the role of a lens for the probing radiation, propagating through the tissue. When the mechanical compression is applied to a relatively large area of the tissue surface (of the order of a few $\mathrm{cm}^{2}$ ), the lens effects are absent, but the compaction of the medium can manifest itself in the change of its optical characteristics due to the variation of the packing density of the scatterers.

Since the external mechanical compression can essentially change the optical and structural properties of the tissue, this method can be considered as an alternative to the widely used immersion method of controlling the tissue optical parameters, based on the influence of chemical agents. As discussed above, the main mechanisms of the immersion clearing are the transport of water from the tissue and the partial replacement of intercellular or intracellular water with a chemical agent, as a result of which the difference of refractive indices of the scatterers and the interstitial fluid becomes smaller, reducing the scattering. Analogous processes partially occur under the compression, since the removal of water from the intercellular space and the increase of protein concentration in it as a result of applying the external compression should also lead to the reduction of scattering.

The effect of increasing the depth of laser radiation penetration into a biological tissue under the application of the external local mechanical pressure was demonstrated more than 30 years ago [173]. From that time a considerable number of publications appeared, related to using the influence of external mechanical compression of tissues on their optical properties (absorption and scattering).

The first studies $[174,175]$ were carried out with the tissue samples ex vivo. The authors noticed that the external compression changed the optical properties of the tissue samples, which manifested itself in the change of diffuse reflection and transmission of light by the samples of tissues. Thus, in Ref. [174] the studies of compression of soft tissue samples demonstrated the growth of the transmission coefficient and the reduction of the diffuse reflection coefficient in the spectral region from 400 to $1800 \mathrm{~nm}$. It was concluded that the compression increases the coefficients of absorption and scattering of the tissue, and the possible mechanisms of the "clearing" are the reduction of the sample thickness and its dehydration. Similar results were also obtained by the authors of Ref. [175]. The studies of the compression effect on the samples of porcine skin have shown that the mechanical compression causes the increase of the light transmission through the samples, and the effect is inertial.

The mechanical compression also changes the optical properties of tissues in vivo, which is accompanied by the spectral changes both in the diffuse reflection [176-186] and in the fluorescence [185, 187189]. The authors of $[176,187]$ were one of the first researchers who noticed the influence of the compression on the spectra of diffuse reflection and autofluorescence of human skin in vivo. It was reported that the pressure exerted on the skin reduces the depth of the dip in the green region of the spectrum that indicates the presence of blood in the tissue, as a result 
of which the reflection coefficient of skin in this region increases, while in the red and yellow region it decreases. In the reflection spectrum an isobestic point was found, for which the reflection coefficient does not change in the presence or in the absence of compression [176]. The external compression also caused the increase of the skin autofluorescence intensity in the short-wave region of the visible spectrum [187].

The reduction of diffuse reflection in the region $1100-1700 \mathrm{~nm}$ was reported [178] in human skin in vivo. It was shown that under the increase of the pressure of the fibre-optical probe on the skin surface the diffuse reflection is decreased. The authors related such behaviour with the change of the internal structure of the skin tissue. A similar fact was also noticed in the visible region of the spectrum [184].

In Ref. [185] the influence of short-time (smaller than 2 seconds) and long-time (greater than 30 seconds) mechanical action upon the diffuse reflection and autofluorescence spectra of human skin in vivo was studied. It was shown that at high pressure the significant spectral changes occur both for short-time and long-time compression, the probe pressure affecting not only the optical, but also the physiological parameters of the skin.

The influence of external compression on the physiological parameters of breast was studied by the authors of Ref. [180]. Under the compression of the tissue the light scattering was reduced, also decreased was the total blood content and the saturation of the tissue with oxygen. After the compression removal the effect of hyperaemia was observed. The changes in the blood circulation system (compression of blood vessels and reduction of blood oxygenation), to the opinion of the authors of Ref. [181], can enhance the sensitivity and specificity of early diagnostics of cancer.

At present the external mechanical compression is used as a method that allows the increase of image resolution and contrast in optical coherence tomography (OCT) and microscopy [28, 190-193].

The method of compression optical clearing of tissues is implemented instrumentally (tissue optical clearing device, TOCD) [29, 31, 194-196].

Finally, the mechanical compression of skin allows the assessment of the content of chromophores in it, whose absorption under the normal conditions is masked by the absorption by other chromophores. Thus, the extrusion of blood from the region of compression makes it possible to evaluation the content of carotenoids in the skin by the spectra of diffuse reflection [197], and the content of melanin in skin by the spectra of fluorescence $[171,172]$.

Although the amount of publications related to the mechanical compression of tissues is relatively large, the results are often somewhat controversial, which is mainly due to the difference in the conditions of the force application (local or distributed) and the detection of the reflected light (fibre-optical or open detecting system) [198]. Besides, it is necessary to take the inertial character of the tissue response to the external action into account.

The compression method of controlling optical parameters has a number of potential advantages in comparison with the immersion method. For example, moderate mechanical compression saves the barrier functions of the stratum corneum and the epidermis as a whole.

In the visible region the absorption coefficient of water is insignificant as compared to the near IR region, where the absorption peaks caused by the combinations and overtones of fundamental vibrations are located. In the skin the absorption spectral bands of water bound with the proteins of interstitial matrix are shifted with respect to the bands of free water towards the long-wave region of the spectrum. Thus, the manifestations of bands in the reflection spectrum of skin at $1160 \mathrm{~nm}$ and $1220 \mathrm{~nm}$ were reported [199], attributed by the authors to the absorption bands of free and bound water. The absorption bands at $1879 \mathrm{~nm}$ and $1890 \mathrm{~nm}$ were attributed [200] to the absorption of free water, and the bands at $1909 \mathrm{~nm}$ and $1927 \mathrm{~nm}$ to the bound water.

The effect of water transport was studied by Rylander et al. [196]. In the skin the natural gradient of water content depending on the depth exists. In the stratum corneum the water content depends upon the air humidity and can be at the level $15 \%$. The water content grows with depth, reaching $70 \%$ in dermis. A considerable part of this amount is free water, the molecules of which due to their high permeability percolate from the region of external compression into the adjacent regions. The water migration from the skin regions subject to compression leads to the matching of the refractive indices of the tissue components [31], which reduces the scattering coefficient.

The water transport in the skin tissue can be analysed on the base of two-phase nonlinear mixture [201], according to which the skin is presented as a solid elastic matrix, formed mainly by elastic fibrils and cells and filled with water. This model is sufficient to present the composition and mechanical properties of the skin well enough [196, 201]. Basing on this model the authors of Ref. [193] studied the influence of mechanical compression on the optical properties of the skin. The samples of porcine skin ex vivo and human skin in vivo were studied using OCT at the wavelength $\lambda=1310 \mathrm{~nm}$. It was found that for the porcine skin samples ex vivo the compression reduces the water fraction in the tissue by more than three folds (from 0.66 to 0.2 ).

The detailed analysis of possible mechanisms affecting the skin optical properties was carried out in Ref. [199] where the influence of human skin compression on the variation of its scattering properties and the free and bound water content were studied. The changes in the diffuse reflection spectra were correlated with the effects of tissue deformation within the framework of two-phase nonlinear mixture model. The optical properties of the skin were considered basing on the three-layer medium (epidermis, dermis, subcutaneous fat), and the scattering properties of the 
tissue were determined as the combination of scattering by large (Mie scattering) and small (Rayleigh scattering) particles. The expressions for the scattering coefficients of each of the skin layers were taken from Refs. [202, 203], and the skin absorption in the near IR region was determined as the superposition of absorption by water and lipids. The water contribution into the absorption amounted to $20 \%$ for epidermis, $70 \%$ for dermis, and $60 \%$ for subcutaneous tissue (fat and muscle) [203, 204].

Experimental diffuse reflection spectra were analysed for two absorption lines of water in the near IR region, $1160 \mathrm{~nm}$ and $1220 \mathrm{~nm}$, attributed by the authors to the absorption of free and bound water, respectively, basing on the comparative analysis of the reflection spectra of skin and pure water.

The measurement of water content in the skin in vitro has shown that under compression the intensity of the band at $1220 \mathrm{~nm}$ significantly grows, while the intensity of the band at $1160 \mathrm{~nm}$ decreases. When the pressure is increased to $376 \mathrm{kPa}$, the absorption peak at $1160 \mathrm{~nm}$ almost vanishes. This indicates the fact that under the compression of skin the free water leaves the compressed region, while the bound water that forms complexes with proteins stays. When the pressure achieves $400 \mathrm{kPa}$, the volume of free water decreases to $30 \%$ of its initial value. This is the main cause of the tissue deformation. Under the long-time compression the absorption peak of free water decreases with time, and the peak of bound water increases. At the early stages of the deformation due to the large stress in the tissue the free water leaves the compressed region with sufficiently high rate. As the stress relaxes, the deformation of the tissue and the rate of free water migration gradually decrease. After nearly 6 minutes the tissue deformation and the water transport stop. The duration of this process is also related to the compression magnitude.

Thus, for the analysis of the structural and optical changes occurring in the skin in vivo under the conditions of external compression the above model of the tissue can be considered, according to which the skin consists of a solid matrix formed by the collagen fibres and the interstitial fluid, the major part of which is water. When the skin is compressed, the solid matrix is deformed and the interstitial fluid leaves the region subject to compression with the rate determined by the density of packing of the matrix fibres and the viscosity of the fluid. This hypothesis is in good agreement with the experimental data. The relation of skin deformation and relaxation time under the conditions of compression depends upon the elastic properties of the fibrils and the density of their packing, as well as upon the amount and viscosity of the fluid in the tissue. Since the bound water is integrated in the tissue solid matrix, the measurements of free and bound water content variations can reflect the deformation of the solid matrix and the transport of free water in the tissue under the conditions of compression.

\section{Photochemical and photothermal clearing}

For a number of applications, particularly, in the case of laser therapeutic or surgical interventions, one can control the optical properties of the tissues by means of photochemical or photothermal action. The heating and coagulation of a tissue change its optical properties, and this should be taken into account in the calculation of the radiation doze in the process of treatment [3, 22]. The method of controlling optical properties of fat tissue, which is usually a strongly scattering tissue, was proposed in $[205,206]$. The method is based on the combined photochemical and photothermal effect [2, 207] induced in the fat tissue cells.

The selective photothermal action on the fat tissue can be implemented by the laser radiation wavelength choice using the absorption by the endogenous (own) tissue chromophores, in the present case the lipids contained in the fat drop of adipocytes, under the exposure to light with the wavelength $1210 \mathrm{~nm}$ [208]. However, with exogenous chromophores, e.g., the indocyanine green (ICG), the efficiency of light interaction with tissue may be essentially higher and more selective [209-213]. The intensity and position of ICG absorption peaks depend upon the solvents used [214-216]. The solutions with complex compositions, e.g., such as water-alcohol-glycerol, stabilise the ICG absorption peaks [215]. Besides that, the alcohol component of the solution makes the cell membrane permeable for the dye [217-219]. The next step of the interaction between the dye and the cell is related to the light action. The light causes photochemical reactions; for ICG they simultaneously follow two scenarios: 1) photodynamic reactions; 2) reactions yielding toxic products [216]. Depending on the intensity, the biological response of the cell may lead to reversible of irreversible injury of the cell membrane. Reversible membrane injury consists in the creation of new pores or enlargement of the already existing ones, which facilitates efficient exchange between the cell content and the environment. In fat cells the presence of pores increases the lipolysis, as a result of which the intercellular space becomes filled with the cell content and decay products (triglycerides, fatty acids, water and glycerol) [37, 220-223]. The appearance of such immersion fluid in the intercellular space facilitates the process of optical clearing of the adipose tissue [37].

The probability of triglyceride leaving the cell through the membrane pores is rather small due to the relation between the pore diameter $(0.1-2 \mathrm{~nm})$ and the triglyceride molecule size (nearly 1-2 nm) [221-223]. The hydrolysis of triglycerides occurs in two stages. At the first stage the hydrolysis of external complex ether bonds occurs; this process is catalysed by the lipase enzyme. The hydrolysis of triglycerides is referred to as lipolysis. The monoglyceride produced at the first stage of the triglyceride decay, is further hydrolysed by the nonspecific esterase, producing glycerol and three molecules of higher fatty acids [221-223]. The 
hydrolysis products can easily leave the cell through the pores, since their molecular size is small compared to the pore size. In this process the refractive index of the intercellular fluid $\left(n_{\mathrm{M}}=1.36\right)$ [45] approaches the refractive index inside the adipose cell itself $\left(n_{\mathrm{B}}=1.44\right)$, the medium becomes more optically homogeneous and, as a result, more transparent [22].

In Refs. [37, 220] the photodynamic effect in adipose cells in vitro sensitised with brilliant green (BG) was studied. The result was also the cell lipolysis. The hypothesis of pore formation is in good agreement with the experimental results [37, 206, 220, 224].

Fig. 5 presents the transmitted light images of the subcutaneous fatty tissue sample, stained with BG, before (a) and after (b-e) the irradiation with a dental diode lamp Ultra Lume Led5 with the wavelengths 442 and $597 \mathrm{~nm}$ and the total power density $75 \mathrm{~mW} / \mathrm{cm}^{2}$ during 15 minutes at the constant temperature $33^{\circ} \mathrm{C}$. The cell lipolysis is seen to stimulate the leakage of a part of intracellular fluid into the intercellular space and the tissue gradually undergoes immersion clearing.

\section{Applications of optical clearing}

\subsection{Optical coherence tomography}

OCT is a noninvasive method of visualising the internal structure of optically inhomogeneous objects that allows the study of tissue internal microstructure with high resolution and without disturbing its integrity [18]. However, the multiple scattering essentially worsens the OCT imaging characteristics, namely, the image resolution, probing depth, and the precision of localisation [21]. In this connection the progress of optical clearing techniques is of huge potentiality for noninvasive OCT medical diagnostics $[28,29,35,36$, 39, 190, 192, 196].

The efficiency of mechanical compression for better differentiation of chronic inflammation and carcinoma in the OCT images was studied by Agrba et al. [28]. They also determined the threshold impact that allows the detection of difference between these cases. Using the endoscopic probe of unique construction that allowed the control of the compression force applied to the tissue, the possibility of differentiating the pathologic changes of rectum ex vivo with inflammation and carcinoma was demonstrated.

The same research team has shown that the application of compression to human skin causes various changes of the optical properties of skin layers depending on their elasticity. These changes increase the contrast of the OCT-imaged boundaries between the layers [192].

The efficiency of the mechanical device for biotissue optical clearing, designed by Rylander et al. [196] was determined using OCT [29]. The authors have shown that the depth of light penetration into the human skin in vivo at the OCT wavelengths 850 and $1310 \mathrm{~nm}$ increase by 3 folds in the area of compression. The contrast of the OCT image of the epidermis-dermis boundary was also increased. OCT allowed the specification of compression clearing mechanism. Thus, the OCT Mscans recorded during the pressure application have shown that the optical penetration depth monotonically increases, undergoing a jump at the initial time period (5-10 s), during which the water content in the tissue abruptly decreases and the group refractive index increases in the local area of pressure application.

The authors of Ref. [191] proposed to use OCT with compression for continuous noninvasive monitoring of blood glucose content. The results of in vivo skin studies at different pressures have shown that the pressure of the OCT probe on the skin reduces the artefacts related to the object motion, but may shift the OCT signal slope that allows the blood glucose monitoring. Thus, the controlled external pressure $<1 \mathrm{kPa}$ significantly improved the precision and reproducibility of the glucose OCT monitoring.

The potentialities of immersion optical clearing are mainly related to the fact that OCT allows the imaging of relatively thin layers of tissues that can be rapidly impregnated with OCA applied to the surface. In Refs. $[21,22]$ it was demonstrated that the internal tissues, such as the walls of blood vessels, oesophagus, ventricle, large intestine, and other organs can be imaged to the depth of 1-2 $\mathrm{mm}$. The application of immersion liquids increases the probing depth nearly by 3.5 folds and significantly improves the image contrast of the internal inhomogeneities [225, 226]. The possibility of malignant melanoma diagnostics, observation of subepidermal cavity, and control of the skin scattering properties under the application of glycerol and propylene glycol to its surface was shown by the example of OCT visualisation of human skin in vitro and in vivo [22]. Moreover, the variation rate of the OCT A-scan slope in the course of the optical clearing allows additional differentiation of the healthy and tumour tissue of the human oesophagus and mammary gland [103-105, 227, 228].

Optical coherence tomography offers a unique possibility to assess the variation of the tissue light scattering coefficient with sufficient depth resolution. The total light attenuation coefficient $\mu_{t}$ of the tissue local volume, which is a sum of the absorption coefficient $\mu_{a}$ and the scattering coefficient $\mu_{s}$, may be found by fitting the parameters of the approximating curve, calculated within the framework of the appropriate model, using the local A-scan slope of the OCT signal [18, 118, 230-232].

The single scattering model is based on the assumption that only the light undergoing singe scattering (ballistic photons) preserves the coherence properties and contributes to the OCT signal. In this case the OCT signal $i(z)$ is determined as $[18,230,231]$ : $\left(\left\langle i^{2}(z)\right\rangle\right)^{1 / 2} \approx\left(\left\langle i^{2}\right\rangle_{0}\right)^{1 / 2}\left(\exp \left(-2 \mu_{\mathrm{t}} z\right)\right)^{1 / 2}$, where $z$ is the depth, from which the reflected signal comes. 


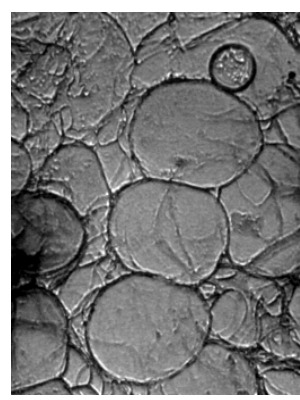

a

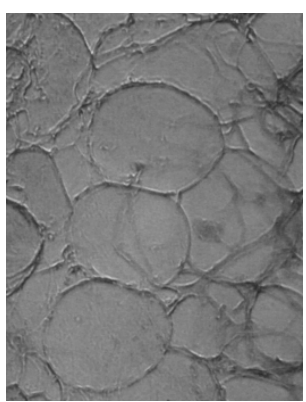

b

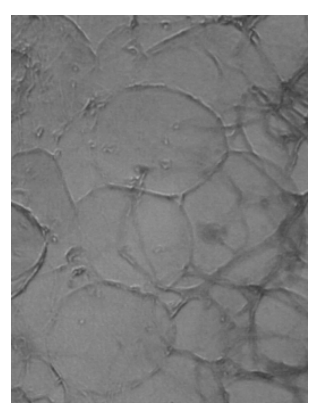

c

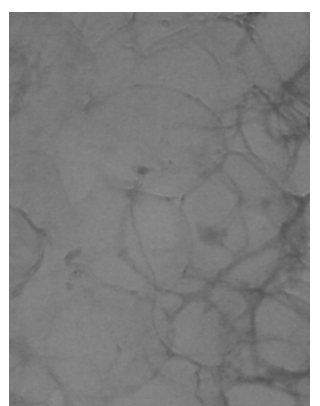

d

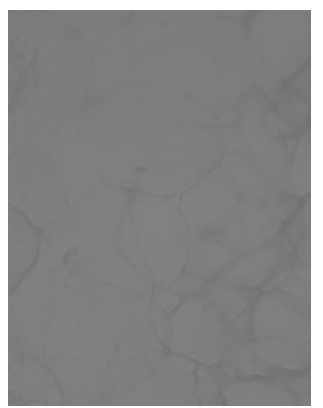

e

Fig. 5 Transmitted light images of a subcutaneous fatty tissue sample stained with brilliant green before (a) and after (be) light exposure during $15 \mathrm{~min}$. The time interval between the image recording and the end of exposure is 8 min (b), 19 $\min (\mathrm{c}), 39 \mathrm{~min}(\mathrm{~d}), 120 \mathrm{~min}(\mathrm{e})$. The sample temperature is $33^{\circ} \mathrm{C}$. Diode lamp, 442 and $597 \mathrm{~nm}$, the total power density $75 \mathrm{~mW} / \mathrm{cm}^{2}$.

It is known that the result of OCT is the measurement of the reflected signal intensity from the studied tissue, $R(z) \propto\left(\left\langle i^{2}(z)\right\rangle\right)^{1 / 2}$, upon the depth $z$. The OCT signal intensity depends upon the reflectance $\alpha(z)$ of the tissue at the given depth and the total attenuation coefficient $\mu_{t}=\mu_{a}+\mu_{s}$ of the tissue. In accordance with the singe scattering model that is valid both for weakly scattering tissues and for the surface layers of strongly scattering tissues [231], the reflected power in proportional to $\exp \left(-\mu_{t} z\right)$ [18], i.e., can be approximated with the expression [118]: $R(z)=A \exp \left(-\mu_{t} z\right)+B$, where $A$ is the coefficient equal to $P_{0} \alpha(z)$, with $P_{0}$ being the optical power of the beam, incident on the tissue surface, $\alpha(z)$ being determined by the local capability of the tissue to scatter the light in the backward direction (to reflect), which is largely dependent upon the local value of the refractive index, and $B$ being the background signal.

Since the absorption coefficient is essentially smaller than the scattering coefficient for many tissues in the near IR spectral range, the exponential decay of the ballistic photons is mainly determined by the scattering coefficient [18]. The scattering coefficient depends on the difference of refractive indices in the tissue volume, so that the increase of the refractive index of the interstitial fluid and the corresponding reduction of scattering is recorded as the change (decrease) of the slope of the OCT signal amplitude as a function of the probing depth $[18,35,89,90,93,95$ $100]$.

This method allows the measurement of the permeability coefficient of tissues both for OCAs and for the medicinal preparations, possessing the properties of OCA, using two approaches: measuring the OCT signal slope (OCTS) and the OCT signal amplitude (OCTA) (Fig. 6a) [35, 95, 232]. In the OCTS approach, analysing the variation of the OCT signal slope due to the OCA diffusion, one can calculate the mean permeability coefficient of a certain region in the tissue. In this case two-dimensional OCT images are averaged over the lateral coordinate ( $x$ axis) to get a one- dimensional depth distribution of the OCT signal intensity. In the tissue it is necessary to choose the region, for which the signal is linear and its fluctuations are minimal, where the tissue thickness $\left(z_{\text {region }}\right)$ must be measured. Then the monitoring of the agent diffusion in the chosen region is performed and the time of diffusion $\left(t_{\text {region }}\right)$ is recorded. The mean permeability coefficient $(\bar{P})$ can be calculated as the thickness of the region divided by the time, during which the diffusion of the agent through the chosen region occurs $\left(\bar{P}=\frac{z_{\text {region }}}{t_{\text {region }}}\right)$ [232].

The OCTA approach can be used to calculate the permeability coefficient at a definite depth in the tissue: $P(z)=z_{i} / t_{z_{i}}$, where $z_{i}$ is the measurement depth and $t_{z_{i}}$ is the time of agent diffusion to the given depth. The value of $t_{z_{i}}$ should be calculated from the time of the agent application to the time of the beginning of the OCT signal amplitude variation, caused by the OCA [232].

These approaches allowed the assessment of the following permeability coefficients: rabbit cornea for mannitol $(8.99 \pm 1.43) \times 10^{-6} \mathrm{~cm} / \mathrm{s}$ [95], rabbit sclera for mannitol and $20 \%$ glucose solution $(6.18 \pm 1.08) \times 10^{-6}$ and $(8.64 \pm 1.12) \times 10^{-6} \mathrm{~cm} / \mathrm{s}$, respectively, [95], human sclera for cortexin $(2.40 \pm 0.32) \times 10^{-5} \mathrm{~cm} / \mathrm{s}$ (Fig. 6b) [93], porcine aorta for $20 \%$ glucose solution $(1.43 \pm 0.24) \times 10^{-5} \mathrm{~cm} / \mathrm{s}$ [99], epidermis and dermis for $40 \%$ glucose solution $(6.01 \pm 0.37) \times 10^{-6} \mathrm{~cm} / \mathrm{s}$ and $(2.84 \pm 0.68) \times 10^{-5} \mathrm{~cm} / \mathrm{s}$, respectively, [97], lung tissue for $30 \%$ glucose solution $(1.35 \pm 0.13) \times 10^{-5} \mathrm{~cm} / \mathrm{s}$ (the norm) [100], and lung tissue for $30 \%$ glucose solution in the case of different malignant neoplasms [100].

The depth-resolved analysis of the tissue optical properties using OCT allows the reconstruction of twodimensional diffusion maps. The visual representation of the molecular diffusion front was first demonstrated by Ghosn et al. [97] in the course of noninvasive determination of the penetration rate of $20 \%$ glucose 
solution into the rhesus macaque skin in vivo.
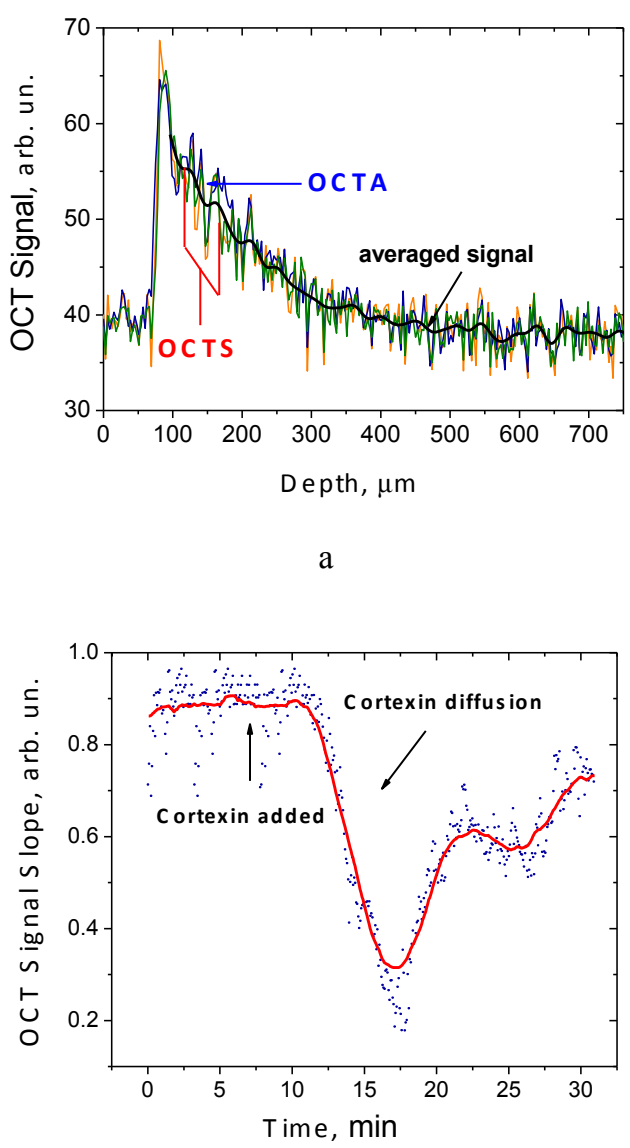

b

Fig. 6 The region and the depth, indicated in the averaged OCT signal, used in OCTS and OCTA approaches (a), and the time dependence of the OCT signal slope in the process of interaction of the sclera with the cortexin solution (b) (from the data of [93]).

Using the OCT methods one can reveal the variations of the effective refractive index of the adipose tissue as a result of the light photodynamic action, which arise both directly after the exposure, and in the process of the system biological response [38, 224]. The observed changes of effective refractive index can be interpreted as the reduction of the relative refractive index of the scatterers, which can be related to the immersion optical clearing.

Fig. 7 shows the series of OCT images of adipose tissue stained with BG before (a) and after (b-d) the irradiation with the light of a diode lamp during 15 minutes and under the heating of the samples to the physiological temperature. Fig. 7,b shows the image of the adipose tissue immediately after the irradiation, while the OCT images in Figs. 7,c and 7,d correspond to relatively long observation time (60 and $120 \mathrm{~min}$., respectively). The mean thickness of the samples amounted to $237 \pm 10 \mu \mathrm{m}$.

The visual comparison of the OCT tomograms of the adipose tissue shows that after the irradiation the tissue structure considerably varies in time. One can easily see the changes of the outer layer of the cellular structure that becomes more homogeneous, which can be associated with partial destruction of cells and formation of immersion layer consisting of intracellular content and the products of the adipose component hydrolysis. In Fig. 7(b-d) this layer is as thick as 80-90 $\mu \mathrm{m}$. The mean size of adipocytes in the tissue amounts to $60-70 \mu \mathrm{m}$.

Provided that the geometric thickness of the studied layer is known, the effective refractive index $n$ is calculated as $n=z / l$, where $l$ is the geometric path length (the true sample thickness in $\mu \mathrm{m}$ ), and $z$ is the layer thickness observed in the OCT image, i.e., the optical path length in $\mu \mathrm{m}$. The geometric thickness was measured using a micrometre gauge. The optical path length was found from the OCT signal as the difference between the depths of two peaks, corresponding to the sample boundaries (see Fig. 7). For better determination of the boundaries the A-scans were averaged over the lateral region of $2 \mathrm{~mm}$. This operation smooths out the stochastic noise and the disordered cell structure of the tissue, while the peaks, corresponding to the sample boundaries, become more distinct. The calculation of the refractive index showed its monotonic decrease with the growth of observation time.

The observed changes in the OCT images can be interpreted as the result of lipolysis and cell destruction at the surface of the sample due to the photochemical effect. The intracellular fluid leaks from the cells and fills the intercellular space, as a rule, containing the intercellular fluid, thus producing the cleared (more homogeneous) outer layer and giving rise to optical clearing inside the tissue by matching the refractive indices of cells and intercellular medium.

In Ref. [233] the chemically induced lipolysis activity was assayed by measuring the amount of glycerol released from the cells into the surrounding medium. Besides, using frame-by-frame CARS (coherent anti-Stokes Raman spectroscopy) processing of a single living cell, the authors could control the morphological changes of lipid droplets in the cells. They found that the microscopic lipid droplets appeared gradually in the course of the experiment, achieving the size of nearly $1 \mu \mathrm{m}$ in $60 \mathrm{~min}$ after the impact. All these observations allow the assumption that analogous processes may occur in the case of light-induced lipolysis.

The results of OCT measurements of the refractive index of adipose tissue after the exposure to light can be explained basing on the idea of forming two layers with the course of time. One of these layers is cleared (the released intracellular fluid) and the other one is scattering (cells). The refractive index $m$ of the scattering medium can be expressed as [128]

$m \equiv n_{0}+\Delta m=\bar{n}+\frac{\overline{n^{2}}-\bar{n}^{2}}{\bar{n}} Q(\lambda / l)$, 


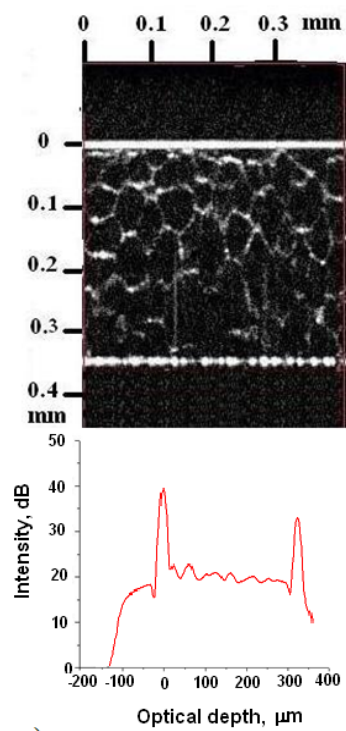

$\mathrm{a}$

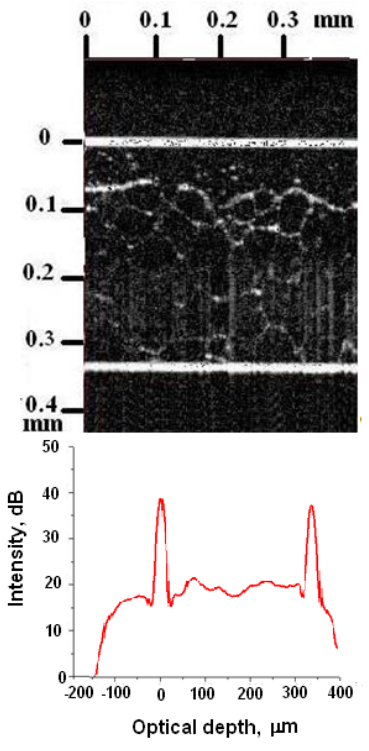

b

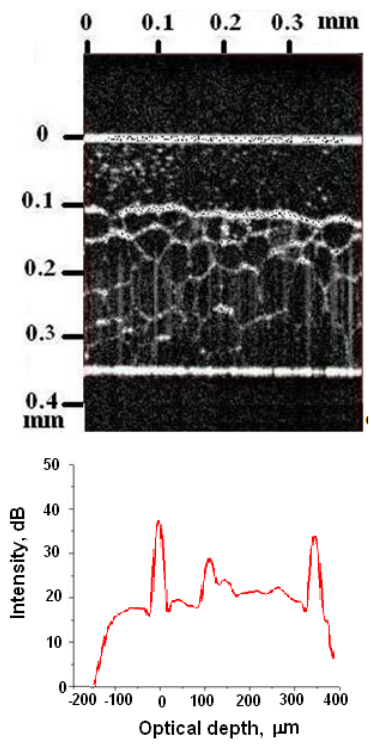

$\mathrm{c}$

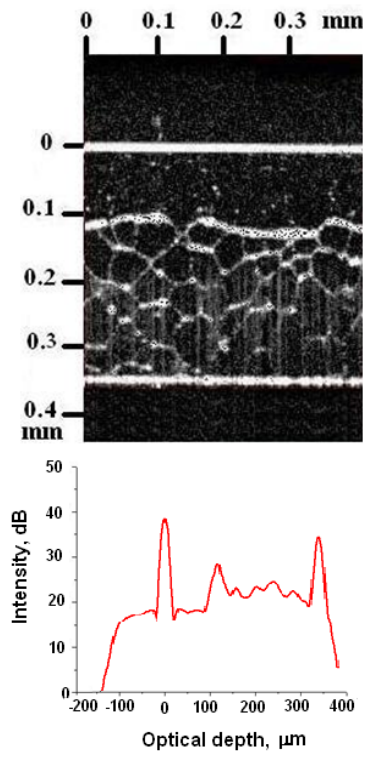

d

Fig. 7 OCT images of adipose tissue stained with BG before the irradiation (a), immediately after 15-minute irradiation (b), in $60 \mathrm{~min}$ (c), and in $120 \mathrm{~min}$ (d) after the irradiation. The source was the dental diode lamp Ultra Lume Led5 (442 and $597 \mathrm{~nm}, 75 \mathrm{~mW} / \mathrm{cm}^{2}$ ). The dye concentration is $6 \mathrm{mg} / \mathrm{ml}$. The sample temperature is $37^{\circ} \mathrm{C}$. The curves correspond to A-scans of the OCT image, averaged over the whole B-scan region [224].

where

$$
\bar{n}=n_{0}\left[1+\left(\frac{n}{n_{0}}-1\right) \frac{V_{s}}{V_{0}}\right],
$$

$V_{s}$ is the total volume of scattering particles, $V_{0}$ is the volume of the scattering medium, $\frac{-}{n^{2}}$ is the mean square value of the refractive index fluctuations, $Q(\lambda / l)$ depends upon the shape and aggregation of scatterers, and $l$ is the correlation length of randomly distributed fluctuations of the refractive index. $Q=1.17$ for the limit case of large correlation length, $l>\lambda$ (large particles). In the process of the adipose tissue degradation the two-phase system appears, consisting of cytoplasm of the adipose cells (the cleared outer layer in Fig. 7,b) and the adipose cells themselves. Each phase of the medium has its own thickness and refractive index. Denoting the time-dependent thickness of the layer of adipose cells as $H(t)$, and the thickness of the outer layer of transparent cytoplasm as $[L-H(t)]$, the mean refractive index of the layer with the thickness $L$, containing two layer with different refractive indices, can be written as

$m_{T}=\frac{[L-H(t)]}{L} \bar{n}+\frac{H(t)}{L} m$,

where $m$ and $\bar{n}$ are defined by Eqs. (1) and (2). Since $m$ is always greater than $\bar{n}$ due to the effect of scattering and tissue degradation, this leads to the decrease of $H(t)$, and the summary refractive index should decrease with time.
In the process of adipose tissue degradation and formation of greater amount of lipolysis products the conditions of refractive index matching can be implemented, which will lead to further reduction of light scattering, i.e., the part of the refractive index $m$, depending on these processes. Both these mechanisms, the tissue degradation and the refractive index matching, explain the experimentally observed reduction of the mean refractive index of the sample layer, i.e., the reduction of its scattering capability, in the course of time.

\subsection{Optical projection tomography}

Optical projection tomography (OPT) is a new approach to three-dimensional visualisation of small biological objects. It fills the gap between the MRT and confocal microscopy $(\mathrm{CM})$, being the most suitable for studying the objects with the size from 1 to $10 \mathrm{~mm}$ [234]. The possibility to analyse the organisation of a biological tissue in three dimensions is inestimable for understanding the embryonal development, a complex process in which the tissues undergo a complex sequence of transformations with respect to each other [235]. Since the OPT allows the registration of both the absorption and emission profiles, this method offers an opportunity to use different staining techniques, developed to observe the spatial distribution of gene activity [234, 235]. Other important applications of the OPT help in the analysis of normal and abnormal morphology and in determining the position of labelled cells in the tissue [235].

The most widely used approach to the OPT imaging implies the suspension of the object in the immersion liquid in order to reduce the surface light scattering and 
to decrease the refractive index nonuniformity all over the sample. This means that the light passes through the sample along nearly straight trajectories (ballistic photons), and the standard algorithm of back projection can generate images with high resolution [234]. Alanentalo et al. [236, 237] have shown that the OPT allows successful construction of three-dimensional images of specially labelled structures inside the cleared organs of a mouse (see, Fig. 8).

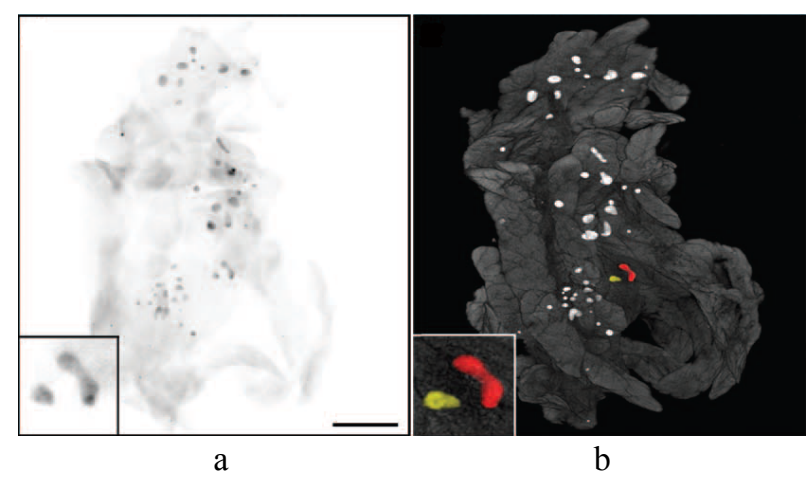

Fig. 8 Single image from the OPT scan datasets with the selected regions of interest (inset) (a) and volume reconstruction of the pancreas based on the background autofluorescence (dark gray) and the signal from insulin-specific antibodies (white-islets) with the regions of interest (inset) (b) [237].

The role of OCA was played by «Murray's clear» (1 part of benzyl alcohol and 2 parts of benzyl benzoate $(\mathrm{BABB}))$ with the refractive index 1.55.

\subsection{Fluorescence imaging}

The methods of fluorescence spectroscopy and microscopy belong to noninvasive methods of biomedical diagnostics. Fluorescence spectra often provide detailed information about the fluorescent molecules, their conformations, sites of bonding and interaction with cells and tissues [238]. Under the excitation with ultraviolet light $(\lambda \leq 300 \mathrm{HM})$ one can observe the autofluorescence of both the proteins and the nucleic acids. The porphyrin molecules are also endogenic phosphors, the content of which in cells considerably increases under some pathologic conditions. Besides, some bacteria, causing, e.g., the inflammation diseases of skin [239] and gums [240], inhabiting the caries tooth lesions [241], can accumulate considerable amounts of porphyrins. Combining the measured autofluorescence spectra with those of reflection and absorption, OCT and other optical methods allows the diagnostics of caries and tooth tissue demineralisation [241-245], skin cancer [246, 247], and pre-cancer changes of cervical tissue [248], mammary gland [249], and other diseases.

Thanks to the growing number of fluorescent dyes, specifically staining the biological molecules (nucleic acids, proteins) or cell organelles, the methods of fluorescence microscopy acquire greater and greater significance [238].
At present in different biomedical studies the confocal microscopy $(\mathrm{CM})$ is widely used, which allows visualisation of internal structure of biological tissues at the cellular and subcellular level [250, 251]. A confocal microscope illuminates a small volume inside the object and detects the scattered light of fluorescence signal from the same small volume. The main $\mathrm{CM}$ advantage as compared to the methods of common microscopy is the capability to obtain the optical cross-sections of thick samples [251]. This method allows the creation of high-quality (with micron spatial resolution) images of cell layers. The high contrast and spatial resolution of $\mathrm{CM}$ images are due to probing a small volume of the medium, limited by the size of the central focal spot formed by the focusing optical system. The main limitation of CM in the skin studies is the considerable scattering that spoils the quality of cell imaging. The increase of the transparency of the outer layers of skin may improve the light penetration depth, the contrast and the spatial resolution of the CM.

In the publications by Meglinsky at al. [48, 49] basing on the Monte-Carlo modelling the possibility of increasing the human skin probing depth was considered theoretically for the first time using the method of reflectance CM with the reduction of spatial fluctuations of the refractive index of the outer skin layers by optical clearing. Later in the paper by Dickie et al. [83] the experimental method was described that allowed visualisation of microvessels of different mouse tissues using the CM at the depth up to $1500 \mu \mathrm{m}$ below the sample surface due to the optical clearing of thick slices of the tissue. The OCA for CM in Refs. [252-256] was the commercially available multicomponent agent FocusClear $^{\mathrm{TM}}$ [257], especially developed for using in fluorescence and non-fluorescence light microscopy. FocusClear $^{\mathrm{TM}}$ does not give rise to the tissue dehydration and allows the improvement of the obtained image quality. The refractive index of this agent is 1.46 .

FocusClear ${ }^{\mathrm{TM}}$ was successfully used for confocal imaging of murine rectum and ileum [252, 253], the wall of the human ileum [254], the murine pancreas [255], and the brain of the insect (Diploptera punctata) [256] in vitro. The optical clearing facilitated the identification of spatial and temporal changes of crypt morphology of the murine large intestine with colitis, as well as the detection of transgene fluorescent proteins, expressed in large intestine and ileum [252]. The increase of resolution and visualisation depth of the microstructure and vascular system of ileum was observed under the combined use of blood vessel staining and optical clearing [253]. The authors of Ref. [255] declare that by using OCA the thickness of the studied samples can be increased by 80 folds, which allows better reproduction of the structure and the vascular system of the tissue (see Fig. 9). The use of OCA allowed three-dimensional reconstruction of microvascular architecture of the insect brain with submicron resolution to the depth of $1500 \mu \mathrm{m}$ [256]. 


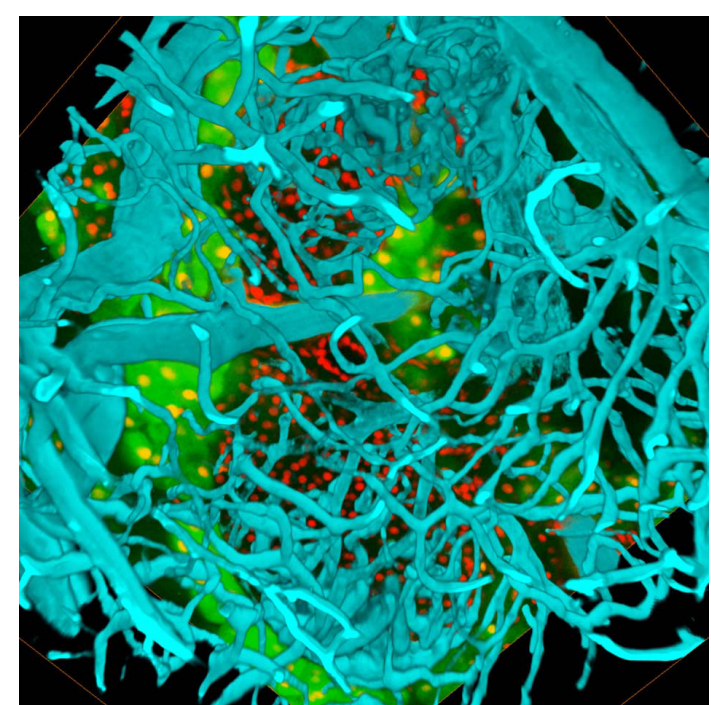

Fig. 9 Fly-through presentation of the islet vasculature using multiple projection angles and magnifications. Dimensions of the scanned volume: $521 \mu \mathrm{m}(x) \times 521$ $\mu \mathrm{m}(y) \times 333 \mu \mathrm{m}(z$, depth). Two islets reside in the scanned volume [255].

However, the visualisation depth of $500-1500 \mu \mathrm{m}$ is not sufficient for three-dimensional reconstruction of neuron networks of the murine brain as a whole. Hama et al. [85] developed an OCA, called Scale, which not only increases the transparency of a biological sample, but also does not reduce the intensity of fluorescence signals from the cleared structures.

Dodt et al. [86] used the idea of illuminating the object with so called light sheet, which allows observation of macroscopic objects, such as the brain as a whole, with micrometre resolution. The sample is illuminated from two sides with the laser radiation in the blue part of the spectrum, forming a thin planar light beam. The fluorescence signal is, therefore, emitted only from a thin optical section and is collected by the objective lenses. The declined light is blocked by a filter, and the image is projected through a cylindrical lens onto the screen of a digital camera. Since all sample parts below or above the light sheet are not illuminated, the emission is not excited beyond the limits of the focus and, therefore, is not to be eliminated from the useful signal. This approach is referred to as ultra-microscopy (UM). In comparison with CM or twophoton microscopy, UM can rapidly create optical sectioning of macroscopic samples, since the objectives with small focal power and small numerical aperture can provide a large field of view. However, the use of $\mathrm{UM}$ is completely dependent upon the optical transparency of biological objects, so that the improvement of optical clearing efficiency, including that due to the development of new OCAs, remains to be an urgent problem [86, 87, 258-262]. In Ref. [258] it was shown that the use of optical clearing allowed cellular resolution in sectioning the fixed mouse brain and detecting individual neurons, labelled with green fluorescent protein, in the removed murine hippocampus. In the isolated hippocampus the three- dimensional images of dendrite structures and processes of neuron populations were obtained. The use of UM includes the imaging of cleared murine organs and total embryo specimens, adult insects Drosophila, and other fixed tissues with the size of a few millimetres [259].

Ertürk et al. [87] found that tetrahydrofurane (THF) in combination with BABB can completely clear the spinal cord, preserving its fluorescence. Recently Ertürk et al. [262] developed a new protocol of optical clearing using the dibenzyl ether instead of BABB in combination with THF to get three-dimensional images of neurons of the whole mouse brain using the UM. This method was called three-dimensional imaging of solvent-cleared organs (3DISCO). In this study the clearing of the tissue took only three hours, and the visualisation was performed during 45 minutes.

\subsection{Photoacoustic imaging}

Optothermal effects occur in a tissue due to its interaction with pulsed or intensity-modulated optical radiation. Such interaction gives rise to a number of thermoelastic effects in the tissue, in particular, the generation of acoustic waves. Detection of the acoustic waves is the base of the optoacoustic (or photoacoustic) methods [1, 3]. The main applications of the photoacoustic (PA) method are in the field of visualisation of strongly absorbing objects, such as blood vessels [263-265] and tumours [266]. This method can be also used for imaging of subcutaneous structures [267] and measuring the blood oxygenation [268]. The quality of the PA signal depends upon the penetration depth of the optical signal and the damping of the acoustic signal.

The optical clearing technologies allow the increase of the tissue transparency, which facilitates the reduction of optical radiation scattering and increases the depth of the detected inhomogeneities. On the other hand, the flow of OCA into the tissue and of water out of the tissue changes the composition and structure of the skin, thus changing the acoustic impedance and absorption and, therefore, the acoustic wave damping [269]. Recently it was demonstrated that the optical resolution of PA microscopy can be significantly increased using the aqueous solutions of glycerol as OCA [270]. Liu et al. [115] studied several OCAs in vitro and in vivo, and showed that PEG-400 in combination with Thiazon improves the visualisation of deep blood vessels of skin, while glycerol is better for imaging small branching blood vessels. In this case the immersion time should be controlled to prevent the reduction of the signal amplification.

Based on the amplification of PA signal at the expense of reduction of scattering, this method can be also efficiently used for noninvasive monitoring of glucose content in blood and tissues, which was demonstrated both in phantoms [271, 272], and in the in vitro and in vivo studies [273].

By means of PA spectroscopy the influence of glucose can be detected measuring the interval between the peaks of the pressure waves induced by the laser 
radiation [272]. The studies demonstrated the applicability of PA spectroscopy to measuring the concentration of glucose [272]. The maximal relative change in the PA response was observed in the region of the second $\mathrm{C}-\mathrm{H}$ overtone at the wavelength $1126 \mathrm{~nm}$ with the additional peak in the region of the second $\mathrm{O}-\mathrm{H}$ overtone at the wavelength $939 \mathrm{~nm}$ [273]. Besides, the analysis of the generated pulsed temporal profile of the PA signal allows the determination of the glucose influence on the tissue scattering, which decreases with the growth of glucose concentration [22, 274].

\subsection{Nonlinear and Raman microscopy}

Multiphoton excitation of molecules is a nonlinear process, involving the absorption of two or more photons, the total energy of which is sufficient to induce a transition of the molecule to the excited state. Twophoton technique uses the photons with the wavelength of the second harmonic of the incident radiation, coming exactly from the focal region of the incident beam $[2,3]$. The unique advantage of the multiphoton microscopy consists in the possibility to study threedimensional distributions of chromophores, excited by the ultraviolet radiation in thick samples. Such investigation becomes possible because the chromophores can be excited by the radiation of the second harmonic (e.g., at the wavelength of $350 \mathrm{~nm}$ ), providing high quantum yield under the irradiation of the tissue, e.g., with the laser light having the wavelength near $700 \mathrm{~nm}$, where the tissues possess high transparency. In this case the long-wave radiation can reach deeper layers with less tissue damage [3].

The use of OCA can appear particularly important for improving the two-photon microscopy [23], since it was shown that the light scattering effect strongly reduces the light penetration depth to values, smaller that the depth of the single-photon fluorescence, whereas the resolution remains generally unchanged [251]. This happens mainly because of the exciting beam defocusing in the scattering medium. On the other hand, this method is useful for better understanding of molecular mechanisms of the optical clearing of the tissue under the immersion and dehydration [23].

The improvement of the deep-tissue two-photon signal by means of optical immersion method using hyperosmotic agents, such as glycerol and propylene glycol in the dehydrated form, and the glucose solution, was first demonstrated by Cicchi et al. [23] in the experiments with human skin ex vivo. The optical clearing of deeper layers of the tissue occurs mainly at the expense of the cumulative effect of reducing the scattering in the near-surface layers of the tissue sample, which provides smaller damping of the incident and detected radiation of fluorescence. Better focusing (smaller distortion of the focused beam) is achieved in a medium with weaker scattering [23].

Tseng et al. [251] have shown that the combined confocal/two-photon microscopy provides a noninvasive method of microscopic studying of the scaffold structure, which can be a valuable tool for complex investigation of biomaterials and their interaction with the molecules/cells of interest inside the scaffold. The integration of optical clearing with FocusClear, confocal/two-photon microscopy, and three-dimensional presentation is an efficient approach to the microscopic study of the scaffold structure.

Additional morphological information is provided by combining the second harmonic generation ( $\mathrm{SHG}$ ) microscopy with the microscopy based on two-photon excitation [275].

At present SHG is one of the new high-resolution nonlinear-optical imaging methods for the study of intact tissues and cell structures [276-284]. Similar to multiphoton fluorimetry, the SHG method has a few important advantages compared to the methods of linear spectroscopy and imaging, since the exciting near infrared light is weakly scattered by the tissue, while the second harmonic generation occurs already inside the tissue, in the small focal region of the focused laser beam. This provides high spatial resolution, acceptable probing depth, and decoupling of exciting and detected signals. Strongly focused laser beams with high power density and very short pulse duration of tens and hundreds of femtoseconds allow the harmonic generation in a living tissue practically without any damage, because of small interaction time and the total energy, too small for molecular ionisation [284].

SHG is a nonlinear optical process of the second order that can occur only in the media, possessing no central symmetry. The method can be used for imaging highly-ordered structure proteins without any exogenous labels, as well as for probing biological membranes with high specificity to the membrane type [277]. In turn, the third harmonic generation is very sensitive to the refractive index variations and can be used to visualise interphase regions in cells and tissues [285].

Due to its coherent nature, the wave of the second harmonic is mainly radiated in the forward direction. For thicker and strongly scattering samples a part of the SHG signal is scattered. The major part of the SHG radiation still propagates in the forward direction. A great part of structural information encoded in the forward signal is lost in the backward signal due to multiple scattering events. Nevertheless, the mode of SHG backscattering allows the study of upper layers of intact skin or whole animals that could not be implemented in the transmission mode [24, 278, 284, 286].

The SHG in skin is provided, mainly, by the dermis due to its major component, the collagen that possesses considerable nonlinear susceptibility [280-283]. Obviously, the reduction of scattering due to optical clearing for the incident long-wave light and, particularly, for the short-wave second-harmonic detected light can improve the SG images of the collagen structures of the dermis in the forward direction and worsen the signal in the reflection mode.

Wen et al. [76] injected glycerol solutions into the rat skin in vivo, and after 10 minutes the samples were 
cut for SHG imaging. With the solution having the concentration $75 \%$ the dehydration (diameter reduction) of dermis collagen fibres was observed.

Fig. 10 illustrates the change of packing density of the dermis collagen fibres under its interaction with $50 \%$ PEG-400 solution. The images were obtained using the SHG microscopy.
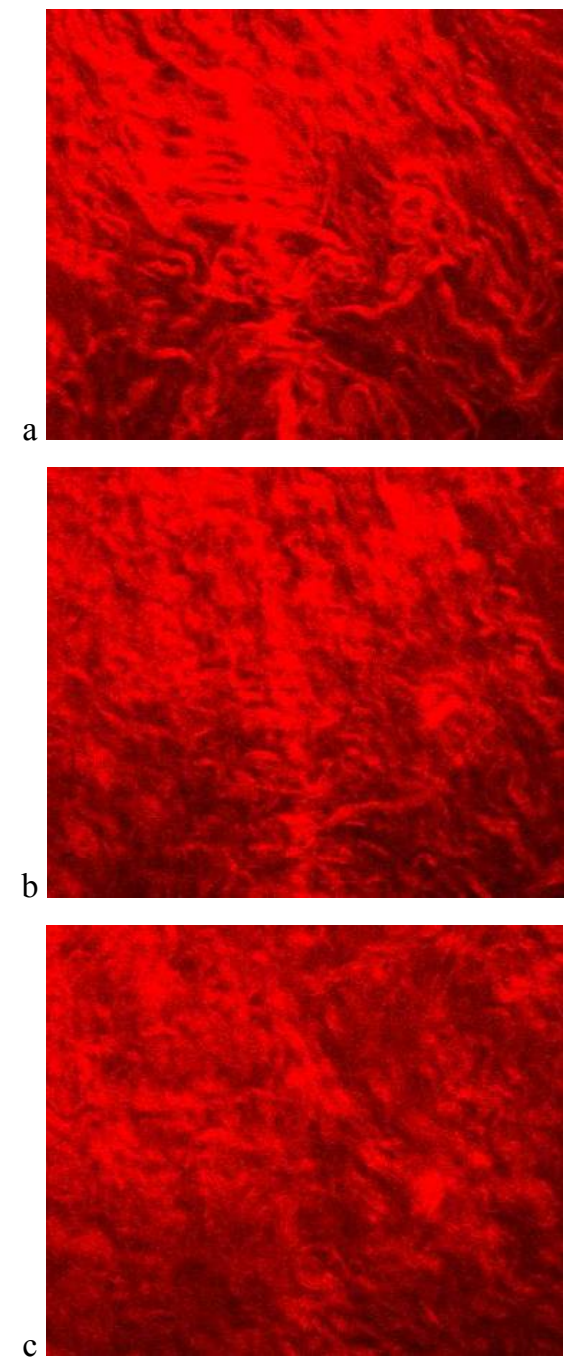

Fig. 10 The packing density change of collagen fibres in the rat skin ex vivo under the action of $50 \%$ aqueous solution of PEG-400: the initial state (a); immediately after the OCA application (b), and in 15 minutes after the application of OCA (c). The images were obtained by means of SHG microscopy. The incident light wavelength was $790 \mathrm{~nm}$, the detected wavelength 395 nm.

Yeh et al. [121] and Wen et al. [76] demonstrated that for the collagen-based connective tissues (samples of tendon and model tissues) the optical clearing process using the high-concentration glycerol (13 M) manifested itself in considerable reduction of the backscattered signal intensity and the increase of the transmitted signal.

For deeper probing of the murine skeletal muscle and tendon samples using three-dimensional SHG microscopy in the transmission mode the authors of Ref. [24] used the $50 \%$ solution of glycerol. They obtained the increase of SHG imaging depth by 2.5 times in the muscle tissue. The amplification of the signal was also due to better packing of the fibrils. It was also shown that the axial attenuation of the direct SHG signal is reduced with the increase of the glycerol concentration $(25,50$, and $75 \%)$ [72]. The backward SHG signal considerably decreased in the process of optical clearing due to the scattering reduction and the change of the local density of dipoles, producing the second harmonic [72].

The Raman nonlinear spectroscopy also finds its application in studying the mechanisms of optical clearing. Thus, e.g., in Ref [287] the signal of coherent anti-Stokes Raman scattering (CARS) served as the reference in the study of DMSO impact on the collagen structure and, therefore, the loss of SHG signal and the reduction of light scattering by human skin. Hirshburg et al. [110] found the correlation between the rate of the water loss by the rodent skin ex vivo under the effect of different OCAs and the potential of optical clearing, which was determined by the slope of the line $\mu_{s}^{\prime}$ (before clearing) $/ \mu_{s}^{\prime}$ (after clearing).

Raman spectroscopy is a potential noninvasive method for studying the bone development and for diagnostics of bone diseases [288]. Essential amplification of commonly undetectable Raman signals from internal tissues can be implemented by means of optical clearing of near-surface layers of the tissue that shade the object of study [288, 289]. In this way the transcutaneous spectroscopy of the rat tibial bone in vivo was performed under the skin optical clearing with glycerol [288]. The process of porcine skin optical clearing was studied in vitro by means of Raman microspectroscopy [289]. The intensity of Raman peaks at the depth of $400 \mu \mathrm{m}$ was increased by 2-4 times. Besides, the shifts of the peaks in the Raman spectrum of skin at different concentrations of glycerol were observed [289].

The confocal Raman spectroscopy can also be used for in vivo monitoring of penetration of clearing agents and permeability enhancers (particularly, DMSO) into the skin stratum corneum [290].

\subsection{Terahertz spectroscopy}

The terahertz $(\mathrm{THz})$ frequency range is intermediate between the IR and microwave frequency ranges (the frequency $v=1 \mathrm{THz}$ corresponds to the free-space wavelength $\lambda=300 \mu \mathrm{m})$. Recent progress in generating and detecting the $\mathrm{THz}$ radiation and its usage offer its promising applications in biology and medicine [291]. Since the energy of $\mathrm{THz}$ photons is too small to ionise molecules in biological systems, the $\mathrm{THz}$ spectroscopy is expected to be a promising method of study in biology and medicine. Many vibrational transitions of biomolecules lie just in this frequency range, and the light scattering is not so strong as in the visible and near infrared spectral region, so that the excitation by ultrashort pulses can allow the study of a wide 
frequency range in a single measurement with high temporal resolution $[3,292-294]$. Terahertz spectroscopy allows the determination of the medium complex refractive index in a single measurement, which is important for creating a functional $\mathrm{THz}$ tomograph with high sensitivity to the change of metabolite concentrations and precise mapping of the pathologic process boundaries [3]. At the same time, due to the difficulties associated with the specific features of such objects, the biomedical applications are considered as medium-term and long-term goals of $\mathrm{THz}$ studies [291].

Keeping in mind that the frequencies of the $\mathrm{THz}$ range mainly coincide with the frequencies of rotational and vibrational transitions of the organic molecules, the study of this range may be used for spectral identification of molecules [295]. This circumstance allows the use of $\mathrm{THz}$ technologies in addition to the spectroscopic techniques, based on using electromagnetic waves of other frequency ranges. In this connection the development of spectroscopic methods of studying biological tissues in the $\mathrm{THz}$ region, providing the detection and visualisation of metabolic and pathologic processes, attracts great interest in recent years, especially as an additional channel of getting information in multimodal systems, in combination with optical methods [296, 297]. In such applications the immersion clearing of the tissue solves many problems of applying optical methods at the expense of reversible reduction of light scattering, and the accompanying dehydration of the tissue facilitates greater permeability for $\mathrm{THz}$ radiation due to the reduction, also reversible, of absorption by water contained in the tissue. Direct in vitro measurements of the effect of porcine muscle tissue dehydration under the immersion of the sample in glycerol during 30 minutes have shown essential reduction of $\mathrm{THz}$ radiation absorption in the region $0.1-$ $1.5 \mathrm{THz}$, measured using the method of frustrated total internal reflection [292]. The loss of the sample mass amounted to $10 \%$ of its initial mass, and the transmission in the visible wavelength range increased upon the average by $5 \%$. This experiment also demonstrated the high sensitivity of the $\mathrm{THz}$ range to the concentration of water in tissues, which apparently can serve as one of the criteria for pathology recognition [296].

The influence of dehydration by freezing (lyophilisation) of tissue samples of different rat organs (kidney, diaphragm, liver, rectum, stomach) on the $\mathrm{THz}$ spectra in the range $0.4-2.2 \mathrm{THz}$ was studied in Ref. [294]. Among the drawbacks of this method it is worth mentioning the impossibility of in vivo studies. Moreover, deep and long freezing of the tissue leads to essential changes of its structure. The dehydration of a tissue can be also implemented by the thermal impact (e.g., using a fan), i.e., by mere drying [298]. However, this method suffers from the same drawbacks as the one presented above.

Obviously, the implementation of in vivo dehydration requires temporary and reversible changes in the tissues under study. In Ref. [299] it is proposed to perform the dehydration of muscle tissue using the hyperosmotic agents. As clearing agents the authors used PEG-600, dehydrated glycerol, and propylene glycol. The possibility of reducing the absorption of radiation in the range $0.25-1.6 \mathrm{THz}$ under its propagation through the tissue by applying OCA has been unambiguously proved, which offers a possibility of essential increase of the probing depth of a tissue with such radiation. Depending on the frequency of radiation within the studied range, the absorption coefficient reduction approached $60 \%$, and the necessary application time was $8-10$ minutes, which is acceptable for using this technology in medical practice [299].

\subsection{Determination of diffusion coefficients for clearing agents and drugs in tissues}

In spite of multiple studies related to the control of optical properties of tissues, the problem of determining diffusion coefficients for hyperosmotic fluids in tissues still remains insufficiently studied. Due to the complex multicomponent structure of tissues and nonlinear character of diffusion processes the measurement of diffusion coefficient of hyperosmotic fluids in tissues is a rather difficult scientific problem. According to the present-day conceptions, the diffusion of different substances in tissues occurs in several stages. At the first stage the penetration of diffusing agents into the intercellular and interfibrillar space and their interaction with cell membranes and interstitial matrix of tissues occurs. At the next stage the transmembrane diffusion of the agent into cells probably occurs, accompanied by the change of the intracellular osmotic pressure. One should not exclude also the possibility of transformation of the membranes themselves, related to the change of the intercellular fluid properties. Under the sufficient saturation of interfibrillar space of a connective tissue with the clearing agent its interaction with the tissue fibrils will obviously take place.

However, the use of sufficiently simple optical and diffusion models allows the solution of the present problem without significant loss of accuracy, and the natural dispersion of optical and structural properties of tissues makes this simplification acceptable. The resulting values of diffusion coefficients can be successfully used in mathematical models, describing the processes of interaction between the hyperosmotic immersion fluids and the tissues, which, in particular is rather urgent in the study of processes, related to transcutaneous delivery of medicinal preparations and metabolic agents.

At present a number of biophysical methods and techniques for determining the diffusion coefficients of different agents exist [300-313], but, unfortunately, only a small part of the methods can be successfully applied to assess the diffusion coefficients in tissues. The available methods are mainly based on using the fluorescence measurement techniques or radioactive 
Table 1 Light penetration depth increase by optical clearing agents in different diagnostic methods.

\begin{tabular}{|c|c|c|c|c|c|}
\hline $\begin{array}{l}\text { Diagnostic } \\
\text { method }\end{array}$ & Tissue & OCA, refractive index & Spectral range & $\begin{array}{l}\text { Light } \\
\text { penetration } \\
\text { depth } \\
\text { increase }\end{array}$ & Reference \\
\hline $\begin{array}{l}\text { Confocal } \\
\text { microscopy }\end{array}$ & $\begin{array}{l}\text { Dehydrated murine } \\
\text { adipose tissue, muscle } \\
\text { tissue, myocardium, } \\
\text { brain }\end{array}$ & Murray's Clear, 1.55 & $334-799.3 \mathrm{~nm}$ & $\sim 35$ folds & {$[250]$} \\
\hline $\begin{array}{l}\text { Two-photon } \\
\text { microscopy }\end{array}$ & Human skin ex vivo & Dehydrated glycerol, 1.47 & $\begin{array}{l}\text { Excitation }-700-1000 \\
\mathrm{~nm} \text {, detection }-370-670 \\
\mathrm{HM}\end{array}$ & 2 folds & [23] \\
\hline $\begin{array}{l}\text { Confocal/two- } \\
\text { photon } \\
\text { microscopy }\end{array}$ & Cellulose membrane & FocusClear, 1.46 & $\begin{array}{l}\text { Excitation }-820 \mathrm{~nm}, \\
\text { detection }-390-465 \mathrm{~nm}\end{array}$ & 2 folds & {$[251]$} \\
\hline $\begin{array}{l}\text { 3-D second- } \\
\text { harmonic } \\
\text { microscopy } \\
\text { (direct wave } \\
\text { mode) }\end{array}$ & $\begin{array}{l}\text { Muscle tissue of a } \\
\text { mouse }\end{array}$ & $\begin{array}{l}50 \% \text { glycerol solution, } \\
1.395\end{array}$ & $\begin{array}{l}\text { Excitation }-890 \mathrm{~nm} \text {, } \\
\text { detection }-445 \mathrm{~nm}\end{array}$ & 2.5 folds & [24] \\
\hline $\begin{array}{l}\text { Raman } \\
\text { microspectros } \\
\text { copy }\end{array}$ & Porcine skin in vitro & $80 \%$ glycerol solution, 1.46 & $785 \mathrm{~nm}$ & 4 folds & [289] \\
\hline $\begin{array}{l}\mathrm{THz} \\
\text { spectroscopy }\end{array}$ & Bovine muscle tissue & Dehydrated glycerol, 1.47 & $0.25-1.6 \mathrm{THz}$ & $45 \%$ & [299] \\
\hline \multirow{3}{*}{ OCT } & Mouse embryo & $\begin{array}{l}50 \% \text { glycerol solution, } \\
1.395\end{array}$ & $1310 \mathrm{~nm}$ & 4.5 folds & [59] \\
\hline & Human skin in vivo & $\begin{array}{l}\text { Pre-polymer mixture on the } \\
\text { base of propylene glycol } \\
\text { and polyethylene glycol, } \\
1.47\end{array}$ & $1305 \mathrm{~nm}$ & 1.2 folds & {$[70]$} \\
\hline & $\begin{array}{l}\text { Whole blood, diluted } \\
\text { by two times with } \\
\text { saline }\end{array}$ & $6.5 \%$ glycerol solution, 1.34 & $820 \mathrm{~nm}$ & 2.4 folds & {$[128]$} \\
\hline
\end{tabular}

labels for recording the flow of diffusing substance. The use of fluorescence measurement technique is impossible for the assessment of diffusion coefficients of non-fluorescent substances (e.g., aqueous solutions of glucose or glycerol), and the use of radioactive substances can be undesirable in the case of in vivo measurements. Moreover, the high sensitivity of fluorescence and radioactive measurements makes their use difficult also because of the natural metabolic activity of the organism, which introduces additional errors into the measurement process. The method that allows the assessment of diffusion coefficients of nonfluorescent hyperosmotic fluids in tissues was proposed in 1997 [43] and later developed in Refs. [47, 90]. This method is based on measuring the time dependence of the tissue scattering characteristics under the action of hyperosmotic fluids and can be successfully used for both in vitro and in vivo measurements.

The process of immersion fluid transport in fibrous tissues can be described using the free diffusion model. In this case the following assumptions related to the transport process are commonly made: 1) only the concentration diffusion takes place, i.e., the exchange flux of the immersion fluid or drug into the tissue and of water from the tissue at a given point is proportional to the gradient of concentration of the clearing agent at this point; 2) the diffusion coefficient is constant at all points in the studied tissue sample.

Geometrically the tissue sample is presented as a plane-parallel plate of final thickness. Since the area of the upper and lower surfaces of this plate is much larger than the side area, it is possible to neglect the edge effects and solve the one-dimensional diffusion problem described by the equation

$\frac{\partial C(x, t)}{\partial t}=D \frac{\partial^{2} C(x, t)}{\partial x^{2}}$

presenting the second Fick law, where $C(x, t)$ is the concentration of the immersion agent (e.g., glucose) in the skin $(\mathrm{g} / \mathrm{ml}) ; D$ is the diffusion coefficient $\left(\mathrm{cm}^{2} / \mathrm{s}\right) ; t$ is the time, during which the diffusion process occurs (s); $x$ is the spatial coordinate along the sample thickness direction $(\mathrm{cm})$. Since in the experiments the volume of the immersion fluid, as a rule, significantly exceeds the volume of the tissue sample, the appropriate boundary conditions have the form 


$$
C(0, t)=C_{0} \quad \text { and } \quad \frac{\partial C(l, t)}{\partial x}=0
$$

where $\mathrm{C}_{0}$ is the glucose concentration in the solution $(\mathrm{f} / \mathrm{ml}) ; 1$ is the tissue sample thickness $(\mathrm{cm})$. The second boundary condition reflects the fact that the diffusion of the immersion fluid into the skin sample occurs only from one side of the sample, i.e., from the dermis side. In the case, when the immersion agent diffuses from both sides of the tissue sample (such situation arises, e.g., in experiments with sclera or dura mater in vitro), the boundary conditions have the form:

$$
C(0, t)=C_{0} \quad \text { and } \quad C(l, t)=C_{0} .
$$

The initial conditions express the absence of the immersion agent in all internal points of the sample before its incubation into the solution, i.e.,

$$
C(x, 0)=0
$$

The solution of the diffusion equation (4) with the initial (6) and boundary (5) conditions taken into account has the form:

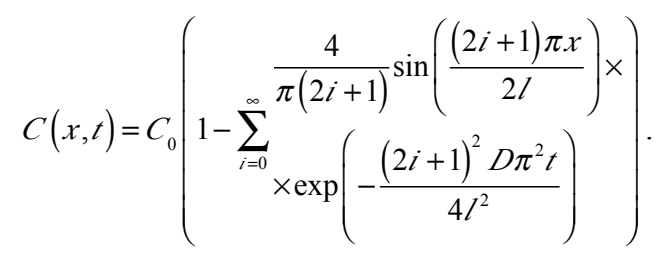

The mean concentration of the immersion solution in the tissue sample $C(t)$ as a function of time is determined by the expression

$$
C(t)=C_{0}\left(1-\frac{8}{\pi^{2}} \sum_{i=0}^{\infty} \frac{1}{(2 i+1)^{2}} \times \exp \left(-(2 i+1)^{2} t \frac{\pi^{2}}{4} D / l^{2}\right)\right)
$$

In the case of double-side diffusion the solution of the diffusion equation (4) with the initial (6) and boundary $\left(5^{*}\right)$ conditions has the form

$$
C(x, t)=C_{0}\left(1-\sum_{i=0}^{\infty} \times \exp \left(-\frac{4}{\pi(2 i+1)} \sin \left(\frac{(2 i+1) \pi x}{l}\right) \times\right)\right.
$$

In this case the mean concentration of the immersion solution in the tissue sample $C(t)$ as a function of time is determined by the expression

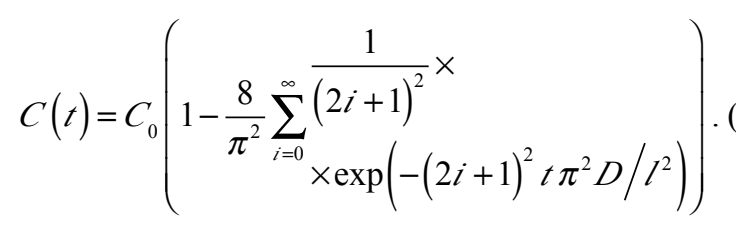

In the first approximation Eq. (7) can be rewritten as

$$
C(t) \approx C_{0}\left(1-\exp \left(-t \pi D / l^{2}\right)\right)
$$

and Eq. $(7 *)$ as

$$
C(t) \approx C_{0}\left(1-\exp \left(-t \pi^{2} D / l^{2}\right)\right)
$$

Note, that Eqs. (8) and $\left(8^{*}\right)$ correspond to the equation describing the diffusion through a thin penetrable membrane.

As the immersion agent penetrates into the tissue, the increase of the refractive index of the interstitial fluid will be observed. The assessment of the refractive index of the interstitial fluid depending on the diffusion time can be performed basin on the Gladstone-Dale law, according to which the refractive index of a mixture of non-interacting liquids is a sum of the refractive indices of individual components multiplied by the volume fractions of these components [314]. Mathematically the Gladstone-Dale law is written as

$n_{\Sigma}=\sum_{i} n_{i} C_{i}$, where $\sum_{i} C_{i}=1$

Here $n_{\Sigma}$ is the refractive index of the multicomponent mixture of non-interacting liquids; $n_{i}$ and $C_{i}$ are the refractive indices and volume fractions of each component. In the case of two-component solutions (in our case the components are the interstitial fluid and the solution of the immersion agent) the Gladstone-Dale law has the form

$n_{I}(t)=(1-C(t)) n_{\text {base }}+C(t) n_{\text {osm }}$

where $n_{\text {base }}$ is the refractive index of the interstitial fluid at the initial moment of time, and $n_{\text {osm }}$ is the refractive index of the hyperosmotic immersion fluid (e.g., glucose or glycerol solution). For the aqueous solution of glucose the value of the refractive index $\left(n_{g l}\right)$ can be found from the expression [315]

$n_{g l}(\lambda)=n_{H_{2} \mathrm{O}}(\lambda)+0.1515 \times C_{g l}$ 
where $n_{\mathrm{H}_{2} \mathrm{O}}(\lambda)$ is the spectrally dependent refractive index of water $([\lambda]=\mathrm{nm})$, and $C_{g l}$ is the glucose concentration in the solution $(\mathrm{g} / \mathrm{ml})$. The spectral dependence of the water refractive index has the form [316]:

$$
\begin{aligned}
& n_{\mathrm{H}_{2} \mathrm{O}}(\lambda)=1.3199+ \\
& +\frac{6.878 \times 10^{3}}{\lambda^{2}}-\frac{1.132 \times 10^{9}}{\lambda^{4}}+\frac{1.11 \times 10^{14}}{\lambda^{6}} .
\end{aligned}
$$

The optical characteristics of skin are determined by the optical properties of dermis (since its thickness is dominating with respect to the thickness of other skin layers). Hence, the optical model of the tissue can be presented as a layer having the thickness $l$, containing the scatterers in the form of infinitely long thin dielectric cylinders, parallel to the sample surface. In the first approximation one can assume that in the process of interaction of the tissue with the immersion fluid the scatterer size does not change. For densely packed tissues, i.e., the tissues with sufficiently large volume fraction of scatterers, to which the skin belongs, it is important to allow for the interference effects that arise because each scatterer is located in the near-field zone of radiation, scattered by the other scatterers, described by introducing the packing factor $[3,317]$. For a system of thin dielectric cylinders, arranged parallel to each other, the packing factor has the form $(1-\varphi)^{3} /(1+\varphi)$ [317], where $\varphi$ is the volume fraction of the scatterers. Thus, the expression describing the tissue scattering coefficient can be written in the form [90]:

$$
\mu_{s}=\frac{\varphi}{a} \frac{\pi x^{3}}{8}\left(m^{2}-1\right)^{2}\left(1+\frac{2}{\left(m^{2}+1\right)^{2}}\right) \frac{(1-\varphi)^{3}}{1+\varphi} .
$$

The time dependence of the collimated transmission coefficient of the tissue sample immersed in the solution of a hyperosmotic liquid or medicinal preparation has the form:

$$
T_{c}(t) \simeq \exp \left(-\left(\mu_{a}+\mu_{s}(t)\right) \times l\right)
$$

where $\mu_{a}$ is the absorption coefficient of the tissue sample.

Equations (4)-(13) determine the dependence of the collimated transmission coefficient upon the concentration of the immersion fluid solution (e.g., the solution of glucose or glycerol) in the sample of the tissue, i.e., formulate the direct problem. The inverse problem is to reconstruct the values of the diffusion coefficient from the time dependence of the collimated transmission. This problem is solved by minimisation of the target functional

$$
f(D)=\sum_{i=1}^{N_{f}}\left(T_{c}\left(D, t_{i}\right)-T_{c}^{*}\left(t_{i}\right)\right)^{2}
$$

where $N_{t}$ is the total number of experimental points, obtained by recording the time dependence of collimated transmission at the fixed wavelength: $T_{c}(D, t)$ is the value of the transmission coefficient, calculated using the formula (14) at the time moment $t$ for the given values of $D ; T_{c}^{*}(t)$ is the experimentally measured value of the transmission coefficient at the time moment $t$.

The flowchart of the program implementing the present algorithm is shown in Fig. 11. The main steps of the algorithm include:

1) Specification of the initial parameters for the chosen wavelength (the absorption coefficient $\mu_{\mathrm{a}}$, the refractive index of the interstitial fluid $n_{s}$, the refractive index of the glucose solution or a drug $n_{I}$, the thickness of the tissue sample $l$ ) obtained either from independent measurements, or from literature data.

2) Specification of the initial value of the diffusion coefficient $D$. The initial value of $D$ can be obtained from the analysis of variation of the sample collimated transmission basing on the equation

$$
\tau=-\frac{\sum_{j=1}^{n} t_{j}^{2}}{\sum_{j=1}^{n}\left(t_{j} \ln y_{j}\right)},
$$

where $t_{j}$ is the time moment of measuring each value of $T_{c}, T_{c}$ is the collimated transmission coefficient, $y=1-T_{c} / A ; A$ is the maximal value of the collimated transmission coefficient; $\tau$ is the diffusion time constant (s); $\tau=\frac{l^{2}}{\pi D}$ in the case of single-side diffusion and $\tau=\frac{l^{2}}{\pi^{2} D}$ in the case of double-side diffusion.

3) Calculation of the kinetics of collimated transmission versus time for given $D$ and $t_{j}$ using the Bouguer's law (Eq. (14)).

4) Comparison of the calculated and measured values of collimated transmission coefficients. If the difference does not exceed the prescribed error, the value of $D$ is found and the process is terminated, otherwise the value of $D$ is changed using the minimisation simplex method [318], and the procedure is repeated till the prescribed accuracy is achieved.

As an example, Table 2 presents the values of diffusion coefficients of glucose aqueous solutions in tissues, measured using the above method at the room temperature (about $20^{\circ} \mathrm{C}$ ). However, for medical applications the most interesting are the diffusion coefficient values measured at the physiological temperature (nearly $37^{\circ} \mathrm{C}$ ). Since the direct measurement of the diffusion coefficients at the physiological temperature requires thermostating of the 
Table 2 Glucose diffusion coefficients in biotissues [47].

\begin{tabular}{|c|c|c|c|}
\hline Tissue & Immersion fluid & $\begin{array}{l}\text { Diffusion coefficient, } \times 10^{-6} \text {, } \\
\mathrm{cm}^{2} / \mathrm{s} \text {, measured at } 20^{\circ} \mathrm{C}\end{array}$ & $\begin{array}{l}\text { Diffusion coefficient, } \times 10^{-6} \text {, } \\
\mathrm{cm}^{2} / \mathrm{s} \text {, at the temperature } \\
37^{\circ} \mathrm{C}\end{array}$ \\
\hline Eye sclera & $\begin{array}{l}\text { Aqueous solution of glucose, } \\
0.2 \mathrm{~g} / \mathrm{ml}\end{array}$ & $0.57 \pm 0.09$ & $0.91 \pm 0.09$ \\
\hline Eye sclera & $\begin{array}{l}\text { Aqueous solution of glucose, } \\
0.3 \mathrm{~g} / \mathrm{ml}\end{array}$ & $1.47 \pm 0.36$ & $2.34 \pm 0.36$ \\
\hline Eye sclera & $\begin{array}{l}\text { Aqueous solution of glucose, } \\
0.4 \mathrm{~g} / \mathrm{ml}\end{array}$ & $1.52 \pm 0.05$ & $2.42 \pm 0.05$ \\
\hline Pachymeninx & $\begin{array}{l}\text { Aqueous solution of glucose, } \\
0.2 \mathrm{~g} / \mathrm{ml}\end{array}$ & $1.63 \pm 0.29$ & $2.59 \pm 0.29$ \\
\hline Skin & $\begin{array}{l}\text { Aqueous solution of glucose, } \\
0.4 \mathrm{~g} / \mathrm{ml}\end{array}$ & $1.10 \pm 0.16$ & $1.75 \pm 0.16$ \\
\hline Skin (in vivo) & $\begin{array}{l}\text { Aqueous solution of glucose, } \\
0.4 \mathrm{~g} / \mathrm{ml}\end{array}$ & & $2.56 \pm 0.13$ \\
\hline
\end{tabular}

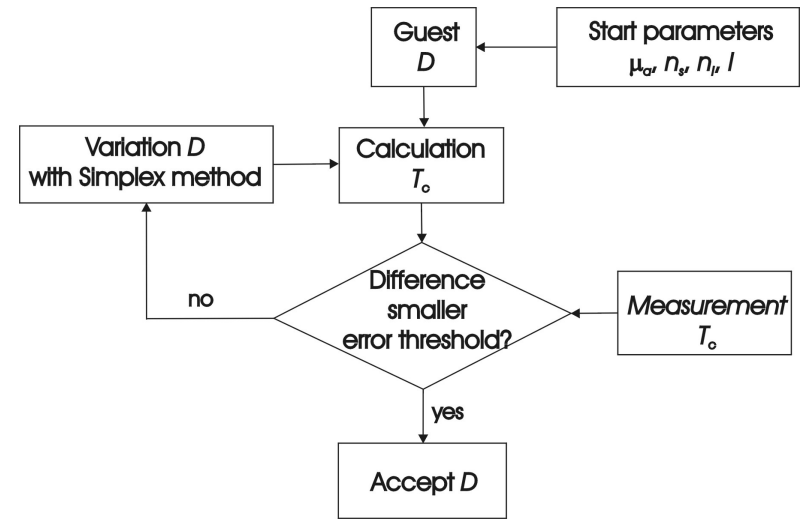

Fig. 11 Flowchart of the program for calculating the diffusion coefficients of glucose and drugs basing on the kinetics of collimated transmission of tissue samples.

tissue sample that essentially complicates the experimental setup and measurement technique, one can determine the diffusion coefficient at the physiological temperature theoretically, using the following dependence of the diffusion coefficient upon the temperature [319]:

$D\left(T_{2}\right)=D\left(T_{1}\right) \frac{T_{2}}{T_{1}} \frac{\eta\left(T_{1}\right)}{\eta\left(T_{2}\right)}$,

where $\eta(T)$ is the viscosity of the medium where the diffusion occurs (e.g., water) at the given temperature $T$. In our case $T_{1}=20^{\circ} \mathrm{C}$ and $T_{2}=37^{\circ} \mathrm{C}$. In Table 2 (4-th column) the values of the diffusion coefficients calculated for the temperature $37^{\circ} \mathrm{C}$ are presented.

From Table 2 it is well seen that the temperature increase from room to physiological, i.e., by $17^{\circ} \mathrm{C}$, causes the increase of the diffusion coefficient nearly by 1.5 times.

\section{Conclusion}

A review of specific features and methods of optical clearing and related interaction of light with biological tissues is presented. The impact of the OCA on a tissue allows efficient control of the optical properties, particularly, the reduction of tissue scattering coefficient, which facilitates the efficiency increase in different methods of optical imaging (optical biopsy) in medical applications. Both immersion and compression techniques of optical clearing possess considerable potential for many diagnostic, therapeutic, and surgical methods, in which the laser impact on the target site hidden in the tissue is used.

The work was supported by Russian Presidential grant NSh-703.2014.2, the Government of the Russian Federation grant 14.Z50.31.0004 (EAG, ANB, IYuY, and VVT), RFBR grant 14-02-00526 (VVT), and The Tomsk State University Academic D.I. Mendeleev Fund Program (EAG, ANB, YuPS, and VVT).

The authors wish to thank Prof. Dan Zhu (HUST, China) and her PhD students for their help in the obtaining of the SHG-images. 